\title{
Intercomparison of MAX-DOAS vertical profile retrieval algorithms: stud- ies on field data from the CINDI-2 campaign
}

Jan-Lukas Tirpitz et al.

Correspondence to: Jan-Lukas Tirpitz (jan-lukas.tirpitz@iup.uni-heidelberg.de)

The copyright of individual parts of the supplement might differ from the CC BY 4.0 License. 


\section{S1 $\quad M^{3}$ algorithm description}

The $\mathrm{M}^{3}$ algorithm developed at the Ludwig-Maximilians-University in Munich is an OEM algorithm with Newton Gauss optimization. The radiative transfer model LibRadTran (Mayer and Kylling, 2005) serves as forward model for the retrieval. LibRadTran provides several radiative transfer equation solvers which can handle both pseudo spherical and full spherical

5 geometry. The Jacobian is calculated numerically using the finite difference method, while the box air mass factors for trace gas profile retrievals are calculated using the Monte Carlo module of LibRadTran (MYSTIC). The $\mathrm{M}^{3}$ retrieval used in the CINDI2 campaign is a modified version of the algorithm described in detail in Chan et al. (2019) with the iterative optimization of the $a$ priori profile disabled. Aerosol extinction profiles are retrieved in the linear space.

\section{$\mathrm{S2} \mathrm{O}_{4}$ scaling factor}

10 By some groups, the $\mathrm{O}_{4}$ scaling factor $S F$ is applied to the measured dSCDs before the profile inversion. Initial motivation for its application are previous MAX-DOAS retrieval studies (e.g Wagner et al., 2009; Clémer et al., 2010) which report on a significant mismatch between measured and simulated dSCDs and/ or between MAX-DOAS integrated aerosol extinction and simultaneously measured sun photometer AOT that could not yet be explained (Wagner et al., 2019; Ortega et al., 2016). Meanwhile a series of studies use an $S F$, empirically determined to values between 0.75 and 0.9 .

15 As described in Sect. 2.1.3, in this study no scaling of $\mathrm{O}_{4}$ measured dSCDs was applied, except for MPIC-mp0.8 (MAPA algorithm with $S F=0.8$ ). For CINDI-2, a $S F$ of 0.8 was observed to enhance the number of valid profiles retrieved by MAPA and to significantly improve the agreement to the sun photometer total AOT in particularly in the UV (Beirle et al. (2019) and within this study). However, as mentioned before, for MAPA (as a parametrized approach without a priori profile and AVKs), a PAC as described in Sect. 3.4, cannot be correctly applied and thus deviations to the sun photometer are expected.

20 To further investigate the impact and necessity of the $S F$ for CINDI-2 retrievals, also HEIPRO (as an OEM retrieval) was run with different $S F$ s. In Fig. S1 the impacts of the $S F$ and the PAC on the agreement between MAX-DOAS profiling results (of HEIPRO and MAPA) and the sun photometer are directly compared. Application of $S F=0.8$ or the PAC, respectively, lead to a very similar improvement in the agreement (regarding RMS), while the application of both together results in a clear overcompensation. This suggests that the PAC and $S F=0.8$ are equivalent to a large extent and that in the case of MAPA the $S F$ is a way to at least partly account for high-altitude aerosol when it comes to retrieving total AOTs. On the other hand a closer look reveals that if only the PAC is applied, a systematic negative offset of $\approx-0.04$ remains in the correlation (for both algorithms and also other participants, compare to main text Sect. 3.4). Indeed, the top row of Fig. S3 shows that for HEIPRO the best RMSD is observed for $S F=0.92 \pm 0.02$ (UV). Regarding Aerosol Vis (Figure S2), the impact of high aerosol is smaller due to the enhanced vertical sensitivity range (see AVKs in main text Sect. 3.1), such that applying the same scaling

30 factor $S F=0.8$ as for the UV (without PAC) should already lead to an overcompensation. Indeed, this is observed for HEIPRO as well as MAPA. The bottom row of Fig. S3 shows that, in contrast to the UV spectral range, the best agreement between sun photometer and MAX-DOAS in the Vis is observed for an $S F>1$.

The second indicator for the need of a scaling factor is a significant mismatch between modelled and measured dSCDs. Figure S4 shows, that for HEIPRO the application of an $S F<1$ indeed improves the agreement between measured and modelled $\mathrm{O}_{4} \mathrm{UV}$ dSCDs by up to $35 \%$ in RMSD under clear-sky conditions. Modelled dSCDs are systematically lower than the measured dSCDs in particular for higher elevation angles. Also, Wagner et al. (2009) reported that, under low aerosol conditions, measured dSCDs sometimes even significantly exceed dSCDs modelled within an aerosol free atmosphere, where $\mathrm{O}_{4}$ dSCDs are close to the largest possible (regarding clear-sky scenarios only). Therefore, the median measured dSCDs during CINDI-2 at low aerosol load $\left(\tau_{s}<0.1\right)$ were compared to a set of aerosol free modelled dSCDs, showing that this did not happen during CINDI-2 except for the two highest elevation angles $\alpha=15^{\circ}$ and $30^{\circ}$.

Finally, as already stated by Beirle et al. (2019) applying $S F=0.8$ to MAPA leads to an increased number of valid profiles (see Sect. S3), which again indicates that scaling brings the RTM closer to reality.

The conclusions drawn are as follows: Even without $\mathrm{O}_{4}$ dSCD scaling, reasonable results and agreement with supporting observations are achieved (if a PAC is applied). In general, a scaling factor of 0.8 seems to be too small but might at least partly be used to account for high-altitude aerosol for algorithms, that cannot quantify their sensitivity or the assimilated $a$ 
priori information. However, there are indications that a less extreme scaling $(0.8<S F<1.0)$ might in general improve the retrieval. Finally, we think that for this study the prescribed $S F=1.0$ is justified. Even though it might not be ideal, it is the most straightforward approach and yields reasonable and consistent results within the uncertainties introduced by other factors. To draw more concise conclusions, further studies similar to Wagner et al. (2019) are necessary.

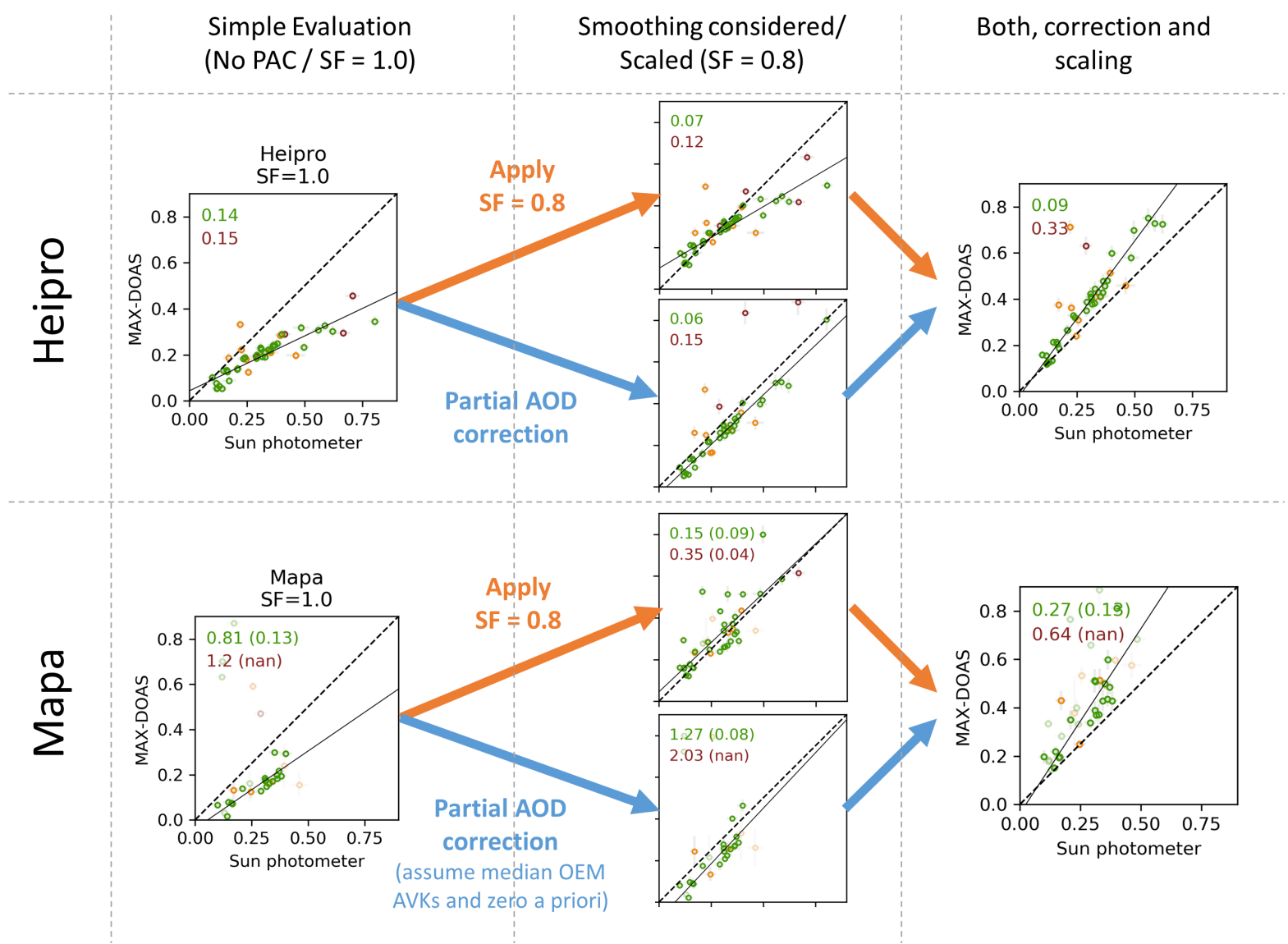

Figure S1. The impact of $S F=0.8$ and PAC on the agreement between sun photometer and MAX-DOAS AOT (Aerosol UV) in the case of HEIPRO (OEM approach, top row) and MAPA (parametrized approach, bottom row) in a direct comparison. Axes limits and labels of the plots on the left apply for all plots in the figure. Left column: A standard retrieval with $S F=1$ yields a clear underestimation of the sun photometer AOT for both algorithms. Middle column: Applying the PAC or $S F=0.8$ leads to a significant improvement. Right column: Applying both leads to overcompensation. Note, that the PAC for MAPA incorporates vague assumptions (median AVKs from all OEM algorithms and $\boldsymbol{x}_{\boldsymbol{a}}=\mathbf{0}$ ) and is therefore less meaningful. 


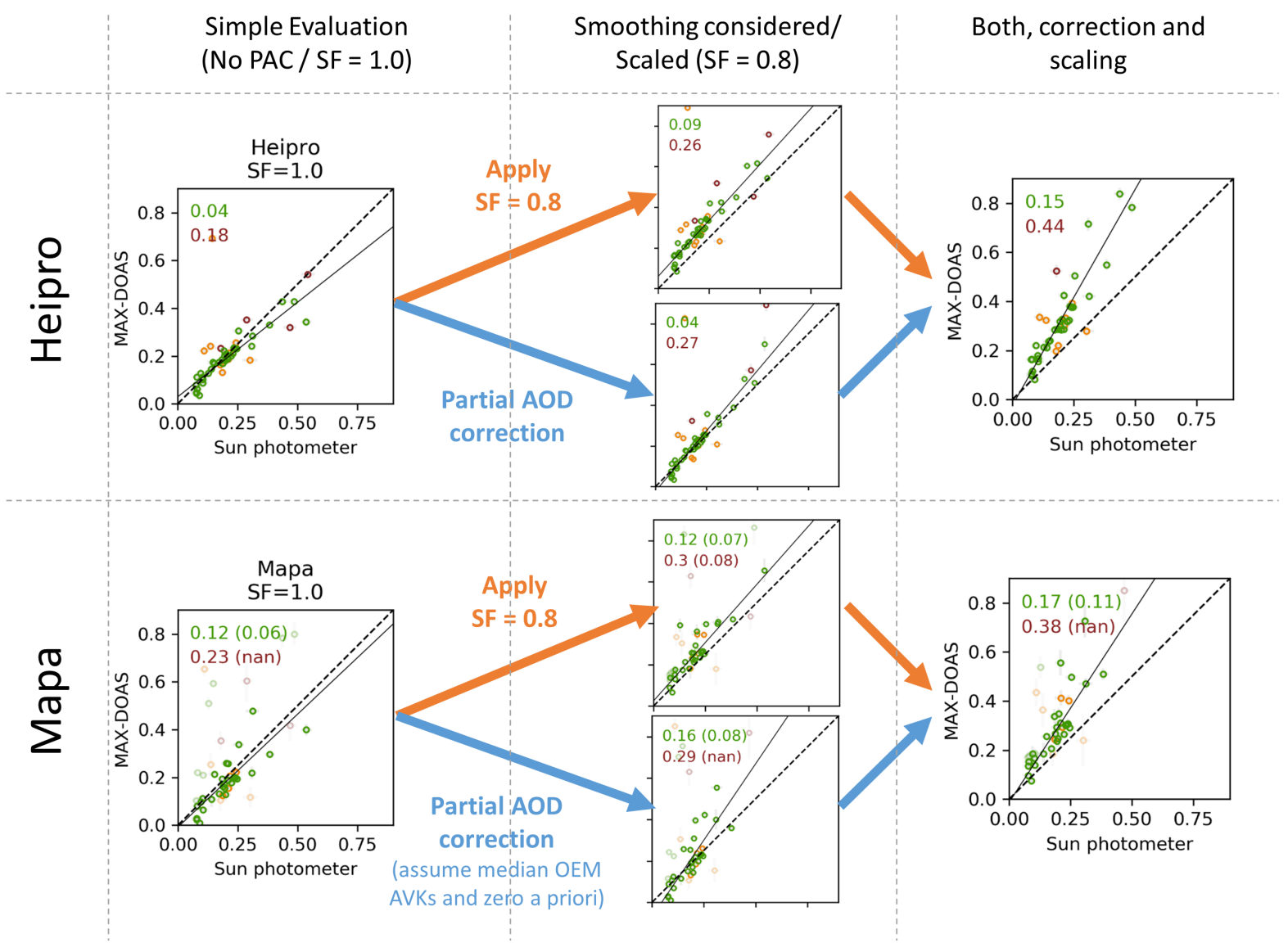

Figure S2. The impact of $S F$ and PAC on Aerosol Vis results. Description of Fig. S1 applies. Due to the extended vertical sensitivity range of the MAX-DOAS observations (compare to main text Sect. 3.1), the effect of high-altitude aerosol is less significant. While this is accounted for in the PAC, the application of the same $S F=0.8$ as for Aerosol UV leads to an overcompensation here already without additionally applying the PAC. 


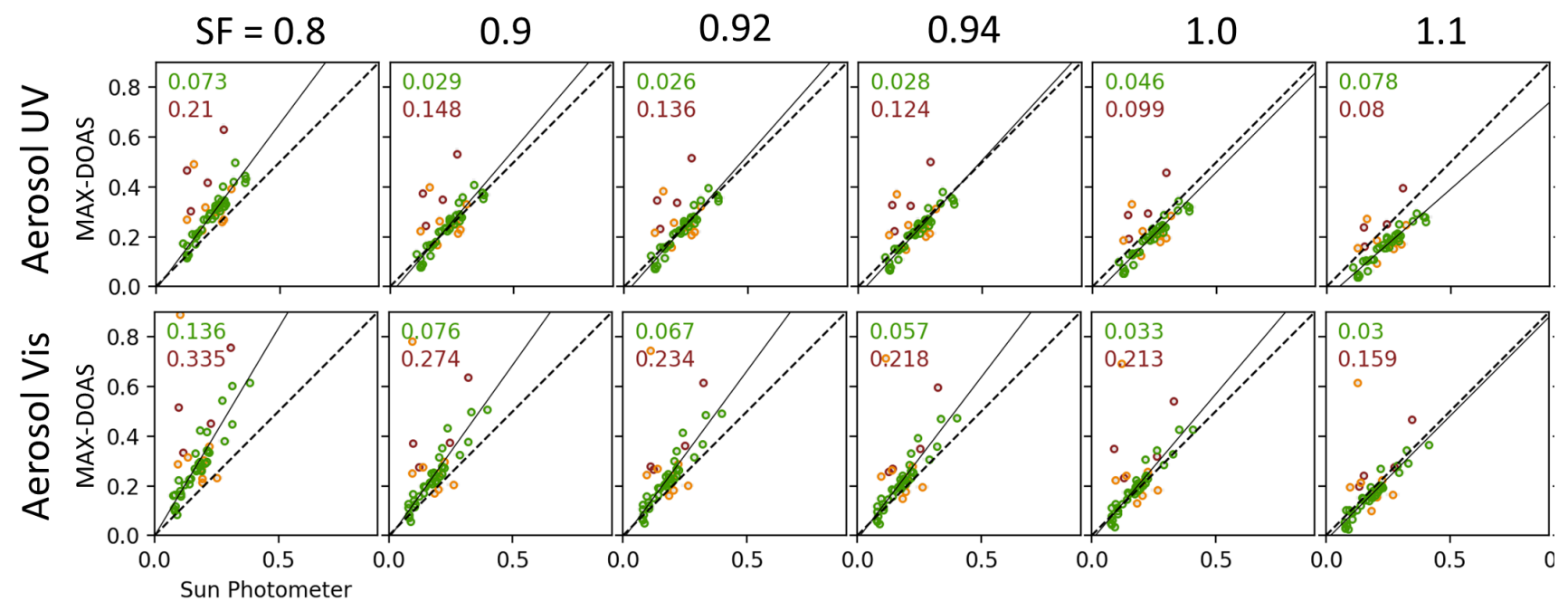

Figure S3. Correlation between the sun photometer AOT (PAC applied) and the HEIPRO algorithms for different $S F$ for Aerosol UV (top row) and Aerosol Vis (bottom row). Symbol colours differentiate between clear-sky (green), and cloudy conditions (orange, red). Numbers in the upper left corners show the corresponding RMSD values. Interestingly, the best agreement for the two spectral ranges is found for different scaling factors, namely for $S F=0.92 \pm 0.02$ (UV) and $S F>1 \pm 0.02$ (Vis). The thin line depicts the linear fit for clear-sky data only.

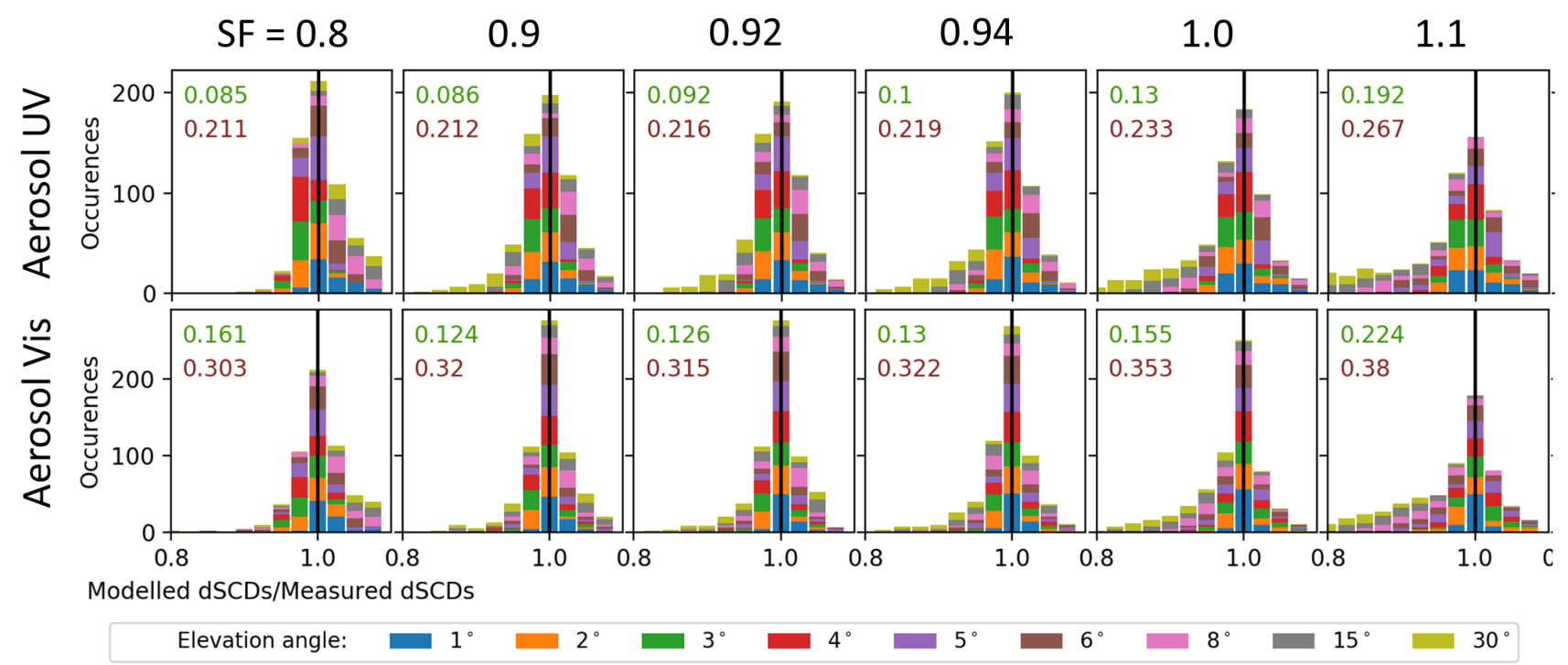

Figure S4. Agreement between modelled and measured dSCDs (depicted as histograms of the ratio) for HEIPRO with different $S F$ for Aerosol UV (top row) and Aerosol Vis (bottom row). Here, only clear-sky and valid data are considered. Numbers in the upper left corners show the corresponding RMSD values. There is a clear tendency, that the agreement improves for $S F<1$. 


\section{S3 Details on profile flagging}

Participants were allowed to submit flags, giving them the opportunity to mark profiles as invalid. Four participants submitted flags based on the following criteria:

- BIRA/ bePRO: Profiles are considered valid if the retrieved degrees of freedom are $>1$ and if the difference between measured and modelled dSCDs is smaller than $30 \%$.

- INTA: Profiles are valid if DOFS > 1 and if the RMSD between measured and simulated dSCDs is smaller than 1.5 times the daily averaged RMS.

- KNMI: Profiles are invalid if the spread in the ensemble of solutions for AOT or the $\mathrm{NO}_{2}$ or $\mathrm{HCHO}$ tropospheric column is larger than $15 \%$ of the retrieved value, or if there are less than 5 out of the ensemble of 20 retrievals for which a solution was found.

- MAPA: Flagging is based on a row of criteria (e.g. the agreement of modelled and measured dSCDs, implausible results or the consistency within the ensemble of possible solutions) with carefully chosen thresholds. A detailed description can be found in Beirle et al. (2019).

Table S1 shows the statistics regarding the number of submitted profiles and the fraction of invalid profiles for all participants and species.

Table S1. Submission and flagging statistics.

\begin{tabular}{|c|c|c|c|c|c|c|c|c|c|c|c|}
\hline & & \multicolumn{2}{|c|}{$\mathrm{HCHO}$} & \multicolumn{2}{|c|}{$\mathrm{NO}_{2} \mathrm{UV}$} & \multicolumn{2}{|c|}{$\mathrm{NO}_{2} \mathrm{Vis}$} & \multicolumn{2}{|c|}{ Aerosol UV } & \multicolumn{2}{|c|}{ Aerosol Vis } \\
\hline & & Total & Valid [\%] & Total & Valid [\%] & Total & Valid [\%] & Total & Valid [\%] & Total & Valid [\%] \\
\hline \multirow[t]{3}{*}{ bePRO } & $\mathrm{AUTH}^{\circ}$ & 170 & 100 & 170 & 100 & - & - & 170 & 100 & - & - \\
\hline & BIRA $^{o}$ & 170 & 93 & 170 & 93 & 170 & 87 & 170 & 93 & 170 & 88 \\
\hline & INTA $^{o}$ & 170 & 78 & 170 & 75 & 170 & 71 & 170 & 87 & 170 & 80 \\
\hline \multirow[t]{4}{*}{ PRIAM } & $\operatorname{AIOFM}_{l}^{o}$ & 170 & 100 & 170 & 100 & - & - & 170 & 100 & - & - \\
\hline & $\mathrm{BSU}_{l}^{o}$ & 170 & 100 & 170 & 100 & 170 & 100 & 170 & 100 & 170 & 100 \\
\hline & $\mathrm{CMA}_{l}^{o}$ & 169 & 100 & 169 & 100 & 169 & 100 & 169 & 100 & 169 & 100 \\
\hline & $\mathrm{MPIC}_{l}^{o}$ & 170 & 100 & 170 & 100 & 170 & 100 & 170 & 100 & 170 & 100 \\
\hline \multirow[t]{2}{*}{ HEPRO } & $\mathrm{IUPHD}_{l}^{o}$ & 170 & 100 & 170 & 100 & 170 & 100 & 170 & 100 & 170 & 100 \\
\hline & $\mathrm{UTOR}_{l}^{o}$ & - & - & 170 & 100 & 170 & 100 & 170 & 100 & 170 & 100 \\
\hline BOREAS & $\mathrm{IUPB}_{l}^{o}$ & 170 & 100 & 170 & 100 & 170 & 100 & 170 & 100 & 170 & 100 \\
\hline $\mathrm{M}^{3}$ & $\mathrm{LMU}^{o}$ & 170 & 100 & 170 & 100 & 170 & 100 & 170 & 100 & 170 & 100 \\
\hline MMF & $\mathrm{BIRA}_{l}^{o}$ & 170 & 100 & 170 & 100 & 170 & 100 & 170 & 100 & 170 & 100 \\
\hline Realtime & $\mathrm{NASA}^{a}$ & 170 & 100 & 170 & 100 & 170 & 100 & - & - & 170 & 100 \\
\hline MARK & $\mathrm{KNMI}^{p}$ & 107 & 38 & 152 & 61 & 168 & 76 & 107 & 43 & 168 & 77 \\
\hline \multirow[t]{2}{*}{ MAPA } & MPIC-1.0 $0^{p}$ & 170 & 31 & 170 & 32 & 170 & 22 & 170 & 32 & 170 & 33 \\
\hline & MPIC- $0.8^{p}$ & 170 & 52 & 170 & 51 & 170 & 37 & 170 & 52 & 170 & 43 \\
\hline
\end{tabular}

15

\section{S4 Further details on supporting observations}

\section{S4.1 Aerosol extinction profiles}

The available raw data from the ceilometer are attenuated backscatter coefficient profiles $\tilde{\beta}(h)$. For altitudes below $180 \mathrm{~m}$, data are invalid due to insufficient overlap between sending and receiving telescope's FOVs of the instrument, thus $\tilde{\beta}(h<180 \mathrm{~m})$ 
was set to $\tilde{\beta}(h=180 \mathrm{~m})$. For profiles with simultaneously available sun photometer AOTs $\tau_{s}(\lambda)$, attenuated backscatter profiles $\tilde{\beta}(h)$ were converted to approximate backscatter profiles $\beta(h)$, applying

$\beta(h)=\tilde{\beta}(h) \cdot \exp \left[2 \int_{0}^{h} \frac{\tau_{s}(\lambda=1064 \mathrm{~nm})}{\int \tilde{\beta}\left(h^{\prime}\right) d h^{\prime}} d h\right]$

Extinction coefficient profiles $\alpha_{\lambda}(h)$ at the MAX-DOAS retrieval wavelengths were then obtained by scaling of $\beta(h)$ with the

sun photometer AOT according to:

$\alpha_{\lambda}(h)=\frac{\tau_{s}(\lambda)}{\int \beta\left(h^{\prime}\right) d h^{\prime}} \cdot \beta(h)$

Integrands with no specified limits in Eq. (1) and (2) indicate integration over the entire available profile. Values for $\tau_{s}(\lambda)$ at the desired wavelengths were derived according to Eq. (4) in the main text. In case of missing sun photometer data, for instance due to clouds, the MAX-DOAS retrieved AOT was used instead of $\tau_{s}$. In this case no attenuation correction (Eq. (1)) could be applied and the integration in Eq. (2) was performed over an averaging kernel smoothed profile (see main text Sect. 2.3.2), to take into account the blindness of MAX-DOAS instruments for higher aerosol layers.

The resulting extinction coefficient profiles at $360 \mathrm{~nm}$ could partly be validated with Raman lidar observations at $355 \mathrm{~nm}$ (the CESAR Water Vapor, Aerosol and Cloud lidar "CAELI", operated within the European Aerosol Research lidar Network (EARLINET, Bösenberg et al., 2003; Pappalardo et al., 2014) and described in detail in Apituley et al., 2009). Since for the

15 Raman lidar there is not sufficient telescope FOV overlap for altitudes $<1 \mathrm{~km}$ to retrieve reliable extinction profiles this comparison is limited to the altitude range between 1 and $4 \mathrm{~km}$. The average RMSD between scaled ceilometer and Raman lidar profiles is $\approx 0.03$. Table S2 summarizes the instrument's properties. Figure S5 shows the available Raman lidar profiles in comparison to the ceilometer derived profiles scaled with the respective sun photometer and MAX-DOAS AOT respectively.

Table S2. Properties of the two lidar instruments.

\begin{tabular}{rcc}
\hline Instrument & Raman lidar & Ceilometer \\
\hline Data product & Aerosol extinction profile & Elastic backscatter profile \\
Operational wavelength & $355 \mathrm{~nm}$ & $1064 \mathrm{~nm}$ \\
Altitude range & 1 to $10 \mathrm{~km}$ & 0.2 to $15 \mathrm{~km}$ \\
Vertical resolution & $7.5 \mathrm{~m}$ & $10 \mathrm{~m}$ \\
Temporal resolution & $30 \mathrm{~s}$ & $12 \mathrm{~s}$ \\
Data coverage & 5 profiles between 13.9. and 15.9. & Whole campaign
\end{tabular}

\section{S4.2 Radiosonde flights}

20 An overview of the radiosonde flights is given in Fig. S6. Example profiles are shown in the course of a comparison between lidar and radiosonde observations in Supplement S4.5. Another preprocessing step of the sonde profiles shall be mentioned: data quality was affected by calibrational drifting of the sensor, as it was optimized for low weight and cost rather than performance. Even though a calibration against the CE-DOAS was performed directly before each launch, most profiles showed a clear instrumental offset of about $(1-2) \times 10^{10}$ molec $\mathrm{cm}^{-3}$ in the free troposphere. The offset was subtracted and the profiles were subsequently rescaled to their initial surface concentration.

\section{S4.3 $\quad \mathrm{NO}_{2}$ lidar}

The $\mathrm{NO}_{2}$ lidar provides profiles consisting of a series of altitude intervals or "boxes" with constant gas concentration between a lower and an upper altitude limit. The conversion to profiles on the MAX-DOAS $200 \mathrm{~m}$ grid is demonstrated in Fig. S7. First, 


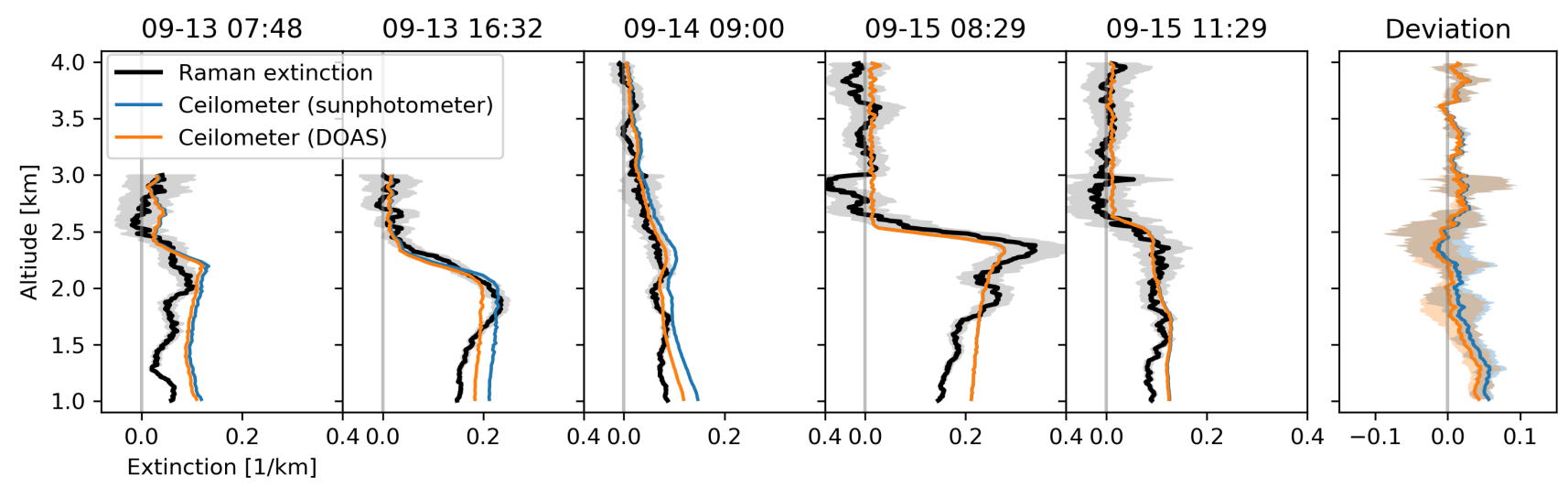

Figure S5. Comparison of the five available aerosol extinction profiles obtained from Raman lidar measurements (in black, with uncertainties indicated by the grey areas) with AOT scaled ceilometer backscatter profiles. Scaling was performed with AOTs from sun photometer (blue) and DOAS data (orange). In the last plot, lines show the mean deviation, whereas the borders of the couloured areas mark maximum and minimum deviation.

Table S3. Overview over the radiosonde sampling flights shown in this study.

\begin{tabular}{rccc}
\hline \hline Launch date & Flight time $^{a}[\mathrm{~min}]$ & Travel distance $^{a}[\mathrm{~km}]$ & Wind direction \\
\hline $9-1308: 42$ & 10 & 7 & $\mathrm{SE}$ \\
$9-1409: 03$ & 12 & 5 & $\mathrm{SE}$ \\
$9-1413: 06$ & 14 & 4 & $\mathrm{SE}$ \\
$9-1508: 04$ & 10 & 8 & $\mathrm{E}$ \\
$9-1510: 25$ & 11 & 8 & $\mathrm{SE}$ \\
$9-2107: 57$ & 12 & 10 & $\mathrm{SE}$ \\
$9-2110: 14$ & 15 & 5 & $\mathrm{SE}$ \\
$9-2506: 59$ & 17 & 7 & $\mathrm{~S}$ \\
$9-2509: 29$ & 12 & 18 & $\mathrm{~S}$ \\
${ }^{a}$ Only considering trajectory through the lowest $4 \mathrm{~km}$ of the atmosphere.
\end{tabular}

the boxes were converted to a continuous profile by linearly interpolating over box overlaps or gaps, which was then averaged down to the $200 \mathrm{~m}$ MAX-DOAS retrieval grid resolution.

\section{S4.4 Long path DOAS}




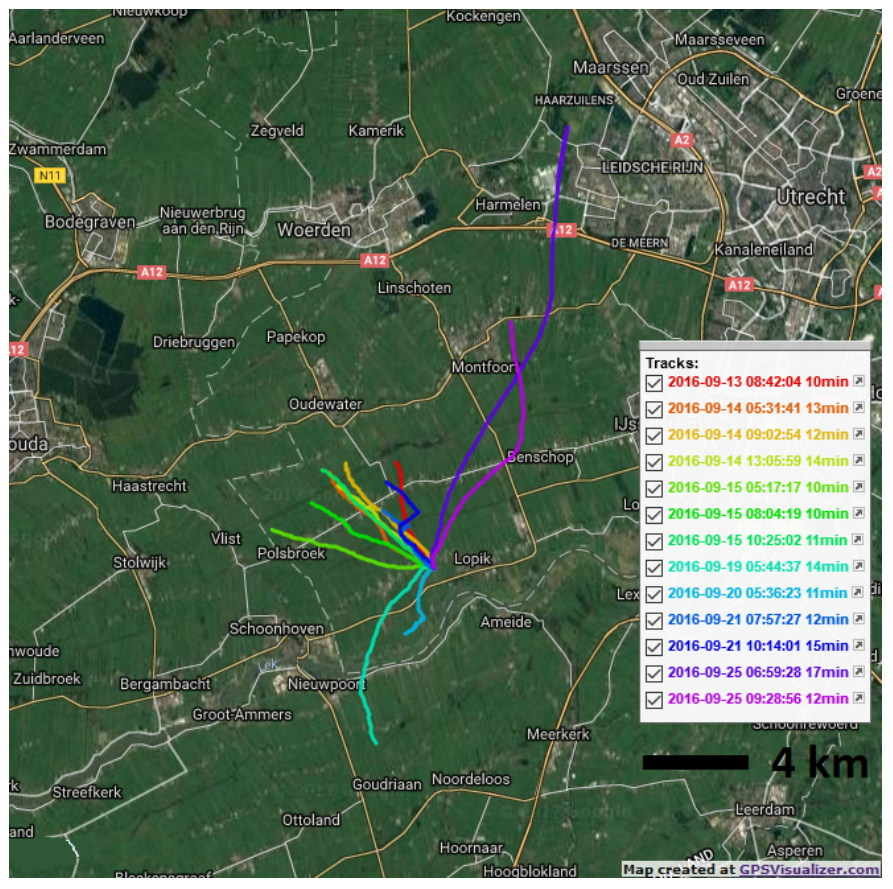

Figure S6. Sonde flight paths in the course of the campaign. Only data of the sonde ascent through the lowest $4 \mathrm{~km}$ of the atmosphere are shown. Some flights shown here are not included in the comparison as they were launched before 6:30 h. The "minute" values in the legend labels represent the flight time.

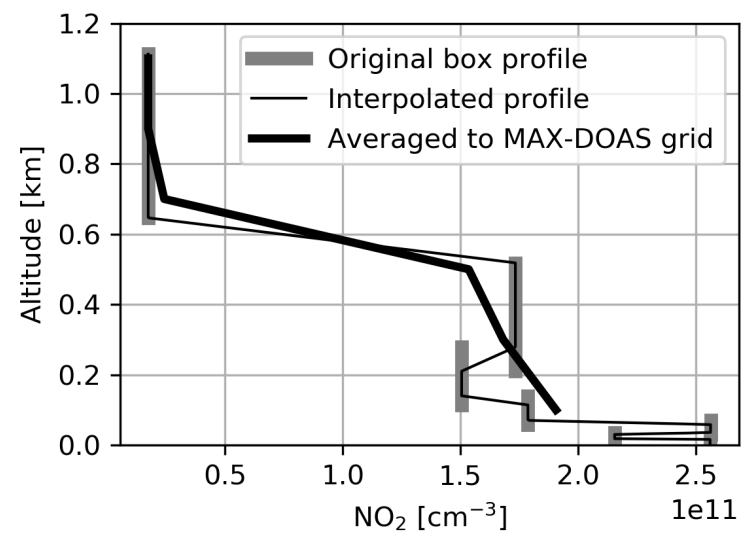

Figure S7. Regridding of an example $\mathrm{NO}_{2}$ lidar box profile (27 September 2016, 11:00) to the MAX-DOAS $200 \mathrm{~m}$ vertical resolution. In a first step, gaps and overlaps within the box profile are linearly interpolated. The resulting profile is then averaged within the MAX-DOAS retrieval layers. 

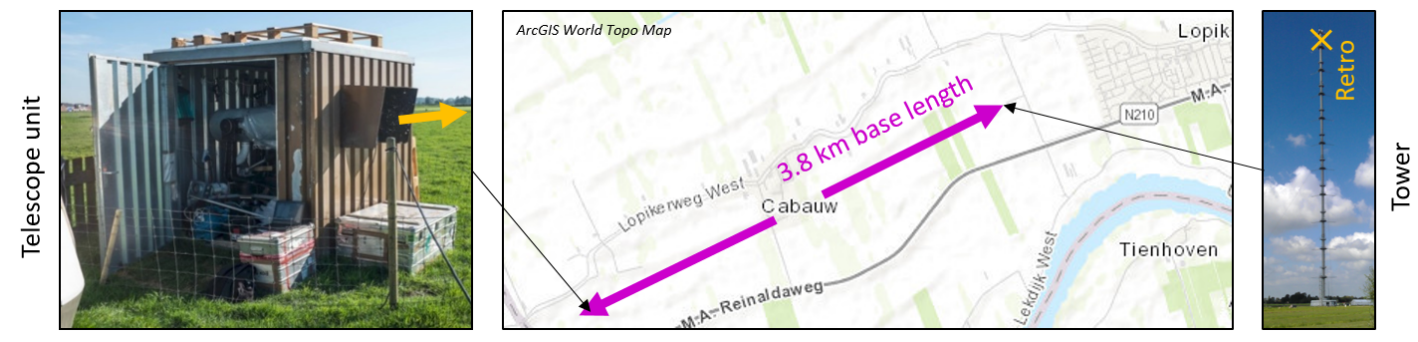

Figure S8. Setup of the LP-DOAS system. As shown on the map (Esri et al., 2018), the light sending and receiving telescope unit (left) was located at $3.8 \mathrm{~km}$ distance to the meteorological tower (right), resulting in a total light path of $7.6 \mathrm{~km}$. There were several retroreflectors installed on the tower at different altitudes. However for this study, only the one at the very top (207 m altitude) was used to obtain the average gas in the lowest retrieval layer, extending from 0 to $200 \mathrm{~m}$ altitude. 


\section{S4.5 Consistency of supporting observations}

The agreement of redundant supporting observations (processed as described in the main text Sect. 2.2) gives an impression of their reliability and/ or representativeness. In the case of $\mathrm{NO}_{2}$ several observations of total vertical columns and surface concentration (note again, that throughout this paper "surface concentration" refers to the average concentration in the lowest (tore series plots are already shown in the main text in Fig. 17 and 20, respectively. Tables S4 and S5 show the RMSD (as observed) and $\sigma$ (the expected deviation according to the specified measurement uncertainties) between each possible pair of observations. For the VCDs, the RMSD is close to $\sigma$ or below. A maximum RMSD of $1.5 \sigma$ is found between $\mathrm{NO}_{2}$ lidar and direct-sun DOAS. For the surface concentrations however, there seem to be systematic deviations which split the observations into two pairs: radiosonde and lidar observations agree well but are both systematically lower than LP-DOAS and tower measurements. MAX-DOAS UV agrees better with LP-DOAS and tower observations, while MAX-DOAS Vis agrees more with sonde and lidar. Between the LP-DOAS and the $\mathrm{NO}_{2}$ lidar, an RMSD of more than $4 \sigma$ is observed. There are several potential explanations:

1. Biases are introduced due to data processing (temporal and spatial regridding, for instance for the lidar profiles described in Sect. S4.3).

2. Spatio-temporal variability of the real gas abundances

3. Imperfect estimates of the measurement uncertainties (in particular systematic deviations)

For the $\mathrm{NO}_{2}$ lidar and the radiosondes, there are four simultaneously recorded $\mathrm{NO}_{2}$ profiles available over the campaign (simultaneous in the sense that for a single MAX-DOAS profile timestamp, profiles from both systems are available according to the definitions in Sect. 2.2.3 in the main text). They are compared in the top row of Fig. S10. For the first situation, where good spatial and temporal overlap is given, there is mostly an agreement within the specified errors. In the case of bad temporal and/ or spatial overlap, strong deviations occur. For the $2^{\text {nd }}$ and the $4^{\text {th }}$ plot, there are several lidar profiles available, which are temporally closer to the radiosonde (however further away from the corresponding MAX-DOAS profile), which in contrast show very good agreement again. This shows that the real $\mathrm{NO}_{2}$ profile varies strongly even on timescales of $\approx 30$ minutes (see also (Peters et al., 2019)) and that improved synchronisation between MAX-DOAS and supporting observations should be considered for future campaigns.

Table S4. Comparison of redundant measurements of the $\mathrm{NO}_{2}$ surface concentration (in $10^{11}$ molec $\mathrm{cm}^{-3}$ ). For each pair of observations, the observed scatter (RMS) is compared to the specified uncertainty $(\sigma)$.

\begin{tabular}{|c|c|c|c|c|c|c|}
\hline & \multicolumn{2}{|c|}{ Tower in-situ (0.56) } & \multicolumn{2}{|c|}{ Radiosonde (0.50) } & \multicolumn{2}{|c|}{$\mathrm{NO}_{2}$-Lidar (0.13) } \\
\hline & RMSD & $\sigma$ & RMSD & $\sigma$ & RMSD & $\sigma$ \\
\hline LP-DOAS (0.06) & 0.32 & 0.56 & 1.01 & 0.51 & 0.57 & 0.13 \\
\hline $\mathrm{NO}_{2}$-Lidar (0.13) & 0.72 & 0.57 & 0.40 & 0.52 & - & - \\
\hline Radiosonde (0.50) & 0.99 & 0.78 & - & - & - & - \\
\hline
\end{tabular}

Table S5. Comparison of redundant measurements of the $\mathrm{NO}_{2}$ total columns (in $10^{16}$ molec $\mathrm{cm}^{-2}$ ). For each pair of observation, the observed scatter (RMS) is compared to the specified uncertainty $(\sigma)$.

\begin{tabular}{lllll}
\hline & \multicolumn{3}{c}{ Radiosonde (0.44) } & \multicolumn{2}{l}{$\mathrm{NO}_{2}$-Lidar (0.15) } \\
& RMSD & $\sigma$ & RMSD & $\sigma$ \\
\hline Direct-sun DOAS (0.23) & 0.24 & 0.51 & 0.40 & 0.26 \\
$\mathrm{NO}_{2}$-Lidar (0.15) & 0.34 & 0.48 & - & - \\
\hline
\end{tabular}



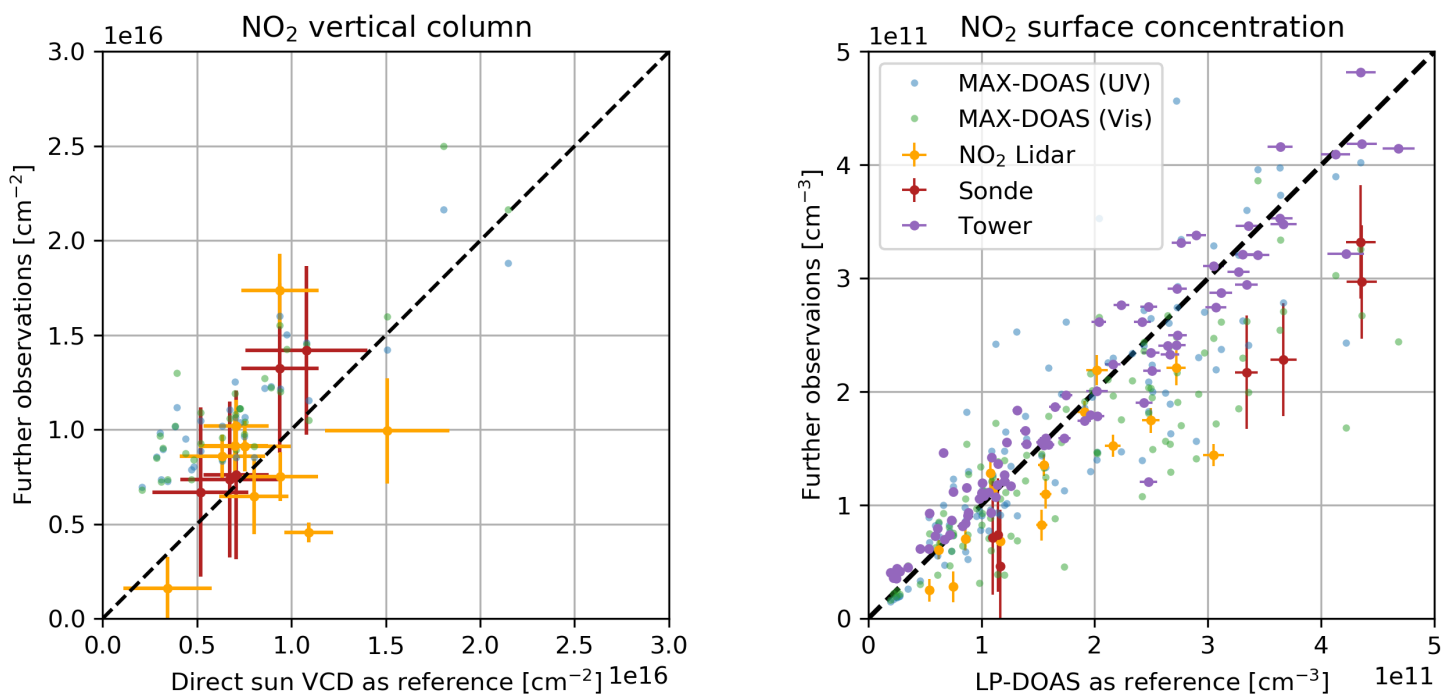

Figure S9. Comparison of redundant supporting observations of $\mathrm{NO}_{2}$ VCDs (left panel) and surface concentration (right panel). MAXDOAS retrieved values are plotted in the background. To improve visibility, tower measurement uncertainties (vertical error bars of typically $(6.0 \pm 0.5) \times 10^{10}$ molec cm $\left.^{-3}\right)$ are not shown. 

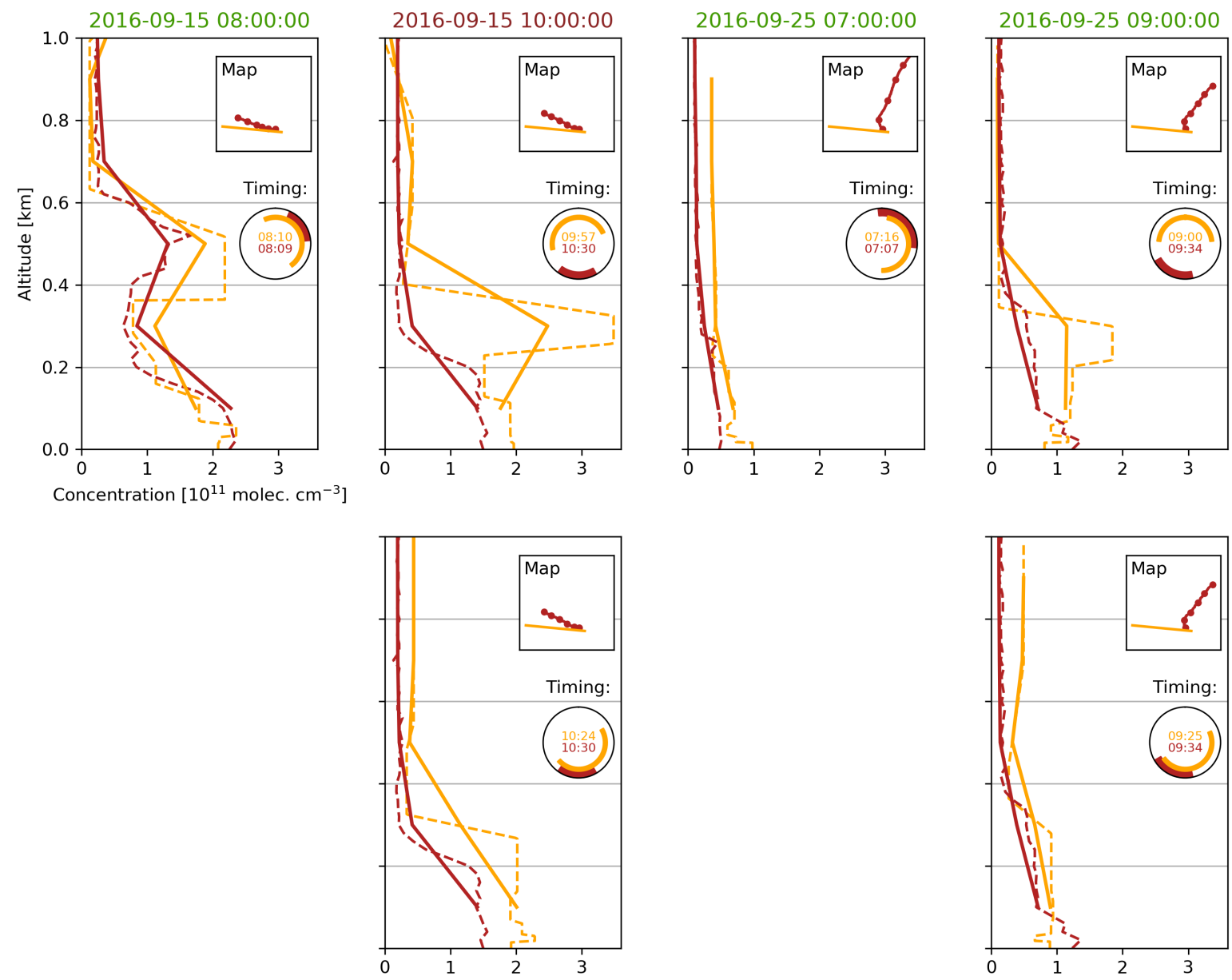

Figure S10. Top row: Comparison of $\mathrm{NO}_{2}$ lidar (orange) and radiosonde (red) profiles, that were assigned to a common MAX-DOAS profile timestamp according to Sect. 2.2.3 in the main text. Dashed lines represent original instrument resolution while thick lines show the concentrations averaged to the MAX-DOAS altitude grid. The colour of the dates indicates the cloud conditions. The rectangular little subplots show a map $(4 \mathrm{x} 4 \mathrm{~km})$ of the lidar line of sight and the sonde flight path. The dots on the sonde flight path mark the transitions between the retrieval layers. The polar plot (to be read like a clock) shows the temporal overlap between the two observations, together with the middle timestamps of each observation. Lower row: For the $2^{\text {nd }}$ and $4^{\text {th }}$ timestamp, there were lidar profiles available with improved temporal overlap (however, with a worse overlap with the corresponding MAX-DOAS profile). 


\section{S5 MAX-DOAS viewing distance}

Wagner and Beirle (2016) derived polynomial relationships between the "horizontal sensitivity range" (HSR, defined as the distance, at which the box airmass factors dropped to $1 / \mathrm{e}$ ) and $\mathrm{O}_{4}$ differential airmass factors (dAMF). Applying this approach to the CINDI-2 $\mathrm{O}_{4}$ dAMFs yields the HSRs shown in Fig. $\mathrm{S} 12$. A constant vertical $\mathrm{O}_{4}$ column of $1.19 \cdot 10^{43} \mathrm{molec}^{2} \mathrm{~cm}^{-5}$ 5 was assumed. The HSR for the actually retrieved layers is more complicated and not assessed here, as information aspects (which elevation contributes to information on which layer), geometrical limitations and the atmospheric state (trace gas and aerosol layer height) would have to be taken into account. Depending on the conditions, HSRs vary between a few and tens of kilometres (as shown in Fig. S11) defining whether only air masses over rural areas and/or urban areas (Gouda at $15 \mathrm{~km}$ distance, Zoetermeer at $30 \mathrm{~km}$ distance and The Hague at $40 \mathrm{~km}$ distance. to the measurement site) are sampled. Further, depending on the wind, plumes of Utrecht, Rotterdam or Amsterdam might be sampled. 


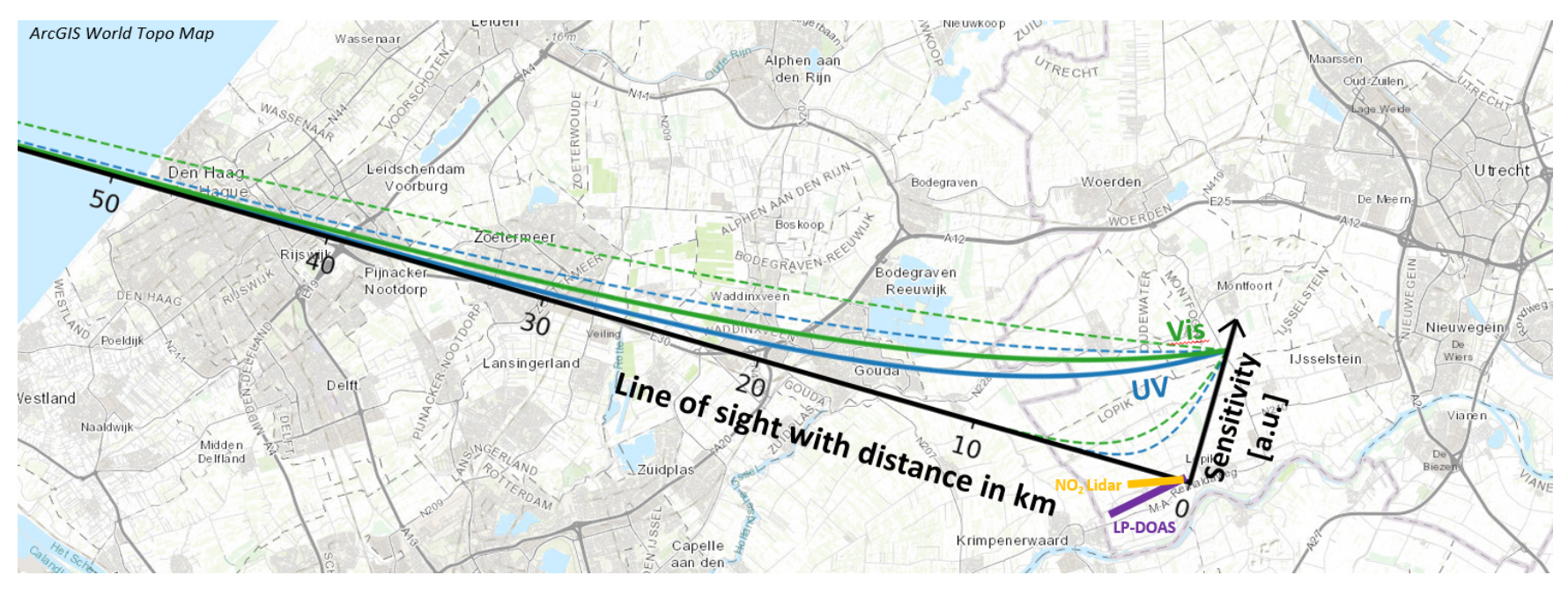

Figure S11. Line of sight of the MAX-DOAS instruments on a map (Esri et al., 2018). The coloured curves indicate the sensitivity for the average (solid), the minimum (dashed) and maximum (dashed) viewing distances encountered during the campaign in the UV (blue) and Vis (green).

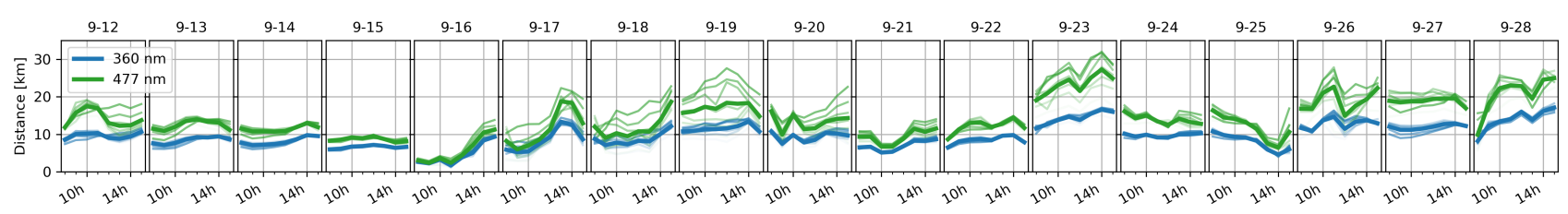

Figure S12. Viewing distance (HSR) of MAX-DOAS instruments during CINDI-2. It was calculated for different elevation angles (1, 2, 3, $4,5,6$ and $8^{\circ}$ with increasing transparency of the curves) and the average value for UV and Vis (thick lines).

\section{S6 Spatio-temporal mismatch and variability}

Given the MAX-DOAS horizontal sensitivity ranges determined in Sect. S5, approximate values for the spatio-temporal mismatch of MAX-DOAS and different supporting observations can be derived. They are given in Table S6. The potential impact

Table S6. Estimates for the average spatio-temporal mismatch of different supporting observations w.r.t. to the MAX-DOAS measurements. For the location of the MAX-DOAS observations the centers of mass of the horizontal sensitivity curves from Sect. S5 were used. For the location of sun photometer and direct-sun DOAS observations, the center of the lines of sight towards the sun up to $2 \mathrm{~km}$ atitude were considered.

\begin{tabular}{rcc}
\hline \hline Observation & Spatial mismatch $[\mathrm{km}]$ & Temporal mismatch [min] \\
\hline Sun photometer & 13 & 8 \\
Ceilometer & 11 & 0 \\
Direct-sun DOAS & 13 & 23 \\
$\mathrm{NO}_{2}$-Lidar & 10 & 9 \\
Radiosonde & 6 & 13 \\
LP-DOAS & 10 & 6 \\
In-situ in tower & 11 & 0
\end{tabular}


of these mismatches can be demonstrated by means of the $\mathrm{NO}_{2}$ surface concentration. The left panel of Fig. S13 shows observations of the $\mathrm{NO}_{2}$ surface concentrations at their original temporal resolution $\Delta t$ and integration time $t_{\text {int }}$. The CE-DOAS as a point measurement with $\Delta t=t_{\text {int }}=1 \mathrm{~min}$ shows very strong variability on short timescales. However, for the tower measurements (all in situ instruments in the tower vertically integrated as described in main text Sect. 2.2 .5 at $\Delta t=20 \mathrm{~min}$ and

$\left.5 t_{\text {int }} \approx 5 \mathrm{~min}\right)$, the LP-DOAS $\left(\Delta t=32 \mathrm{~min}, t_{\text {int }} \approx 100 \mathrm{~s}\right)$ there is already significant smoothing. The 1D-MAX-DOAS data was recorded by DLR (see Supplement S10), who retrieved profiles in the nominal azimuth direction $\left(287^{\circ}\right)$ more or less continuously ( $\Delta t=15 \mathrm{~min}, t_{\text {int }} \approx 10 \mathrm{~min}$ ). In all measurements there is significant variation on the sub-hour timescale. Further, spatial variability might be observed in the form of disagreement between UV and Vis observations of the 1D-MAX-DOAS as viewing distance and thus the sampled air volume changes between the two spectral ranges (see Supplement S5). To estimate the order of magnitude, the right panel of Fig. S13 shows a kind of autocorrelation of the total campaign time series of each observation. The RMSD between the original and a temporally shifted signal is calculated. 1D MAX-DOAS Vis data is not shown, as multiple gaps in the data complicated the autocorrelation. Comparing this figure with values from Table S6 yields that spatio-temporal variability causes RMSD values of around $3.5 \times 10^{10}$ molec cm ${ }^{-3}$ in the $\mathrm{NO}_{2}$ surface concentration, which is indeed of the order of the observed RMSD values in the $\mathrm{NO}_{2}$ surface concentration comparisons within this study (approx.

$155 \times 10^{10}$ molec $\mathrm{cm}^{-3}$, compare to main text Fig. 22).

For another demonstration of the spatial variability, we refer to data from the IMPACT instrument (Peters et al., 2019), an imaging MAX-DOAS operated by IUP-Bremen (IUPB) which allows to perform elevation "scans" in different azimuth viewing directions in quick succession. During CINDI-2, the IMPACT performed full-azimuthal scans in $10^{\circ}$ steps every 15 minutes. Figure $\mathrm{S} 14$ exemplarily shows the observed $\mathrm{NO}_{2}$ Vis dSCDs at $4^{\circ}$ elevation on the 20 September 2016 together with dSCDs measured by the IUPB standard MAX-DOAS instrument in the nominal azimuth direction $\left(287^{\circ}\right.$, compare main text Sect. 2.1). The red shaded area depicts the variation of the dSCD with azimuth viewing direction. In particular around local noon this variation is tremendous, exceeding a factor of five. Further investigation on this issue can be found in Peters et al. (2019).
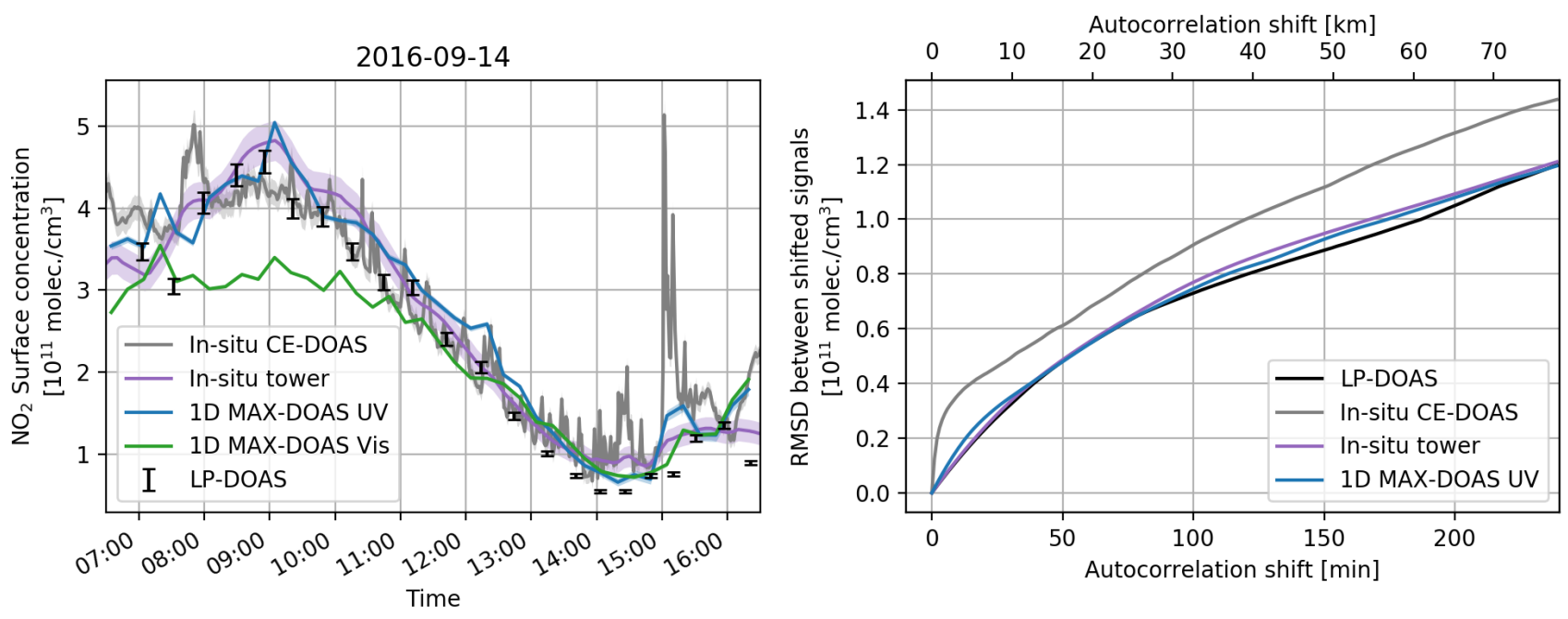

Figure S13. Left: Different observations of the $\mathrm{NO}_{2}$ surface concentrations on 14 September 2016, each at its original temporal resolution to reveal short-term variations. Coloured areas behind the lines indicate the specified uncertainties. Right: RMSD values obtained from a kind of autocorrelation analysis over the whole campaign (night times excluded). For each observation, the RMSD between the original and a temporally shifted signal is calculated. The temporal shift (bottom horizontal axis) was varied between 0 and 4 hours. The temporal shift was roughly converted to its spatial equivalent by multiplication with the average observed wind speed in the surface layer $(\approx 5 \mathrm{~m} / \mathrm{s})$, yielding the top horizontal axis. 


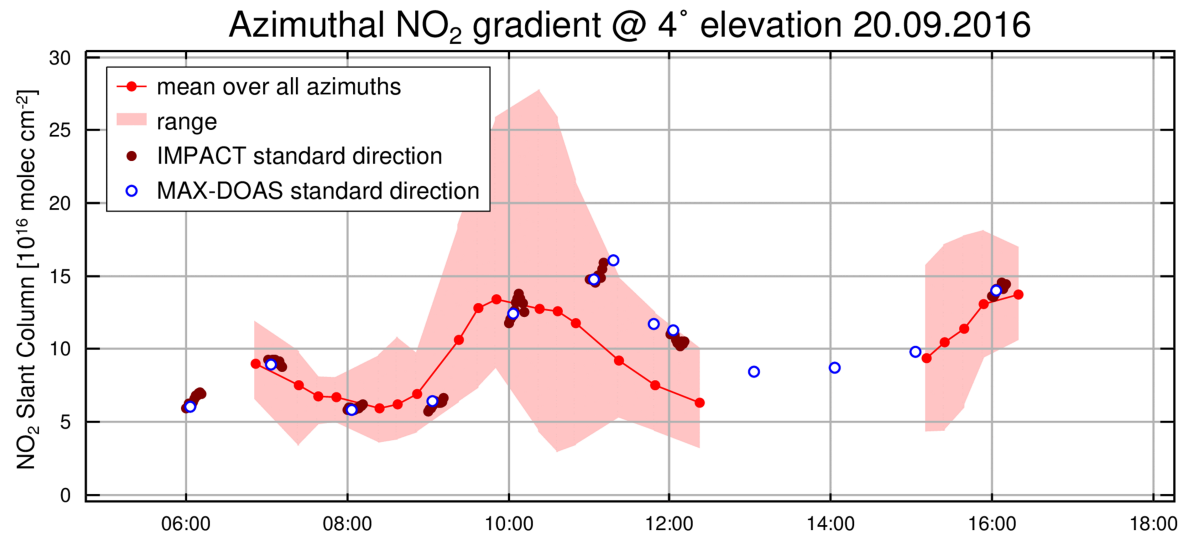

Figure S14. Variation in the $\mathrm{NO}_{2}$ Vis dSCDs with different azimuth viewing directions at $4^{\circ}$ elevation, as observed by the IMPACT imaging MAX-DOAS (Peters et al., 2019). Around local noon this variation is largest, exceeding a factor of 5. The time is UTC.

\section{S7 Impact of the choice of pressure and temperature profiles for the RTMs}

Pressure $(p)$ and temperature $(T)$ profiles used for the RTMs within this study are averaged sonde measurements performed in De Bilt by KNMI during September months of the years 2013-2015 (see main text Sect. 2.1.3). To estimate the effect of this approximation on the results, IUPHD/ HEIPRO retrieved an additional set of profiles, using $p$ and $T$ information from radiosondes launched at KNMI (De Bilt) during the campaign. Between one and three sondes were launched every day except on 16 September. For each profile inversion, the temporally closest sonde observation was used. Table S7 shows the difference in RMSD and Bias magnitude between these results and the "standard" results of IUPHD/ HEIPRO (that used the prescribed averaged $p$ and $T$ profiles from years before) relative to the average RMSDs and average Bias magnitude for all participants.

The impact on the dSCD comparison is less than 5\% for both, RMSDs and Bias magnitudes. For AOTs, VCDs and surface concentrations, significant improvement $(>10 \%$ in RMSD) is only observed for HCHO surface concentrations $(17 \%)$ that contrasts with a deterioration for UV AOTs by $13 \%$. The average improvement in RMSD for AOTs, VCDs and surface concentrations is $3.2 \%$. The overall consistency between MAX-DOAS and supporting observations can thus be considered to remain similar, despite larger changes in some Bias magnitudes are observed (up to $51 \%$ improvement for $\mathrm{NO}_{2}$ Vis surface concentrations and up to $20 \%$ deterioration for UV AOTs).

Table S7. The differences in RMSDs and Bias magnitudes for the IUPHD/ HEIPRO results arising from using daily $p$ and $T$ profiles, relative to the average RMSDs and Bias magnitudes assessed within the main study. Values are given for the comparisons of modelled and measured dSCDs ("dSCDs") and the comparisons against the supporting observations of AOTs, VCDs and surface concentrations as described in the main text. Minus signs indicate improvement. Only clear sky conditions were considered.

\begin{tabular}{lllllll}
\hline & dSCDs & & AOT/VCD & & Surface \\
& $\Delta$ RMSD [\%] & $\Delta$ Bias [\%] & $\Delta$ RMSD [\%] & $\Delta$ Bias [\%] & $\Delta$ RMSD [\%] & $\Delta$ Bias [\%] \\
\hline $\mathrm{HCHO}$ & 2.7 & 3.5 & 6.8 & 10.5 & -17.4 & -22.0 \\
$\mathrm{NO}_{2}$ UV & -0.7 & -1.1 & -2.7 & -2.6 & -3.5 & 8.7 \\
$\mathrm{NO}_{2}$ Vis & -0.7 & -3.3 & -0.8 & -1.0 & -2.8 & -50.9 \\
Aerosol UV & -0.7 & 0.7 & 12.5 & 20.2 & - & - \\
Aerosol Vis & -0.2 & 2.1 & -8.7 & -40.1 & - & - \\
\hline
\end{tabular}




\section{S8 Further details on the comparison results}

\section{S8.1 AVKs of individual participants}

Figures S35 to S39 show the averaging kernels (AVKs) and retrieved degrees of freedom of signal (DOFS) of each participant for aerosol UV. For explanation of colours and symbols please refer to main text Sect. 3.1. The DOFS values in brackets were
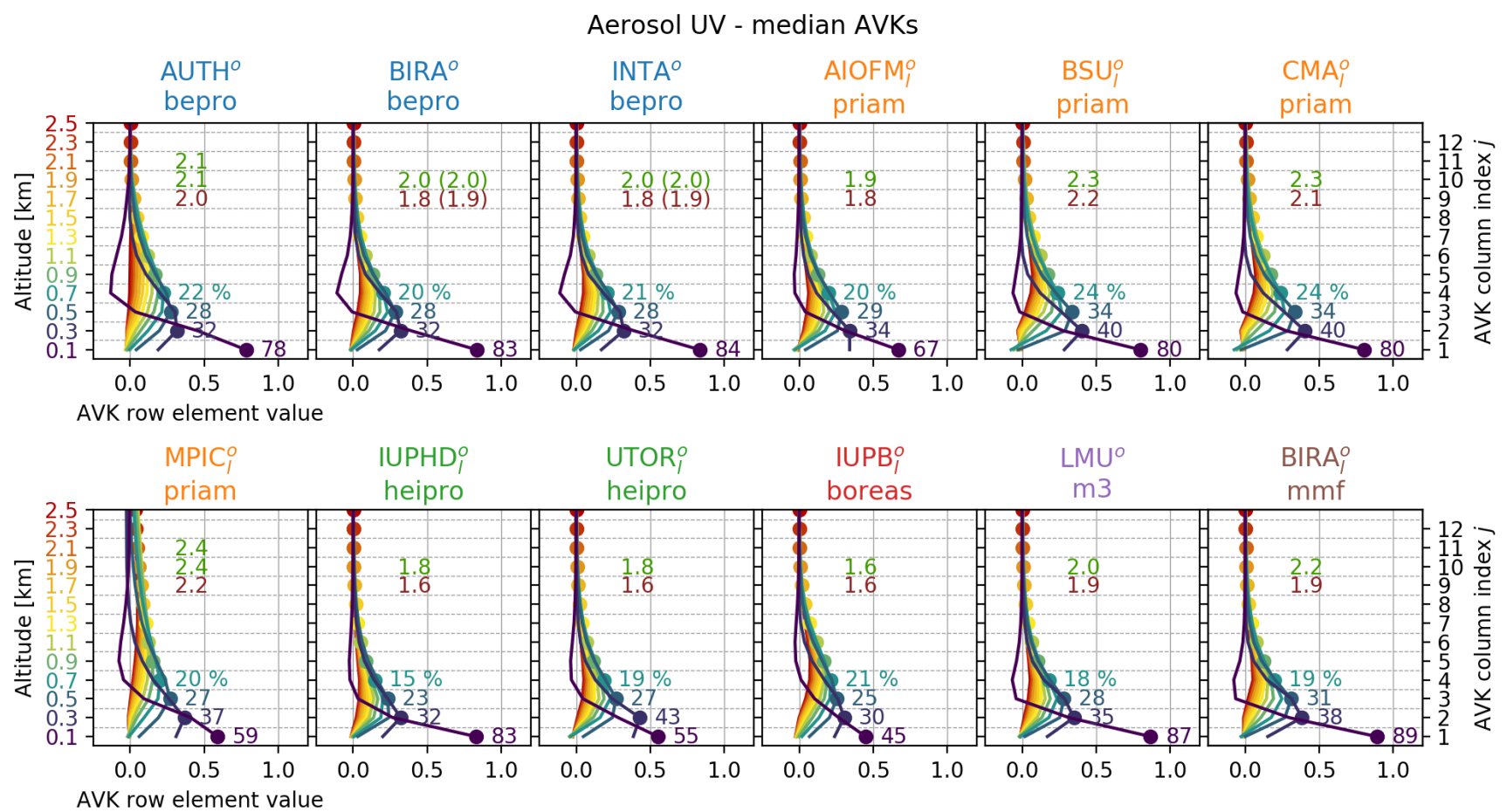

Figure S15. Mean averaging kernels for Aerosol UV for each participant. Coloured values at AVK peaks show the amount of retrieved information on the respective layer in percent. "DOFS" numbers are given for clear-sky (green) and cloudy (red) conditions. Values in brackets are DOFS including flagging. 
Aerosol Vis - median AVKs
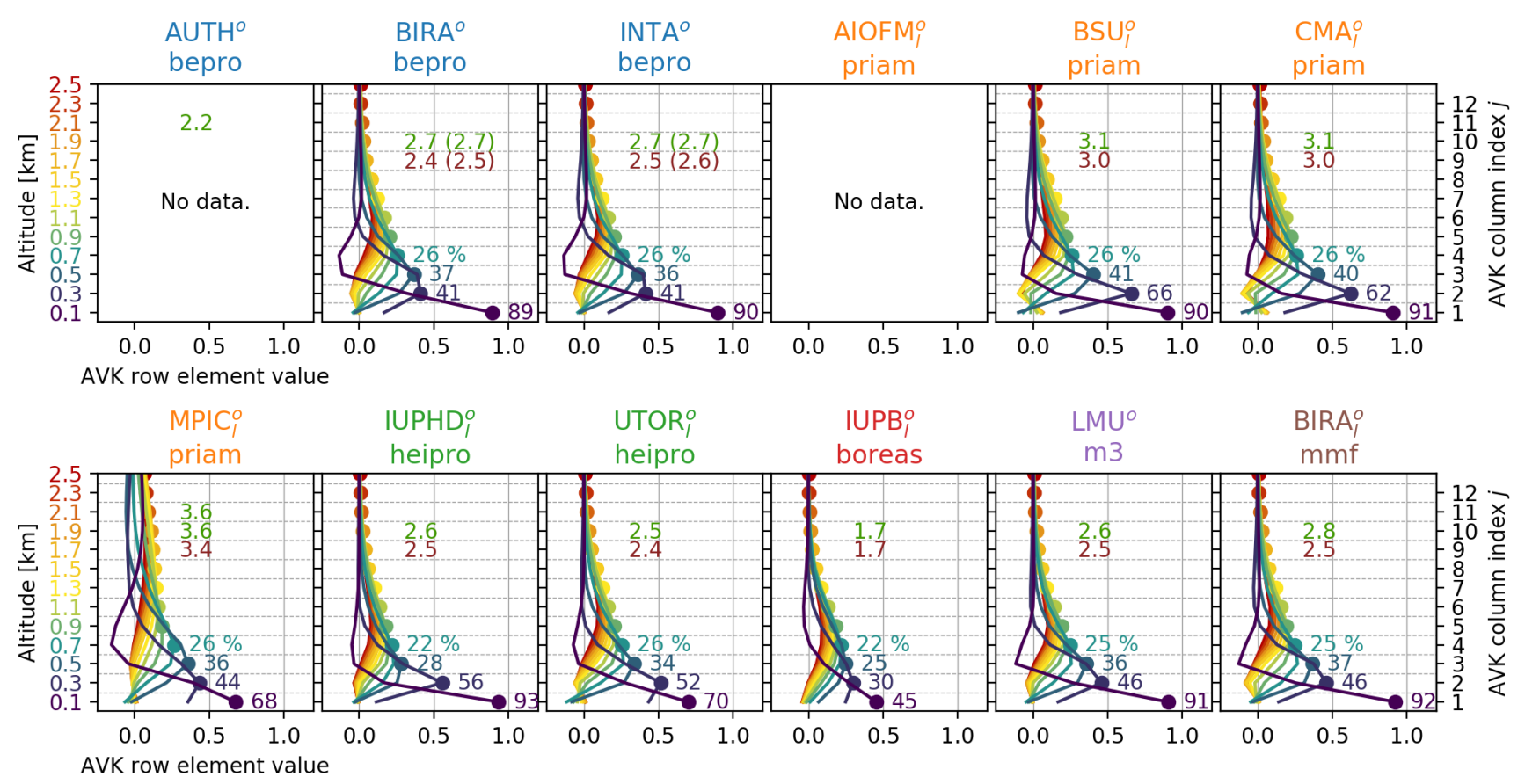

Figure S16. Mean averaging kernels for Aerosol Vis for each participant. Description of Fig. S35 applies. 


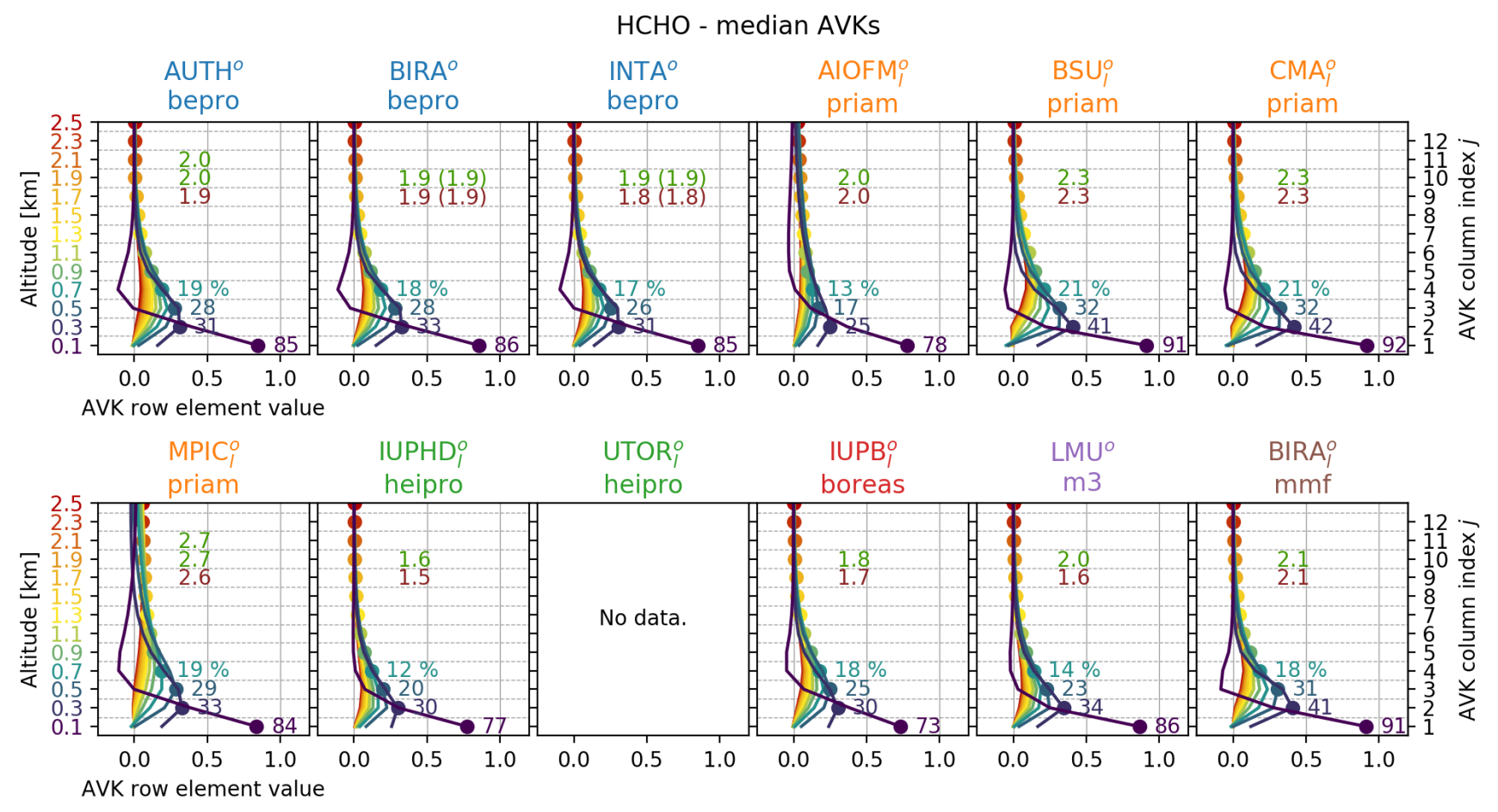

Figure S17. Mean averaging kernels for HCHO for each participant. Description of Fig. S35 applies. 


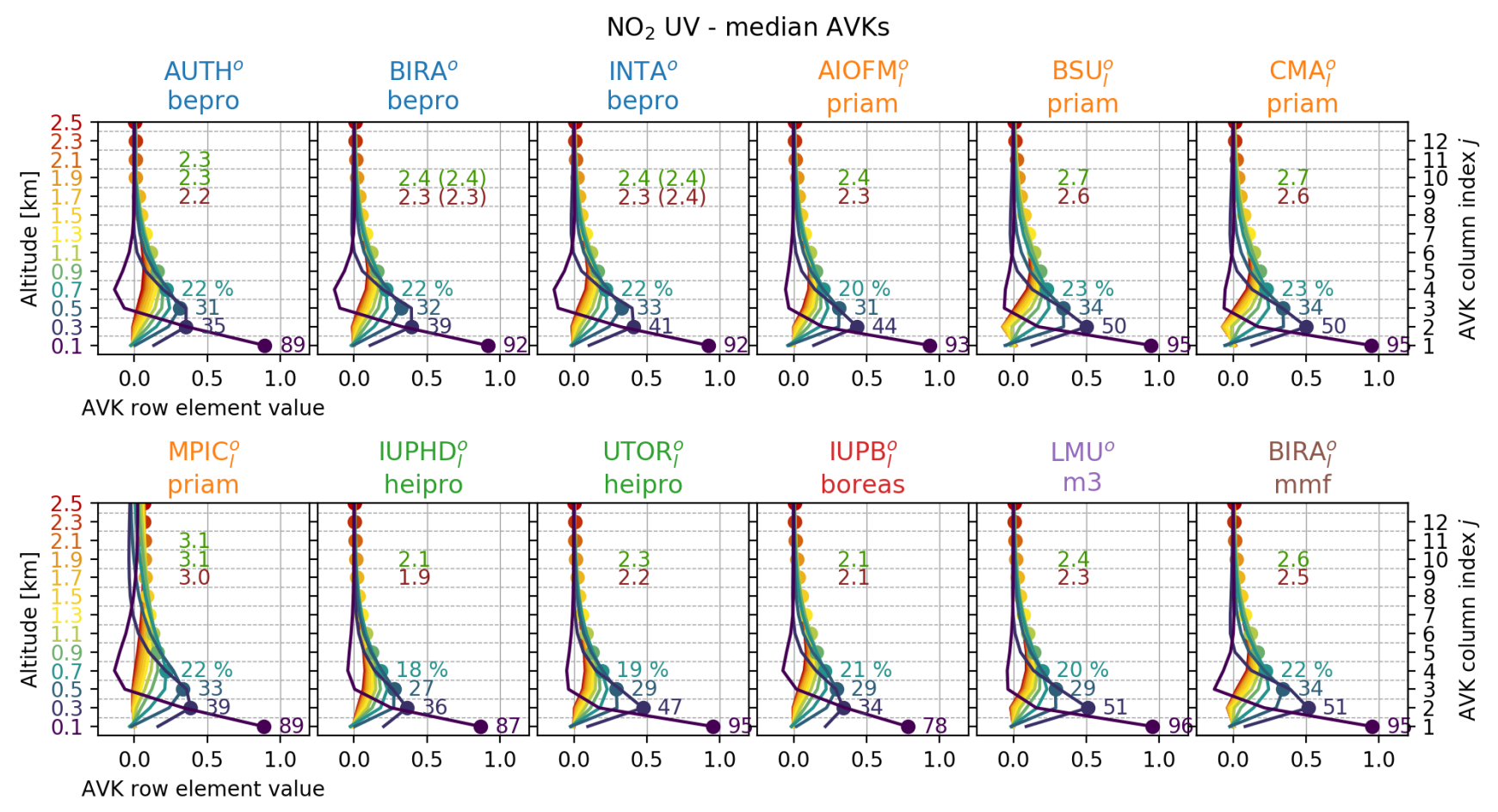

Figure S18. Mean averaging kernels for $\mathrm{NO}_{2}$ UV for each participant. Description of Fig. S35 applies. 


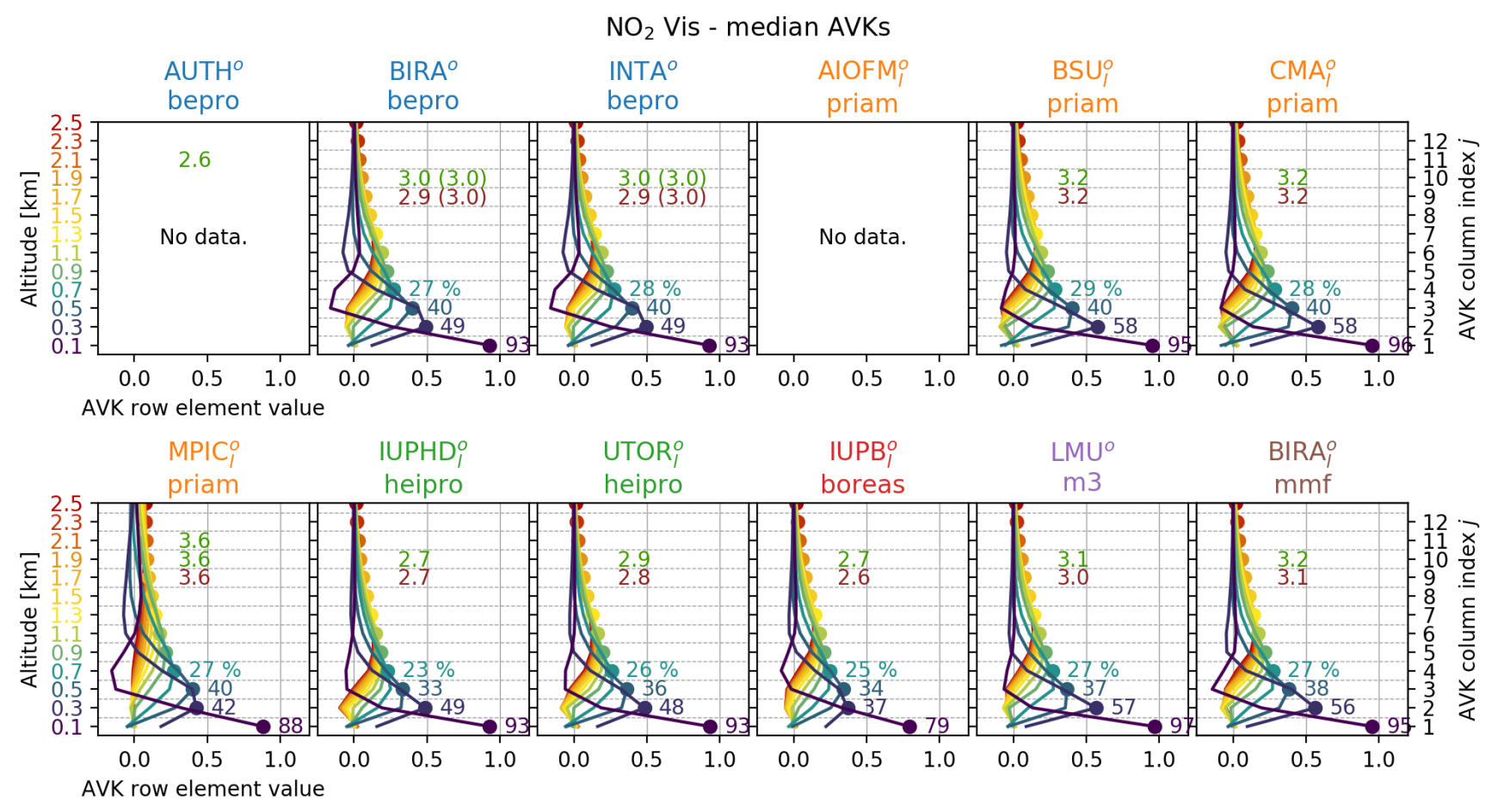

Figure S19. Mean averaging kernels for $\mathrm{NO}_{2}$ Vis for each participant. Description of Fig. S35 applies. 


\section{S8.2 Profile deviation statistics}

Figures S20 to S24 show statistics on the observed differences in the retrieved profiles for all five species. The plots on the left compare the retrieved profiles of individual participants $\boldsymbol{x}$ to the median MAX-DOAS profiles $\overline{\boldsymbol{x}}$. While the vertical axes represent altitude, the horizontal axes depicts the difference $\boldsymbol{x}-\overline{\boldsymbol{x}}$. The coloured boxes indicate the $25 \%-75 \%$ percentile,

5 whiskers are 5\%-95\%. Black dots indicate the mean value. For each layer there are boxplots for clear-sky (green) and cloudy conditions (red). Note that for aerosol there are two different horizontal axes defined for the two cloud conditions: the green scale at the bottom and the red scale on the top of each plot. Only valid data (flagged) was considered. For aerosol and $\mathrm{NO}_{2}$ a plot on the very right shows statistics of the difference of supporting measurements $\boldsymbol{x}_{\text {anc }}$ (lidar/ radiosonde for $\mathrm{NO}_{2}$, sun photometer scaled ceilometer for aerosol) to the median $\overline{\boldsymbol{x}}$, hence $\boldsymbol{x}_{\boldsymbol{a} \boldsymbol{} \boldsymbol{c}}-\overline{\boldsymbol{x}}$. The numbers in all the plots show RMSD deviation of the three lowest (most sensitive) layers. Dashed lines indicate the median retrieval uncertainty as specified by the participants.
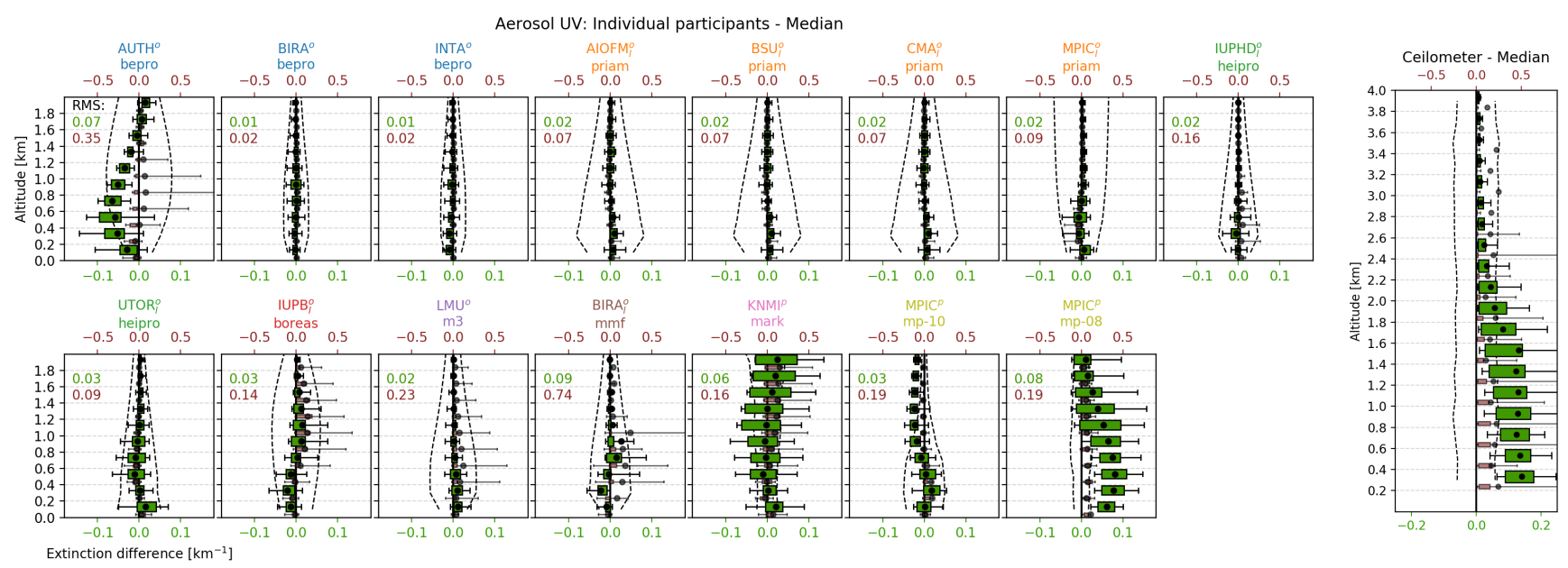

Figure S20. Left: Deviations of Aerosol UV profiles (valid only) of individual participants from the MAX-DOAS median profiles. Dots show the mean, boxes indicate the (25\%-75\%) percentile, and whiskers show (25\%-75\%) percentile. Green (red) box-whiskers represent clear (cloudy) conditions. Note, that there are different x-scales (on top and bottom of the plot) for different cloud conditions. The average standard deviations specified by the participants are indicated by the dashed lines. Right: Deviation of the AOT scaled ceilometer backscatter signal to the MAX-DOAS median profiles. The numbers in the plots indicate RMSD values for clear sky (green) and cloudy (red) conditions. Further details are given in the related text in Sect. S8.2 

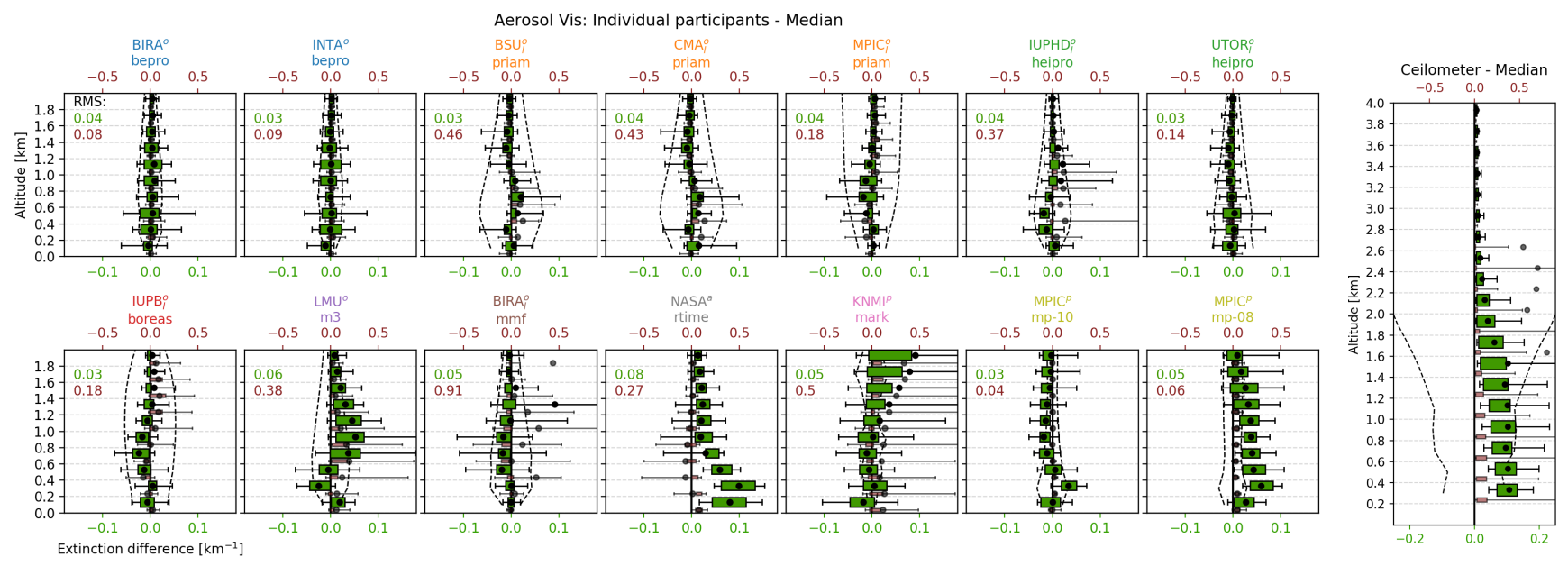

Figure S21. Deviations of Aerosol Vis profiles (valid only) of individual participants from the MAX-DOAS median profiles. Description of Fig. S20 applies.

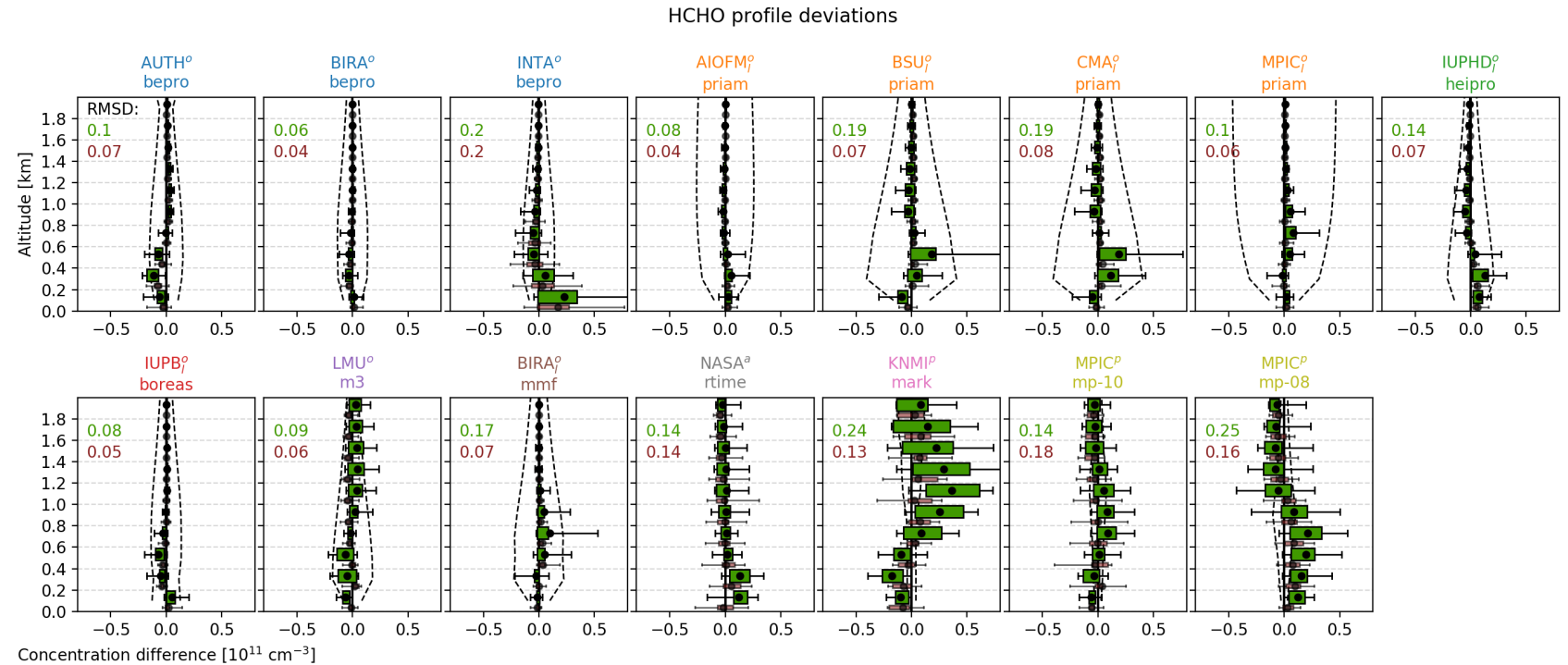

Figure S22. Deviations of HCHO profiles (valid only) of individual participants from the MAX-DOAS median profiles. The description of Fig. S20 applies but for $\mathrm{HCHO}$, there is no independent reference profile available. 
$\mathrm{NO}_{2}$ UV: Individual participants - Median
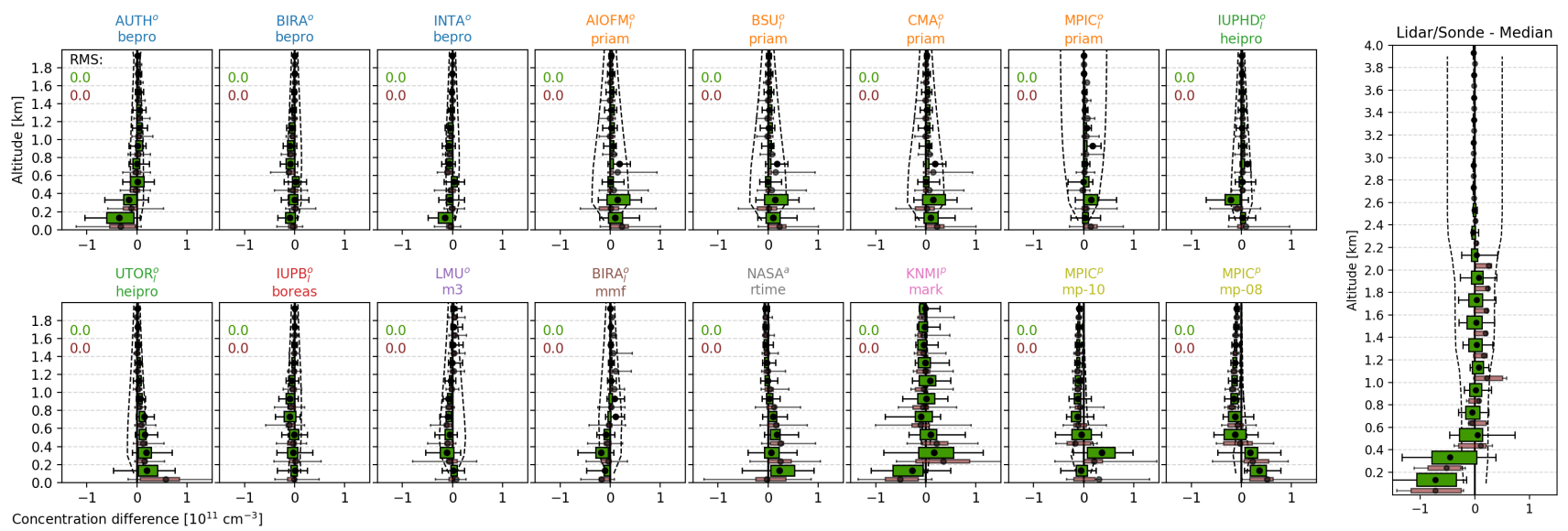

Figure S23. Deviations of $\mathrm{NO}_{2}$ UV profiles (valid only) of individual participants from the MAX-DOAS median profiles. The description of Fig. S20 applies. On the right, deviation of the median retrieved profiles from the few available $\mathrm{NO}_{2}$ lidar and sonde profiles are shown.

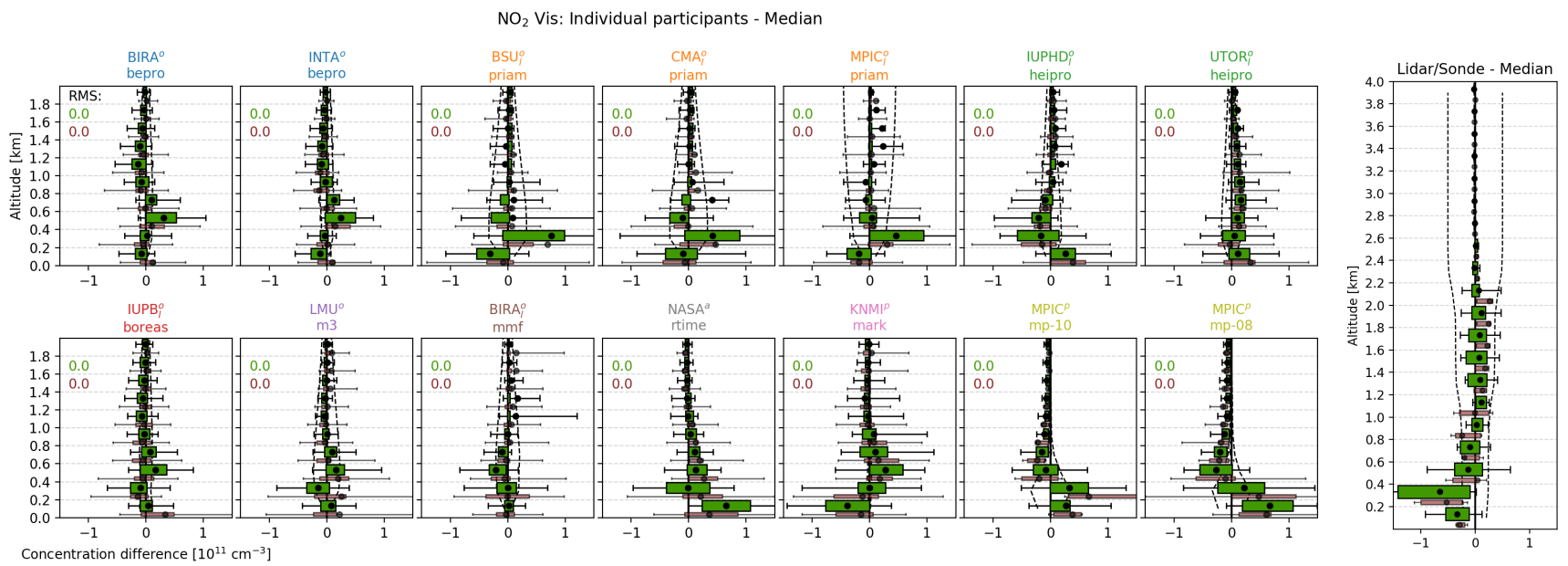

Figure S24. Deviations of $\mathrm{NO}_{2}$ Vis profiles (valid only) of individual participants from the MAX-DOAS median profiles. The description of Fig. S23 applies. 

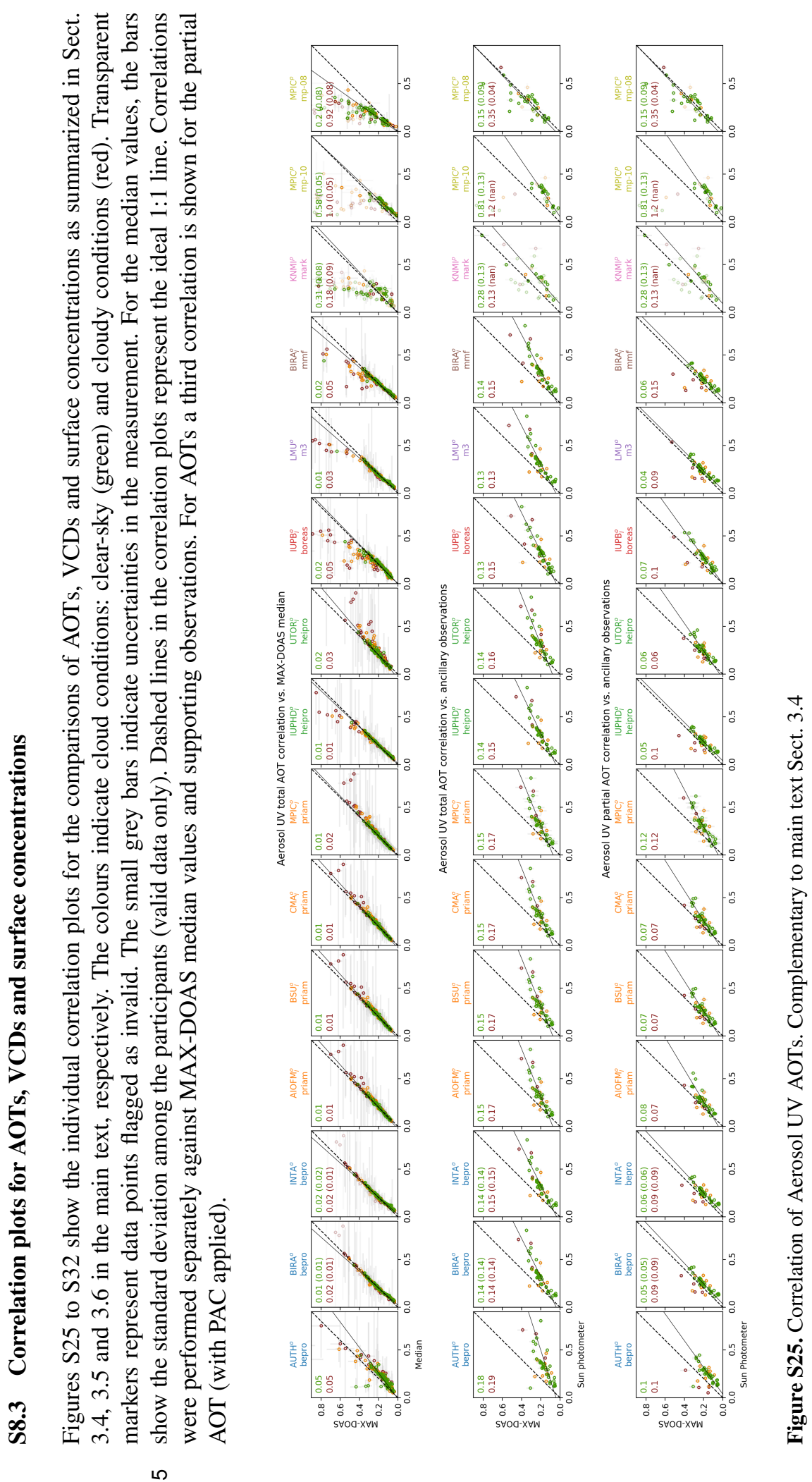

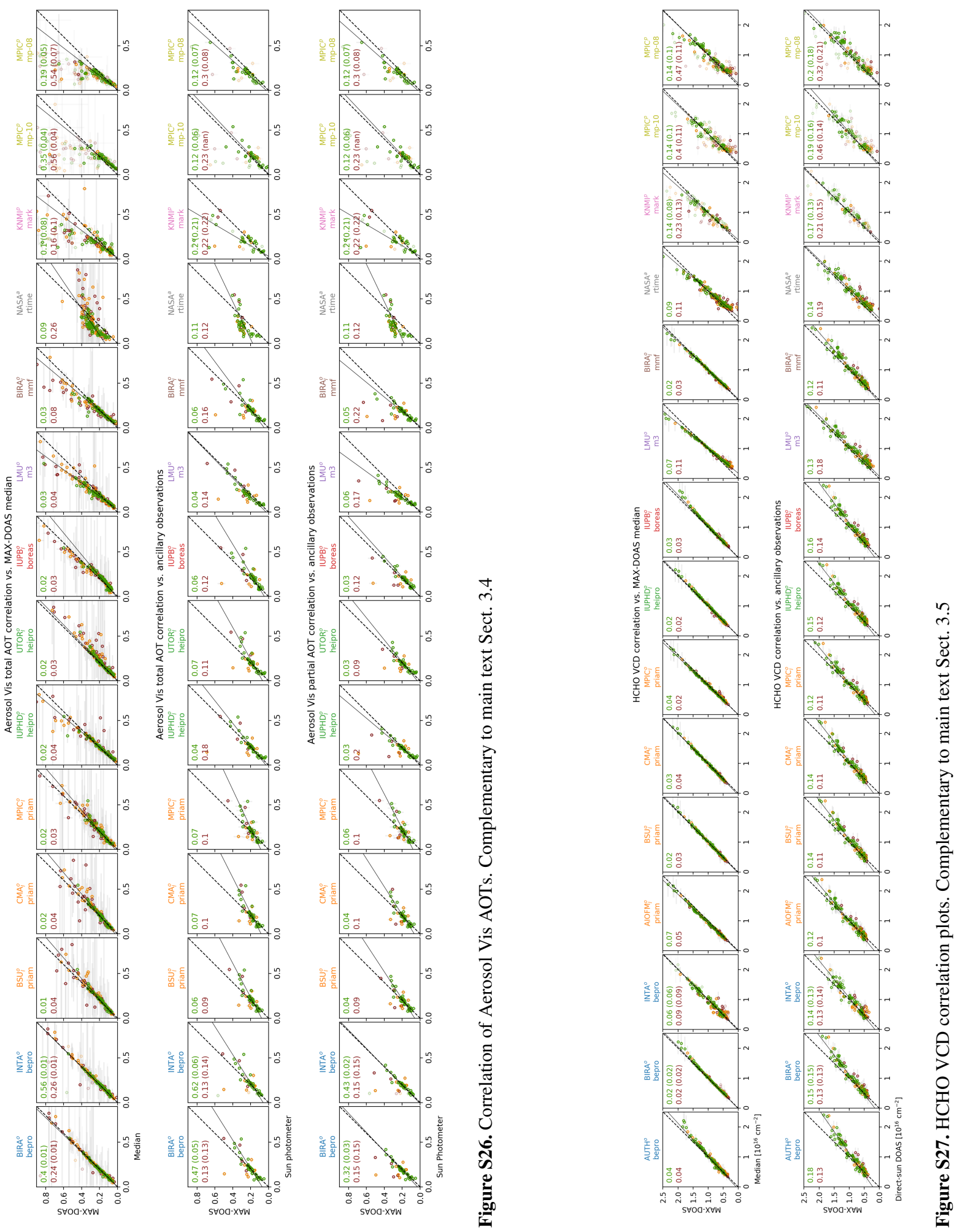

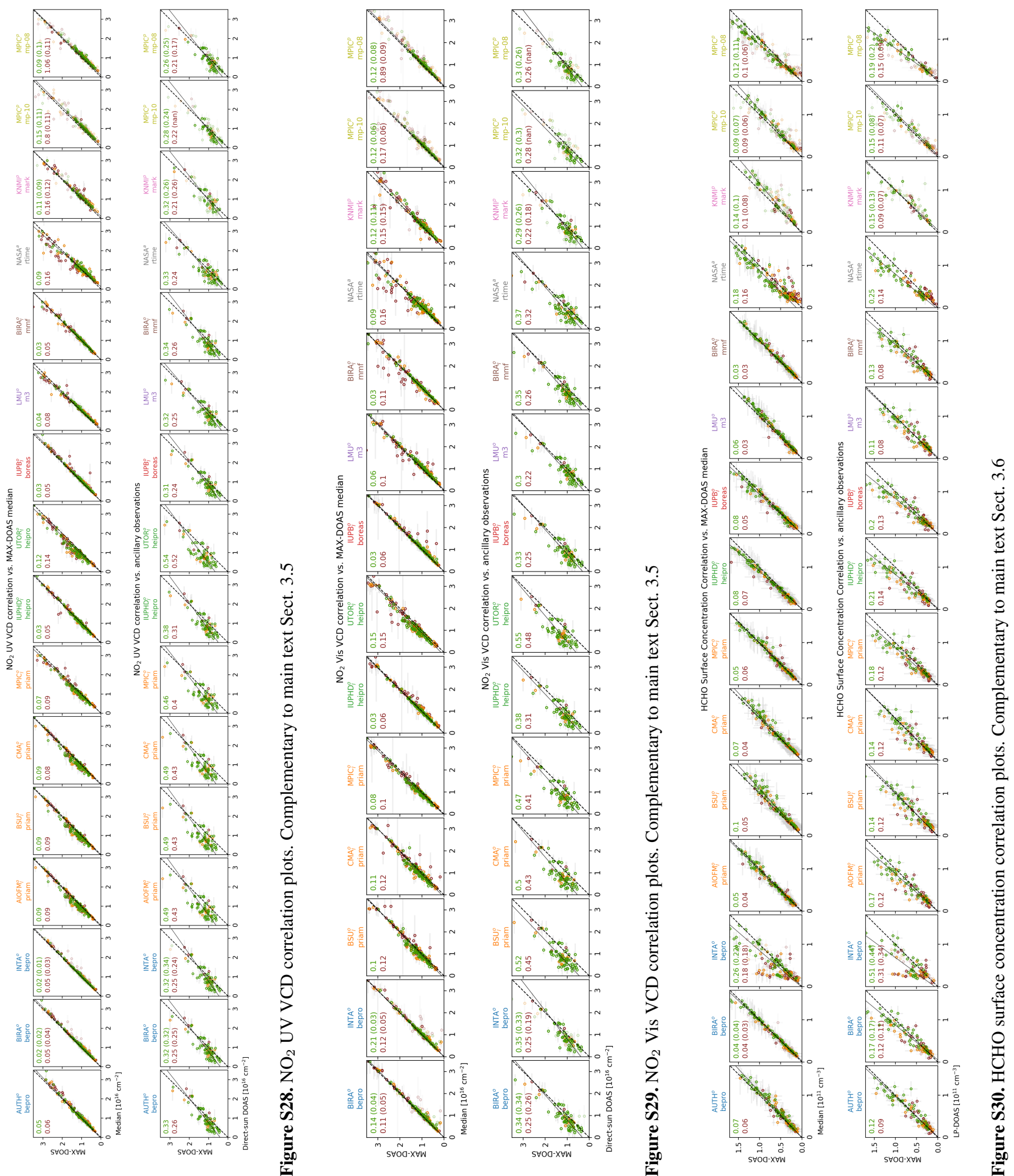

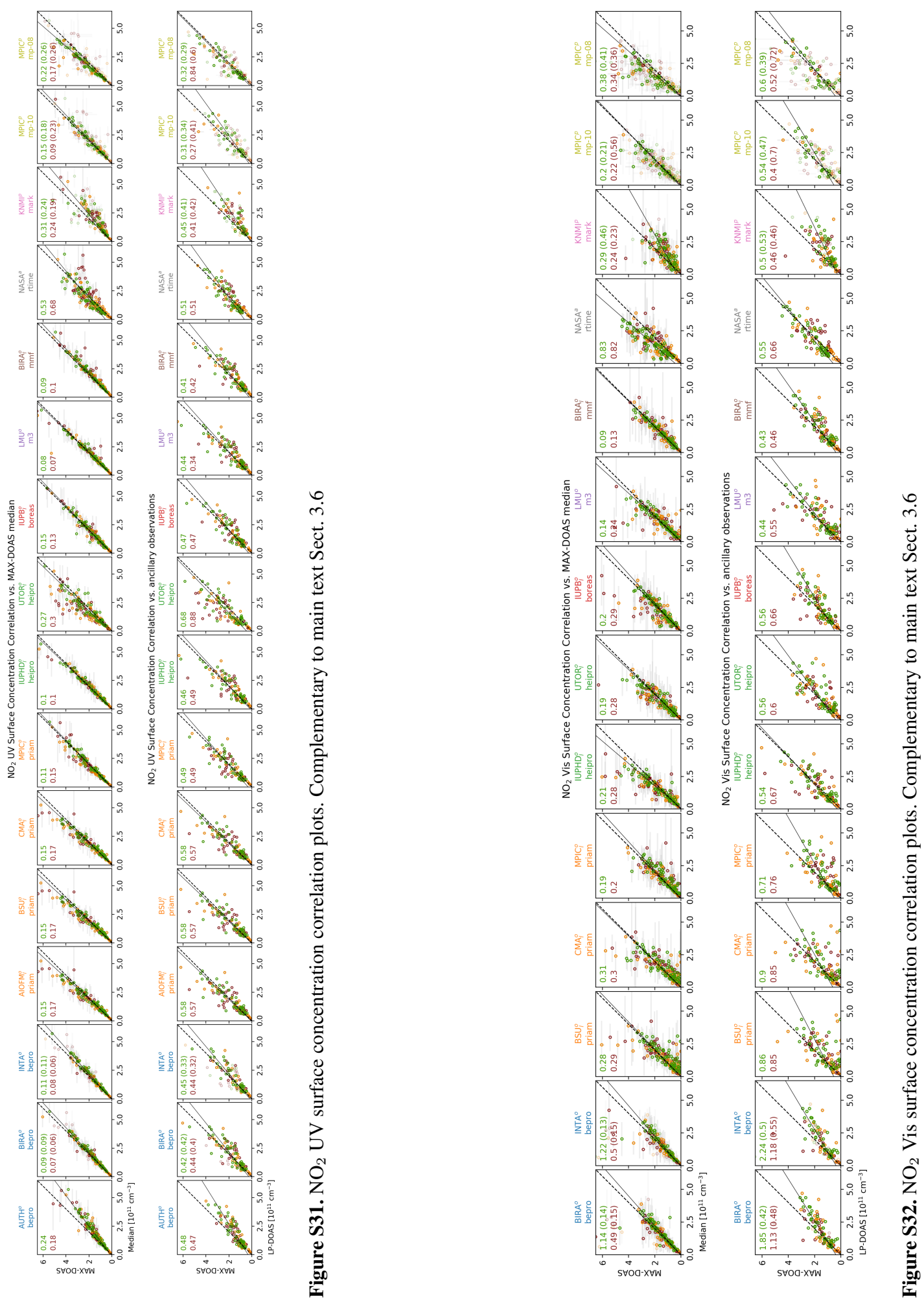


\section{S9 Impact of smoothing on surface concentration}

For $\mathrm{NO}_{2}$ the impact of smoothing effects on the surface concentration retrieved by OEM algorithms can be estimated from profiles of the $\mathrm{NO}_{2}$ lidar and radiosondes. Each profile is smoothed according to Eq. (9) in the main text and the difference in surface concentration between the smoothed and the unsmoothed profile is calculated. Fig. S33 shows histograms of the

5 calculated differences. The standard deviation is about $5 \times 10^{9} \mathrm{molec} \mathrm{cm}^{-3}$ which is only about $10 \%$ of the total average RMSD between MAX-DOAS and LP-DOAS observations. An estimate of the impact of smoothing on the retrieval results is actually provided by the OEM retrievals themselves as the "smoothing error". The specified smoothing errors are also indicated in Fig. S33 and are similar to the standard deviation observed in in this test, meaning that for the surface layer they are well representative for the real impact of smoothing.
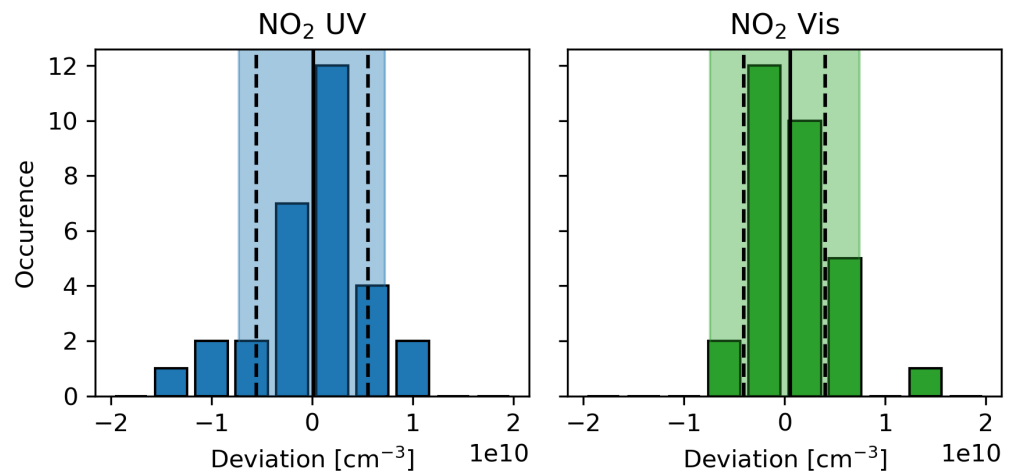

Figure S33. Histograms of the observed deviations in surface concentration between raw and smoothed lidar/ radiosonde $\mathrm{NO}_{2} \mathrm{profiles}$. Solid and dashed lines indicate mean value and standard deviation, respectively. Coloured areas represent the median smoothing errors as specified by the OEM retrievals, which is in good agreement with the deviations obtained from the supporting $\mathrm{NO}_{2}$ profiles.

\section{S10 Participant's own dSCD comparison results}

This section shows the comparison results for the case where each participant uses dSCDs measured with his own instrument. Evaluation and plots are fully equivalent to Sect. 3 in the main text. With DLR (German Aerospace Center, Oberpfaffenhofen, Germany, marked by blue squares) and USTC (University of Science and Technology of China, Hefei, China, marked by green squares), two other participants were included here, retrieving profiles with bePRO and HEIPRO, respectively. Gaps in the data are mostly related to instrument malfunction during the campaign. Further, not all instruments covered the spectral range to detect all desired species and the corresponding participants therefore do not appear in the respective plots.

\section{S10.1 Information content}

Information on the averaging kernels and DOFS. This section is equivalent to Sect. S10.1 in the main text and Sect. S8.1 in this supplement, respectively. 
Median AVKs
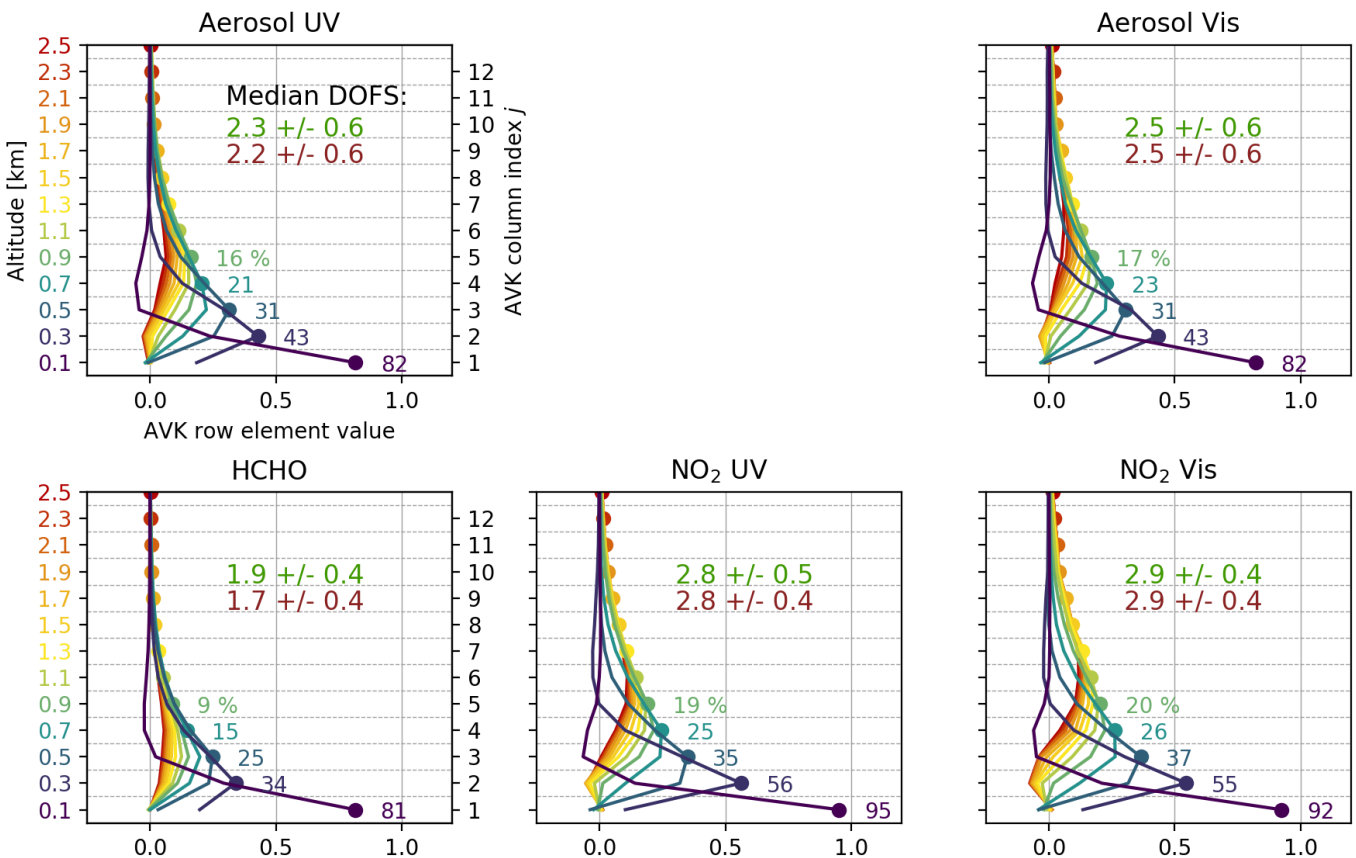

Figure S34. Average AVKs for the retrieved species (median over participants, mean over time). Each altitude and corresponding AVK line are associated with a colour, which is defined by the colour of the corresponding altitude-axis label. The dots mark the AVK diagonal elements. The number next to the dots show the exact value in percent, which corresponds to the amount of retrieved information on the respective layer. In the upper right of each panel, the DOFS (median among institutes, average over time) are given for clear-sky (green) and cloudy conditions (red). 


\section{Aerosol UV - median AVKs}

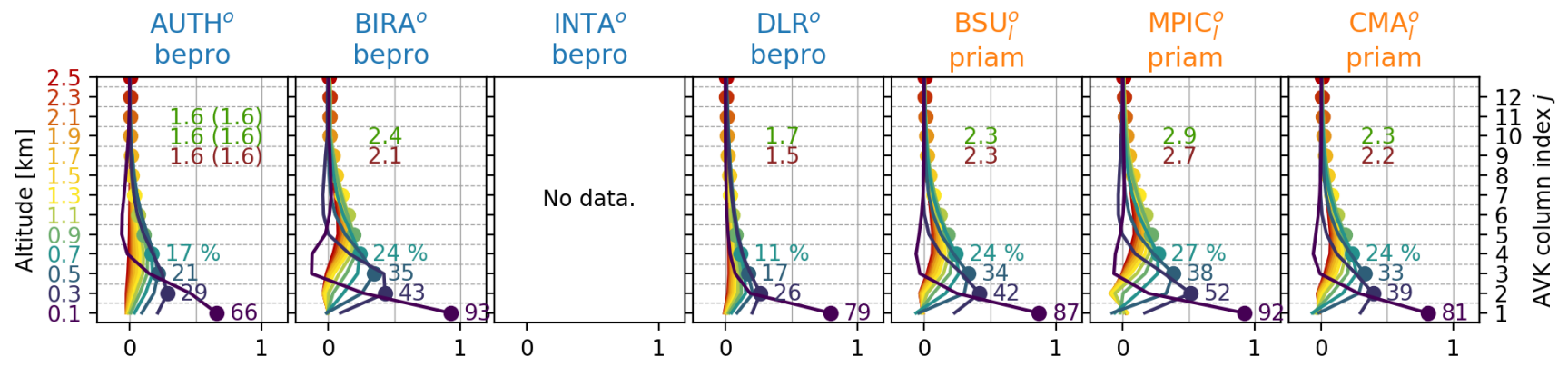

AVK row element value

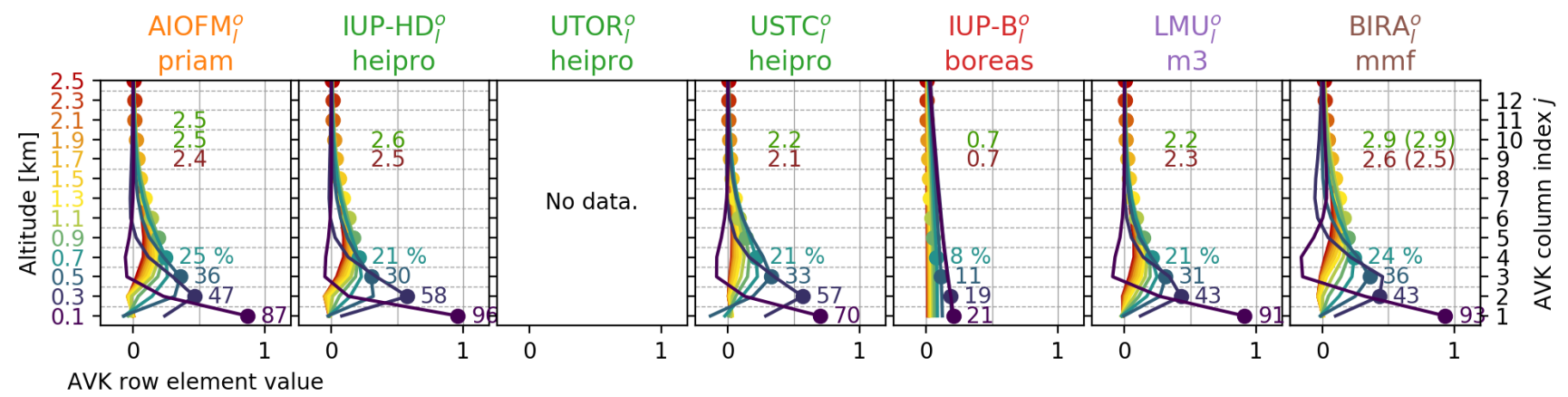

Figure S35. Mean averaging kernels for Aerosol UV for each participant retrieving from their own dSCDs. Coloured values at AVK peaks show the amount of retrieved information on the respective layer in percent. "DOFS" numbers are given for clear-sky (green) and cloudy (red) conditions. Values in brackets are DOFS including flagging. 
Aerosol Vis - median AVKs

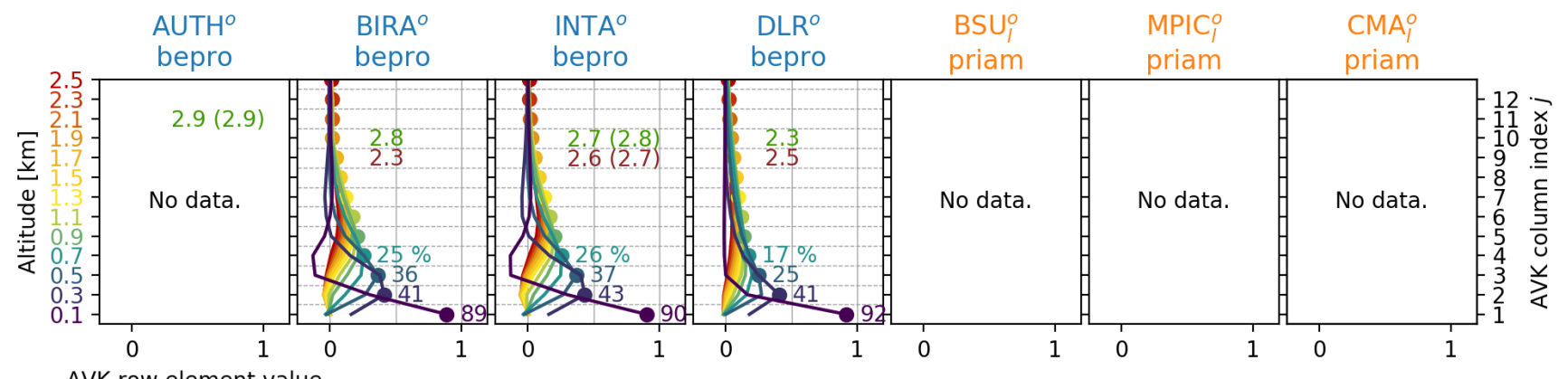

AVK row element value

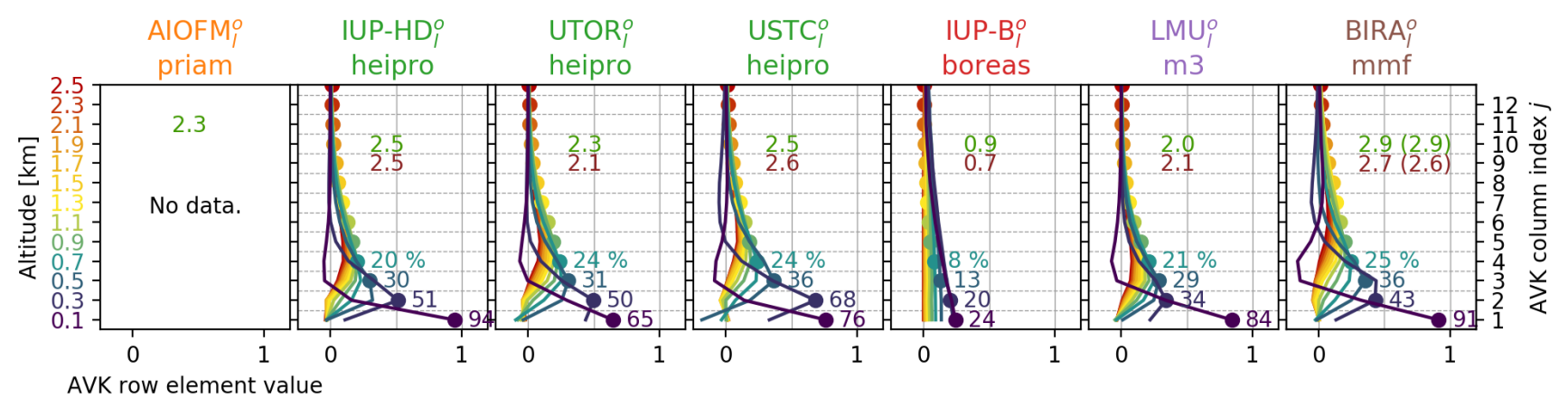

Figure S36. Mean averaging kernels for Aerosol Vis for each participant. Description of Fig. S35 applies. 

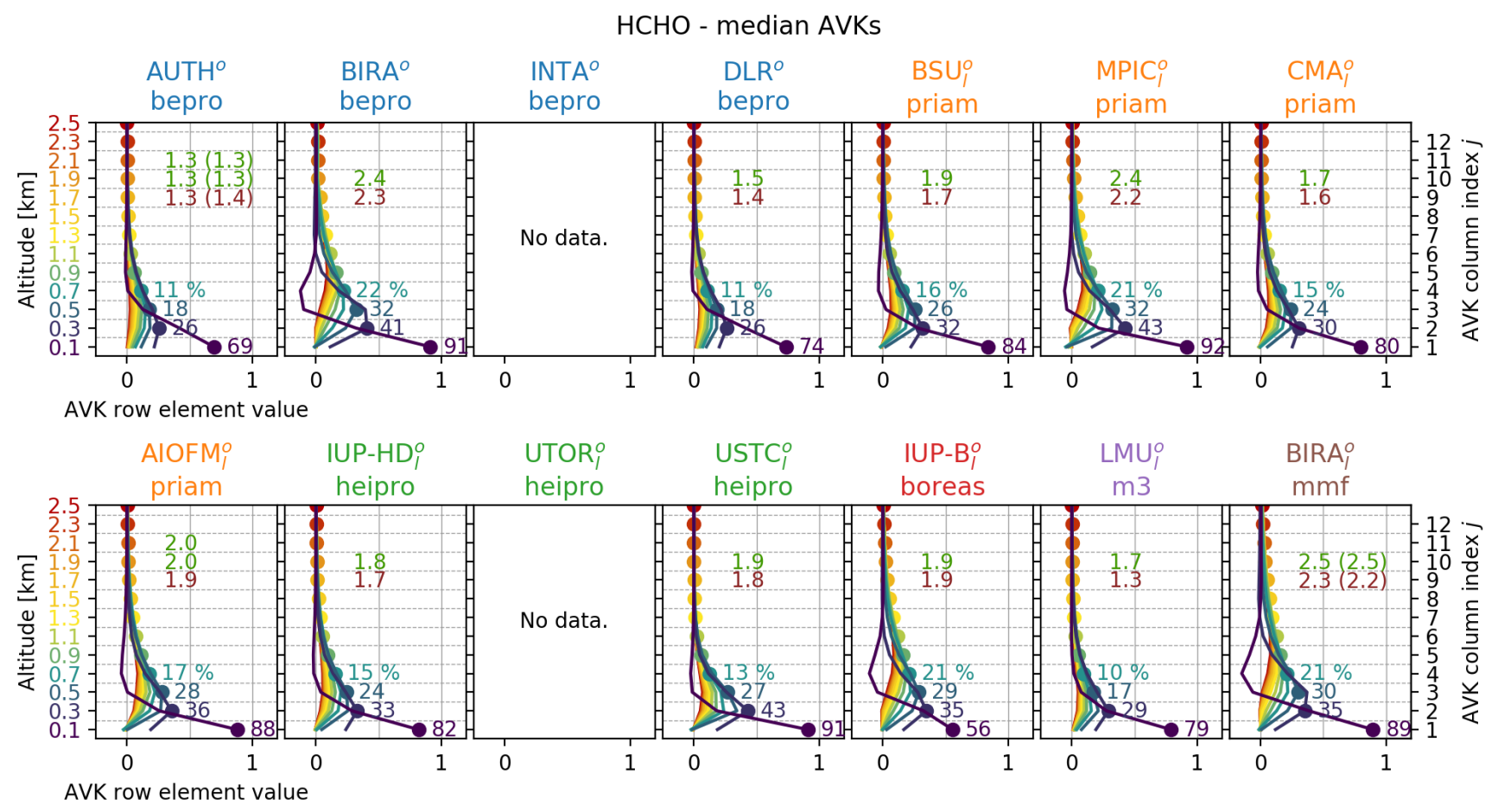

Figure S37. Mean averaging kernels for HCHO for each participant. Description of Fig. S35 applies. 
$\mathrm{NO}_{2}$ UV - median AVKs
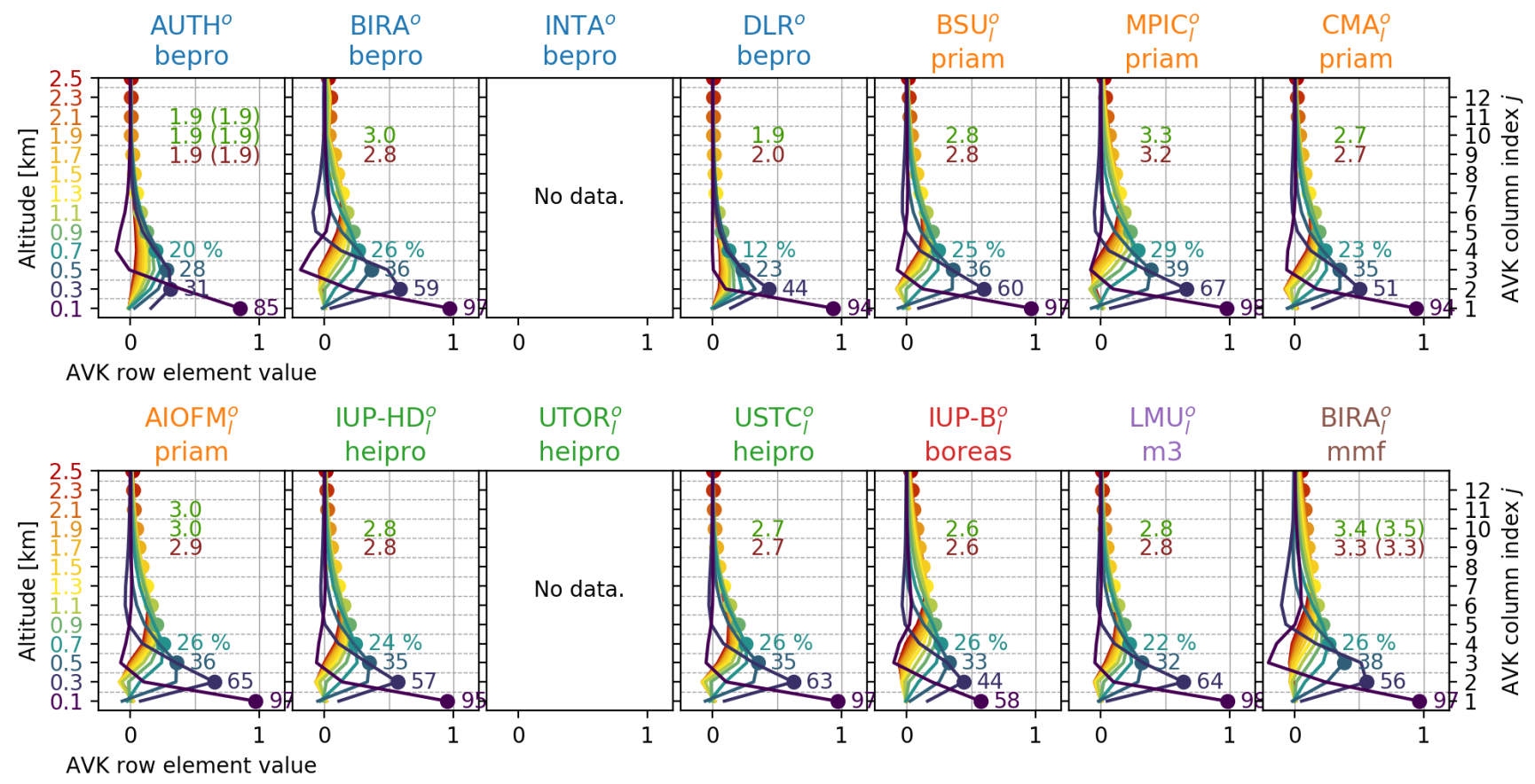

Figure S38. Mean averaging kernels for $\mathrm{NO}_{2}$ UV for each participant. Description of Fig. S35 applies. 
$\mathrm{NO}_{2}$ Vis - median AVKs
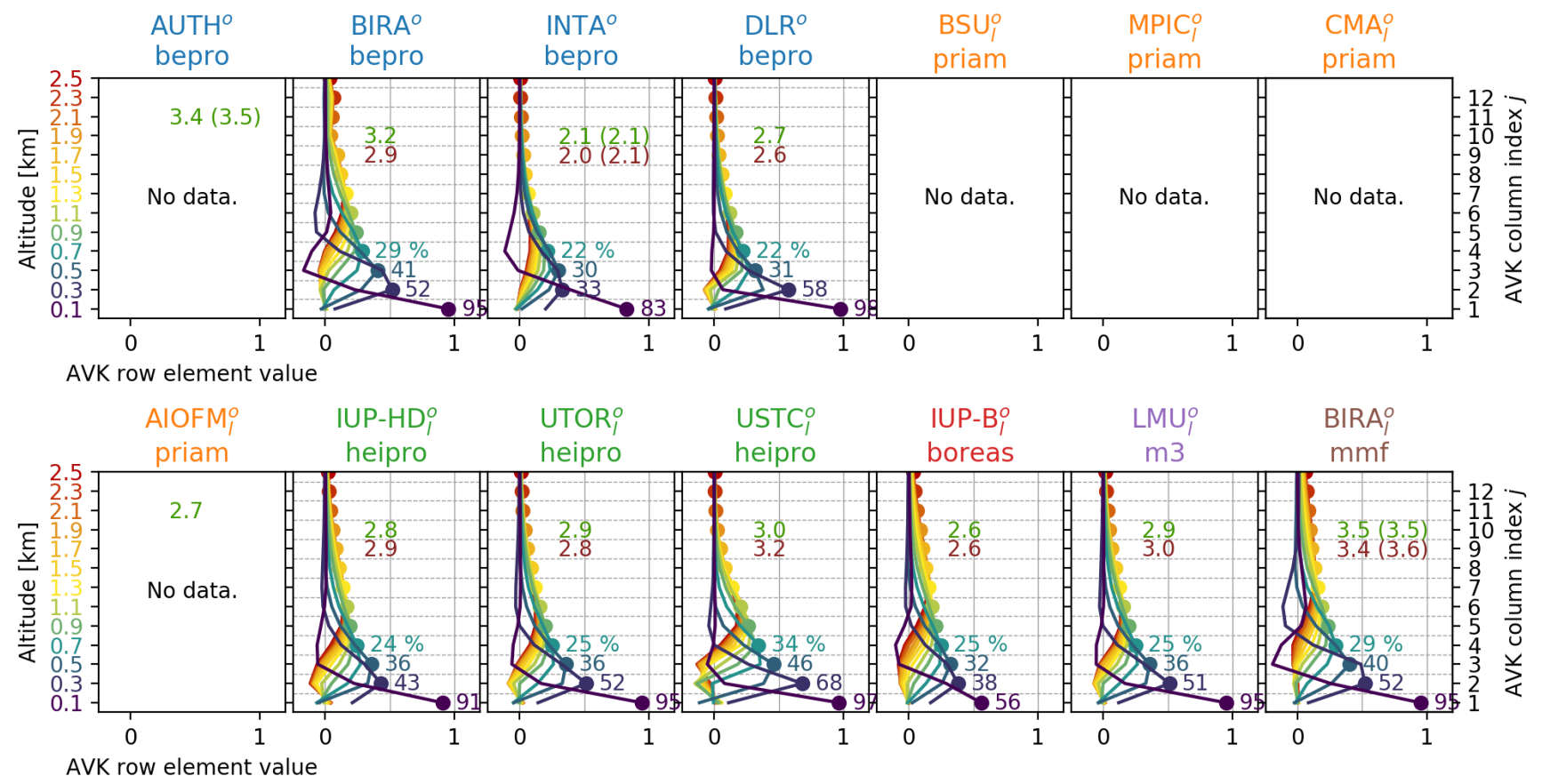

Figure S39. Mean averaging kernels for $\mathrm{NO}_{2}$ Vis for each participant. Description of Fig. S35 applies. 
S10.2 Overview plots

This section is equivalent to Sect. 3.2 in the main text. 


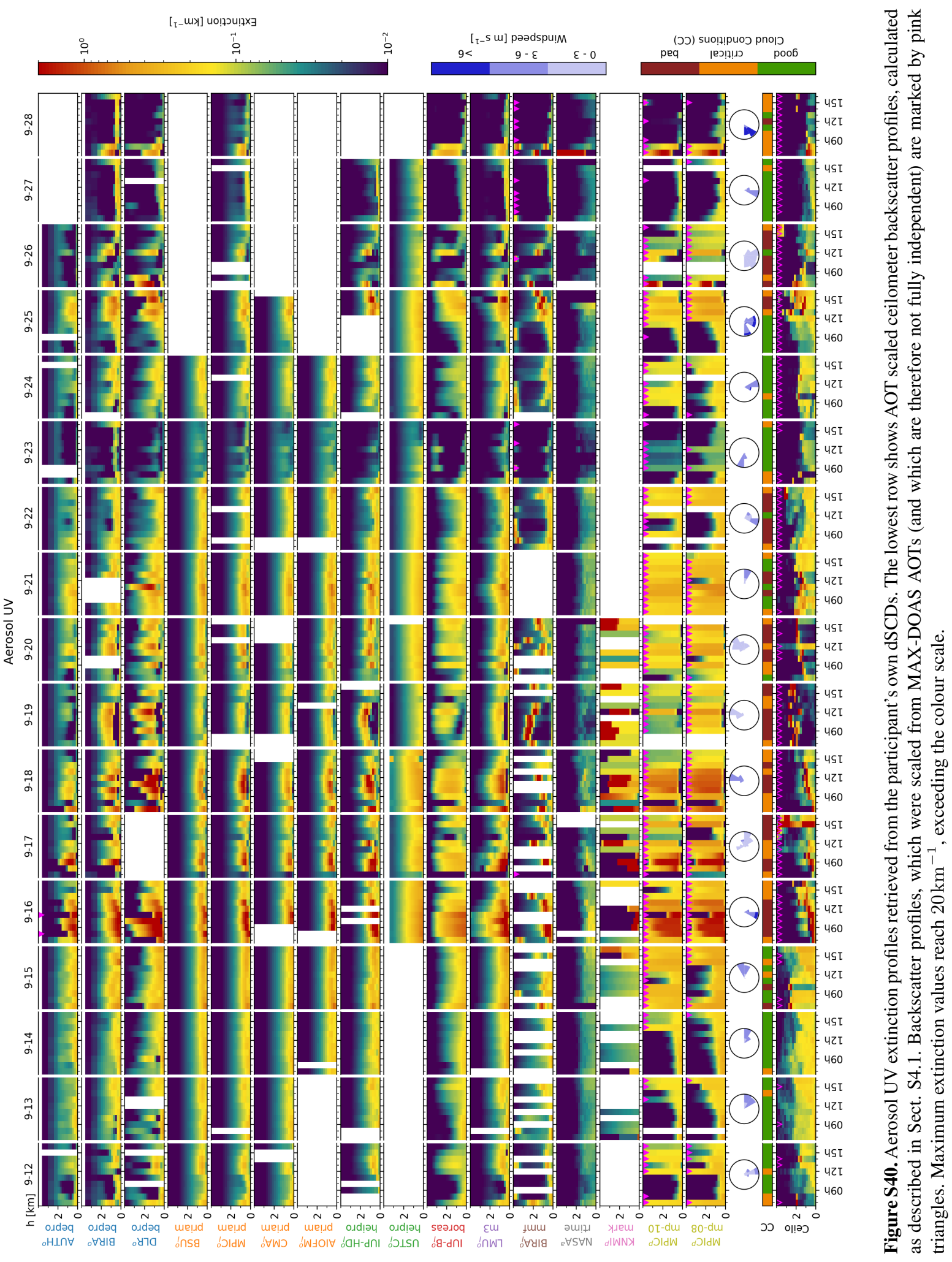




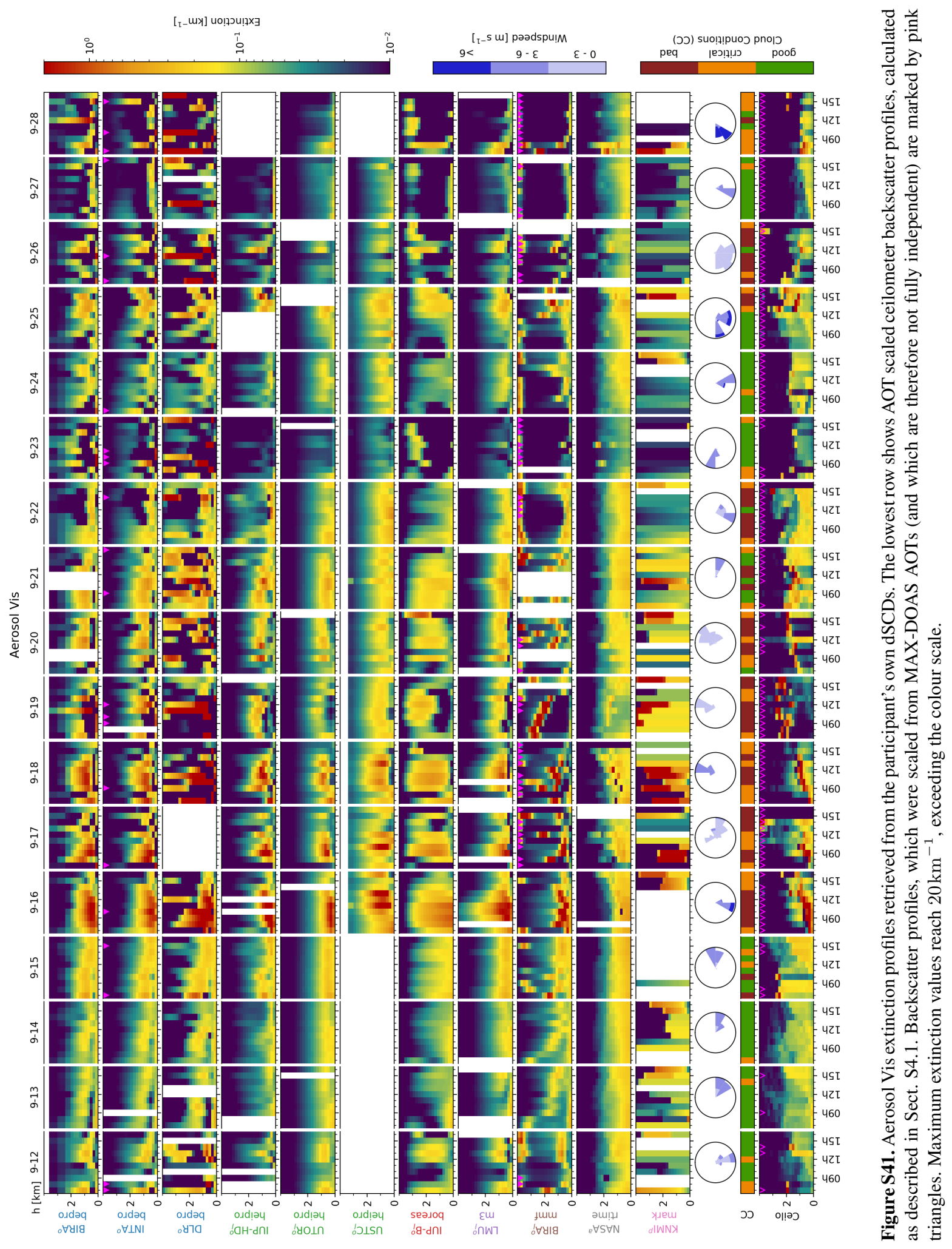




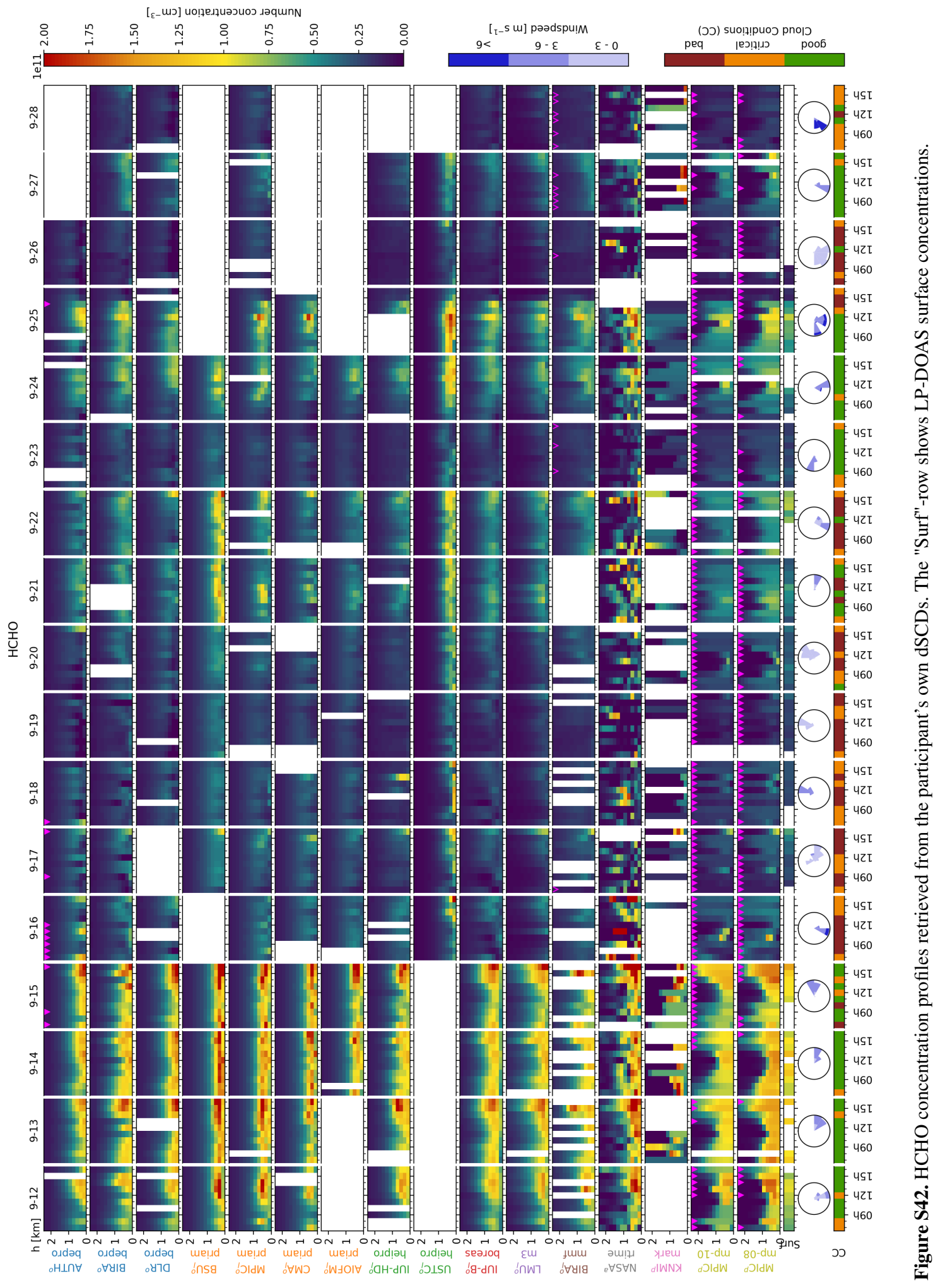




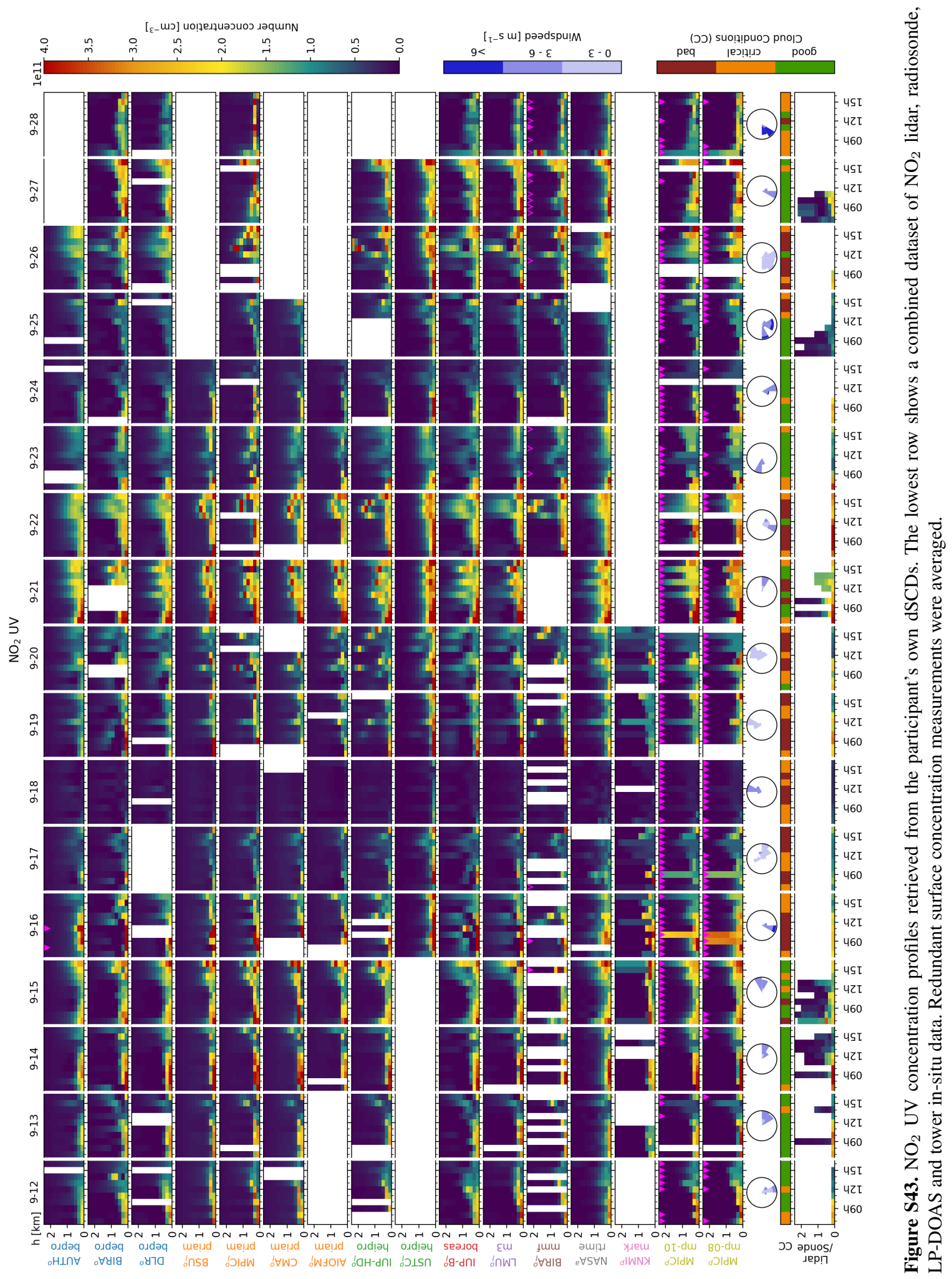




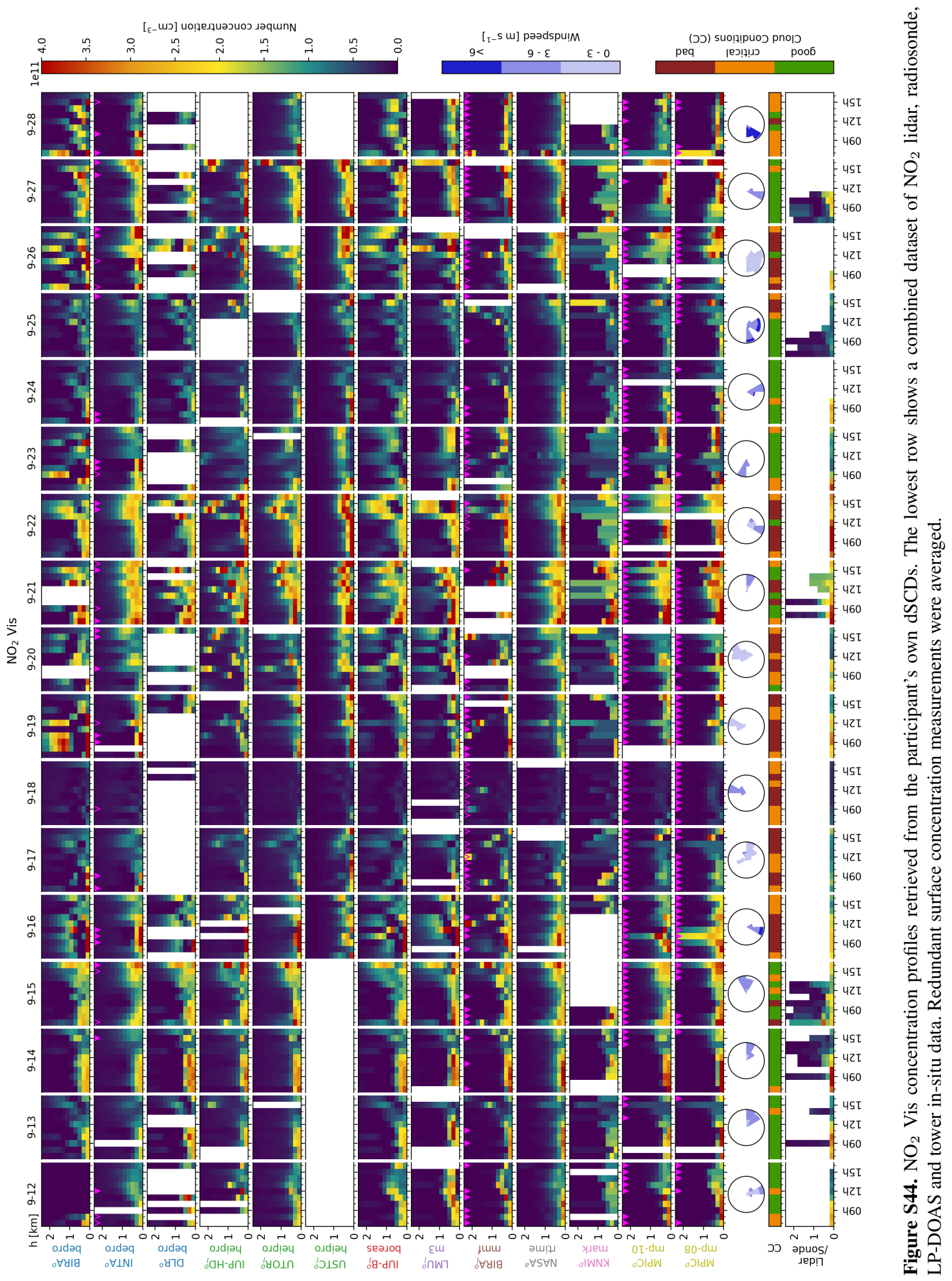




\section{S10.3 Modelled and measured dSCDs}

This section is equivalent to Sect. S10.3 in the main text.

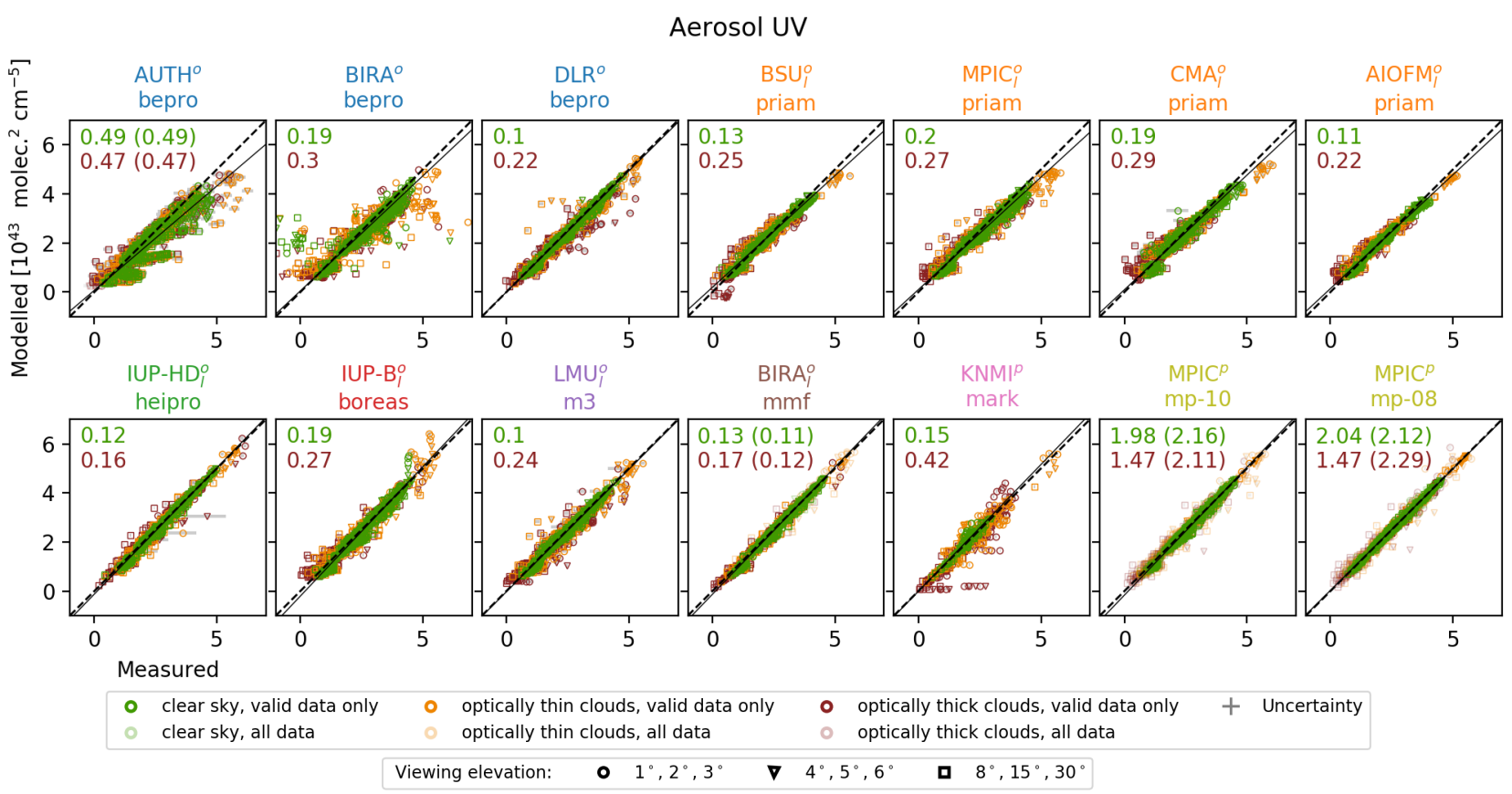

Figure S45. $\mathrm{O}_{4} \mathrm{UV}$ dSCD correlation when profiles are retrieved from the participant's own dSCDs. Marker colours and marker shapes indicate the cloud conditions and viewing elevation angles, respectively. Numbers represent the measurement error weighted RMSD between measured and modelled dSCDs for clear sky (green) and cloudy (red) conditions. Values in brackets were calculated only considering valid data. 
Aerosol Vis

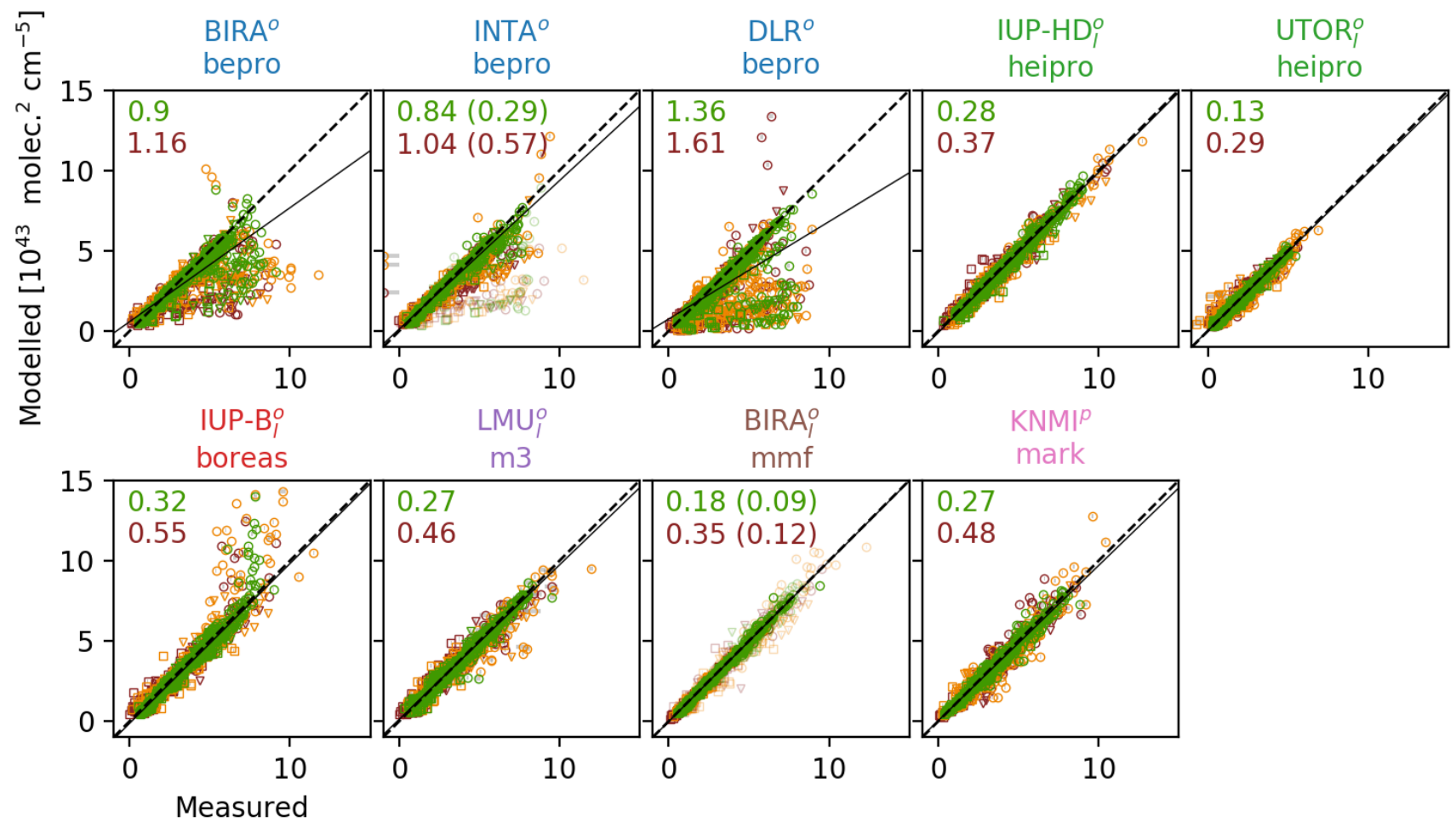

Figure S46. $\mathrm{O}_{4}$ Vis dSCD correlation. Legends of Fig. S45 apply.

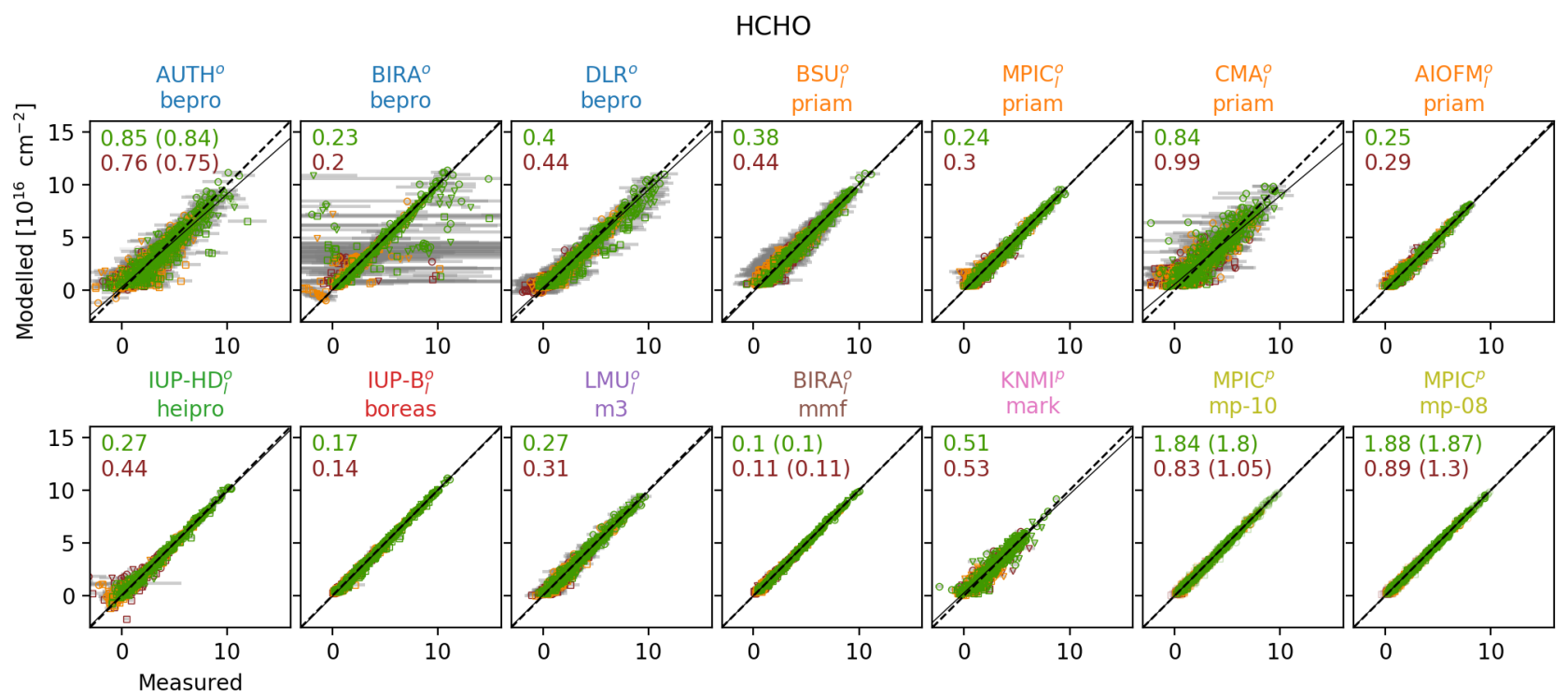

Figure S47. HCHO dSCD correlation. Legends of Fig. S45 apply. 
$\mathrm{NO}_{2} \mathrm{UV}$

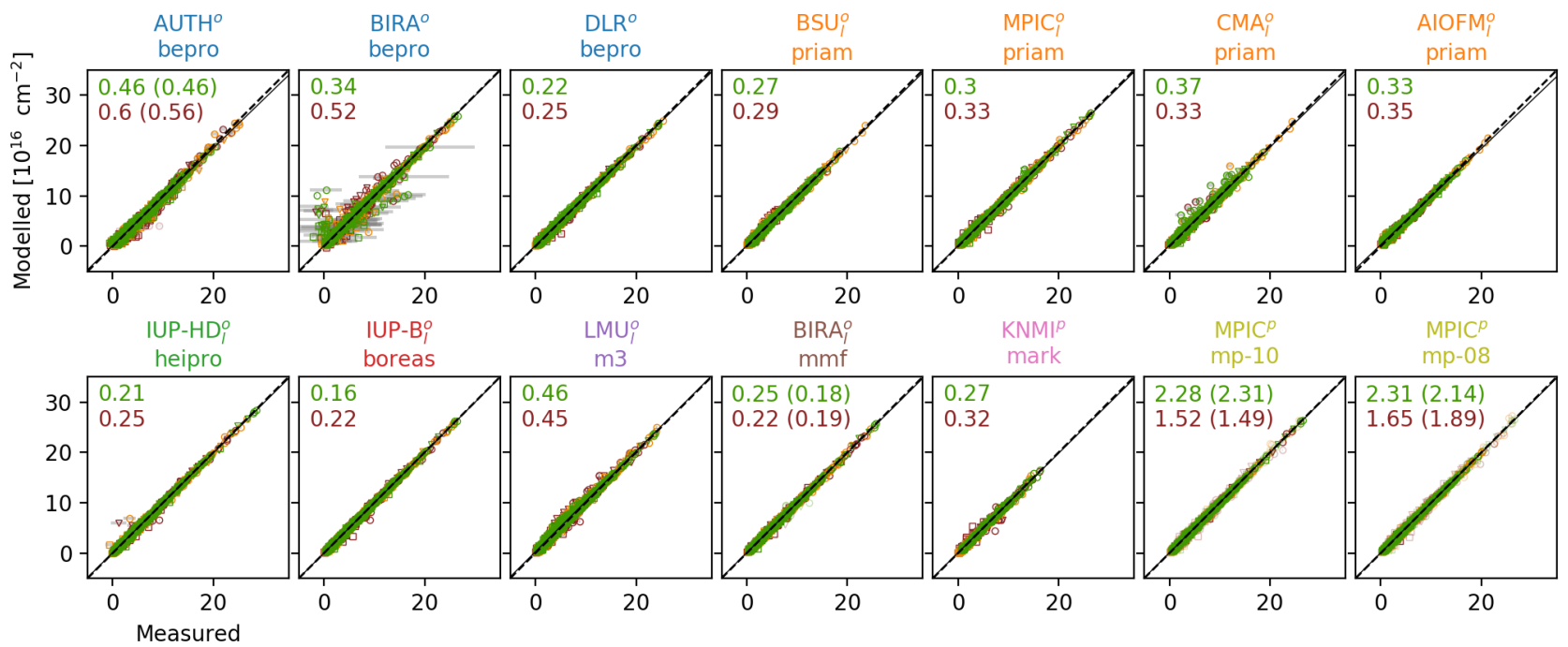

Figure S48. $\mathrm{NO}_{2}$ UV dSCD correlation. Legends of Fig. S45 apply.

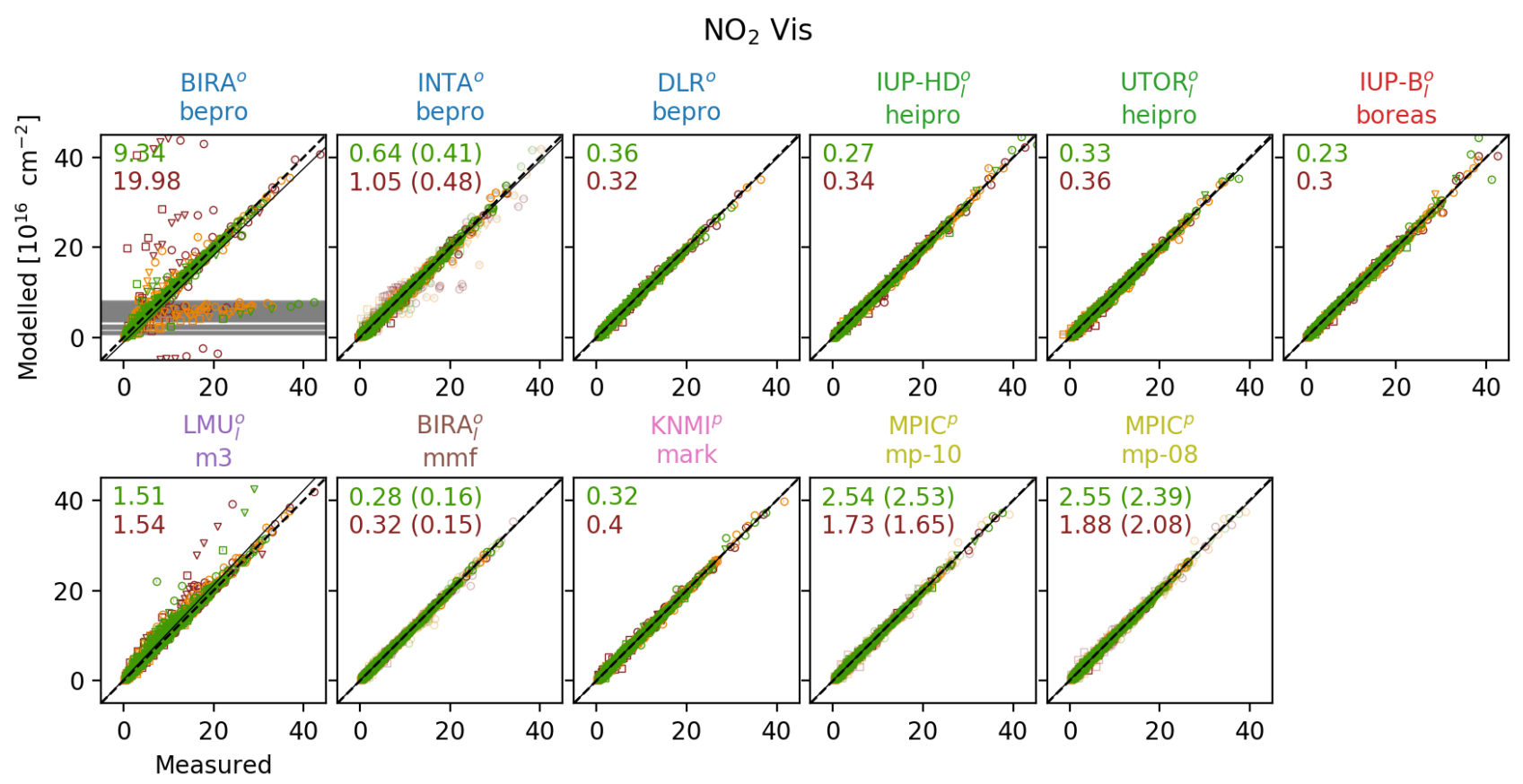

Figure S49. $\mathrm{NO}_{2}$ Vis dSCD correlation. Legends of Fig. S45 apply. 
This section is equivalent to Sect. S10.4 in the main text.

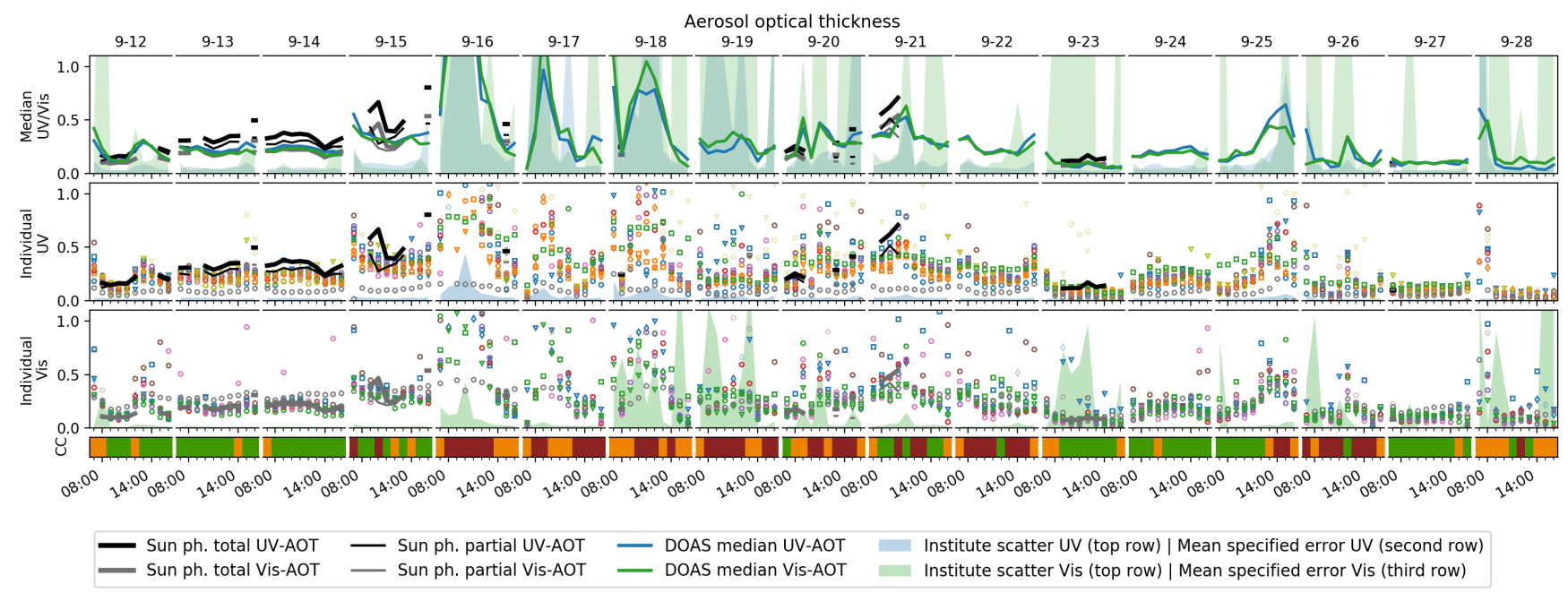

Figure S50. MAX-DOAS AOTs retrieved from the participant's own dSCDs in comparison to sun photometer data. Symbol and symbol colours are chosen according to Table 2 in the main text. Transparent symbols indicate data flagged as invalid. Top row: MAX-DOAS median results vs. the available supporting observations, according to the legend below the plot. The "institute scatter" areas show the scattering among the participants in terms of standard deviation with valid data considered only. Two lower rows: Comparison of the individual participants for the two spectral retrieval ranges. Here the coloured area is the average retrieval error, as specified by the participants. 


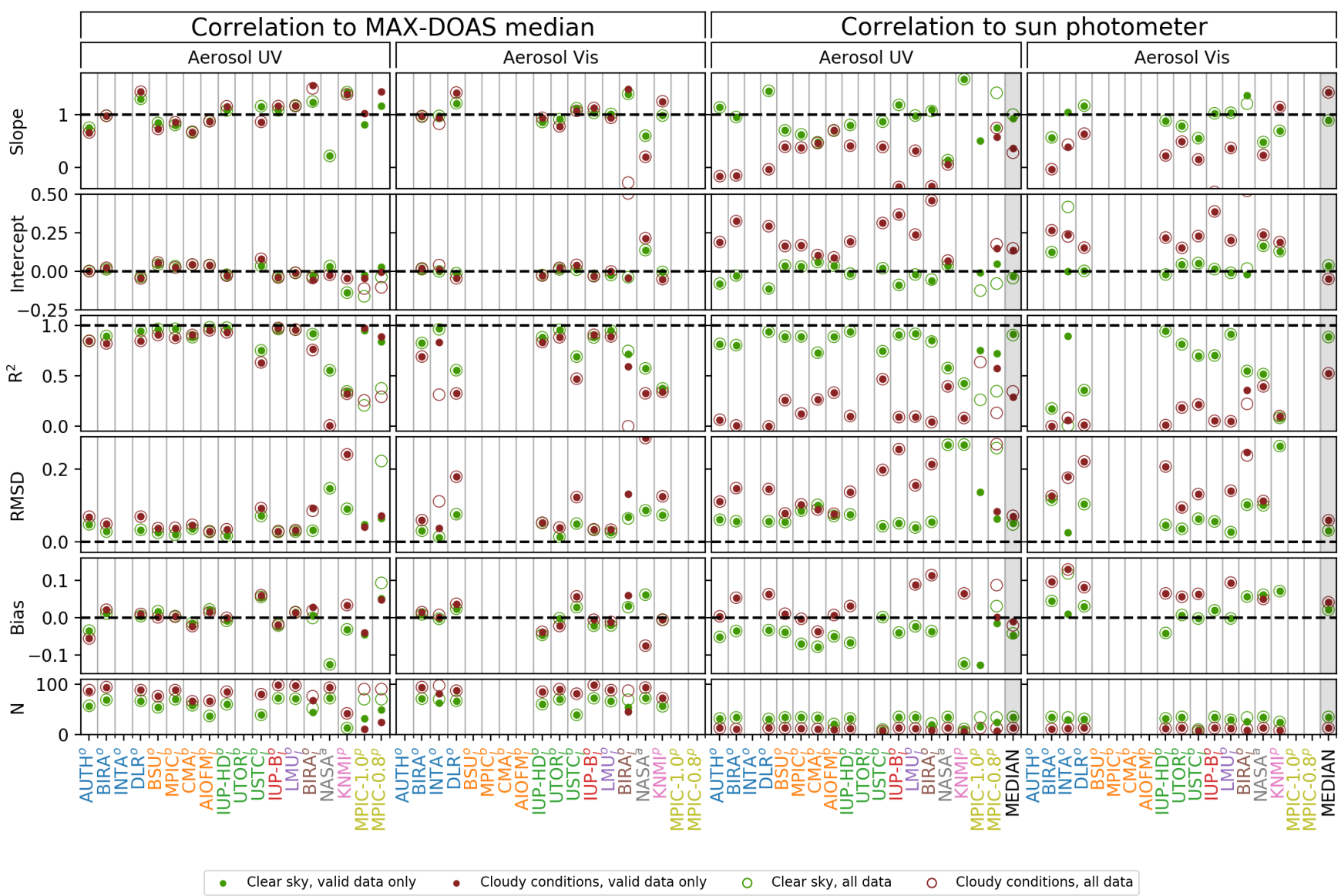

Figure S51. Correlation statistics for AOTs. The two left columns give an impression on the agreement among the institutes, as they show the correlation of the individual participant's retrieved AOT (ordinate of the underlying correlation plot) against the median (abscissa). The two right columns show the correlation against the sun photometer AOT (partial AOT in the case of OEM retrievals) instead of the median. Green and red symbols represent cloud-free and cloudy conditions, respectively. Hollow circles represent values for all submitted data, the dots only consider data points flagged as valid. $N$ is the number of profiles which contributed to the respective data points above. The total number of submitted profiles per participant and species were 170. On the right also the correlation between the MAX-DOAS median results and supporting observations are included (grey shaded columns).

\section{S10.5 Trace gas vertical column densities (VCDs)}

This section is equivalent to Sect. S10.5 in the main text. 
$\mathrm{HCHO}$ vertical columns

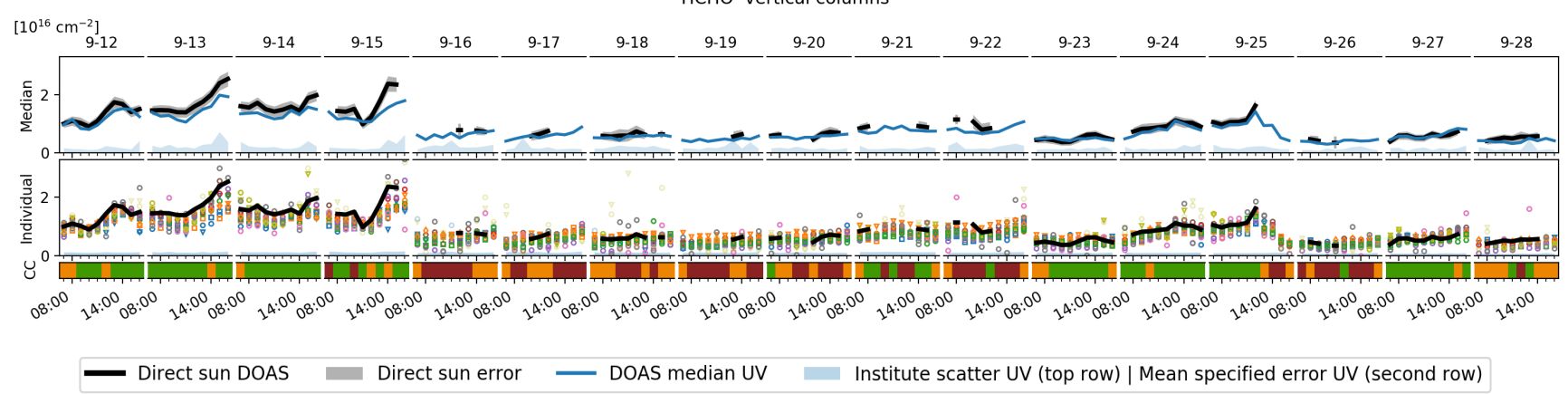

Figure S52. Comparison of MAX-DOAS HCHO VCDs retrieved from the participant's own dSCDs vs. direct-sun DOAS, $\mathrm{NO}_{2}$ lidar and radiosonde. Descriptions of Fig. S50 apply.

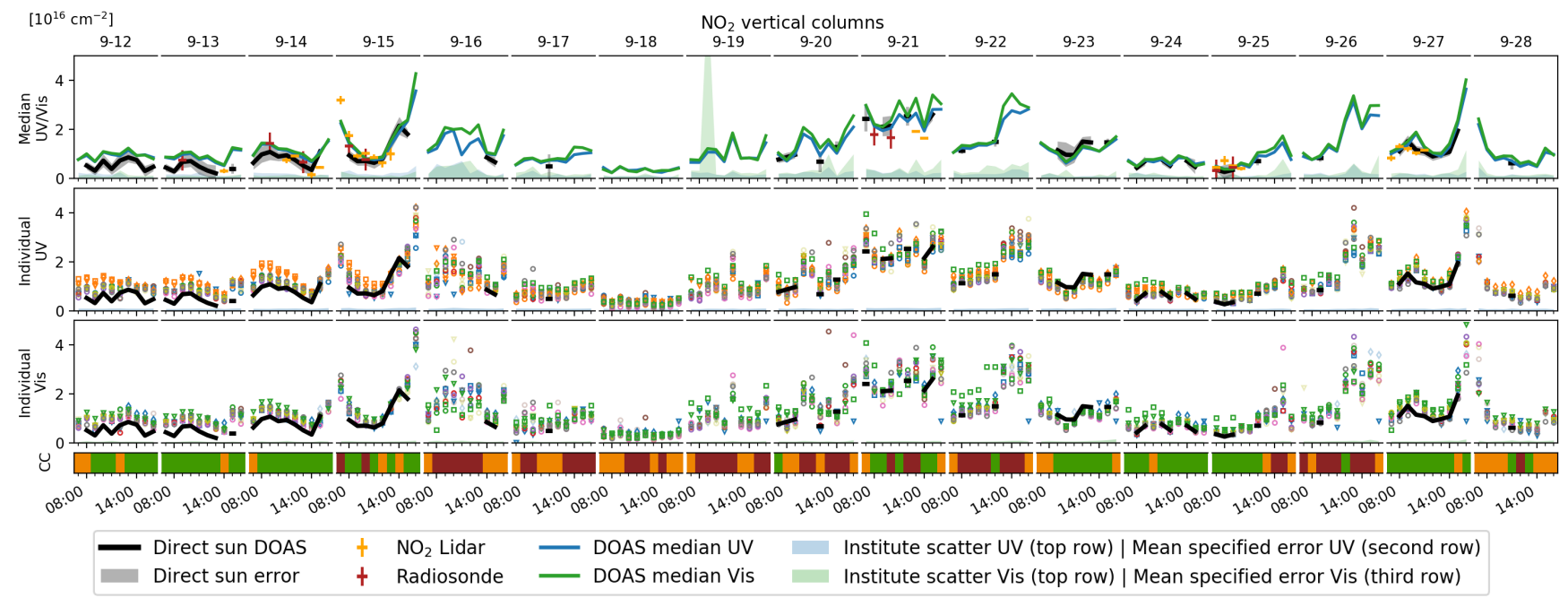

Figure S53. Comparison of MAX-DOAS $\mathrm{NO}_{2}$ VCDs retrieved from the participant's own dSCDs vs. direct-sun DOAS. Descriptions of Fig. S50 apply. 


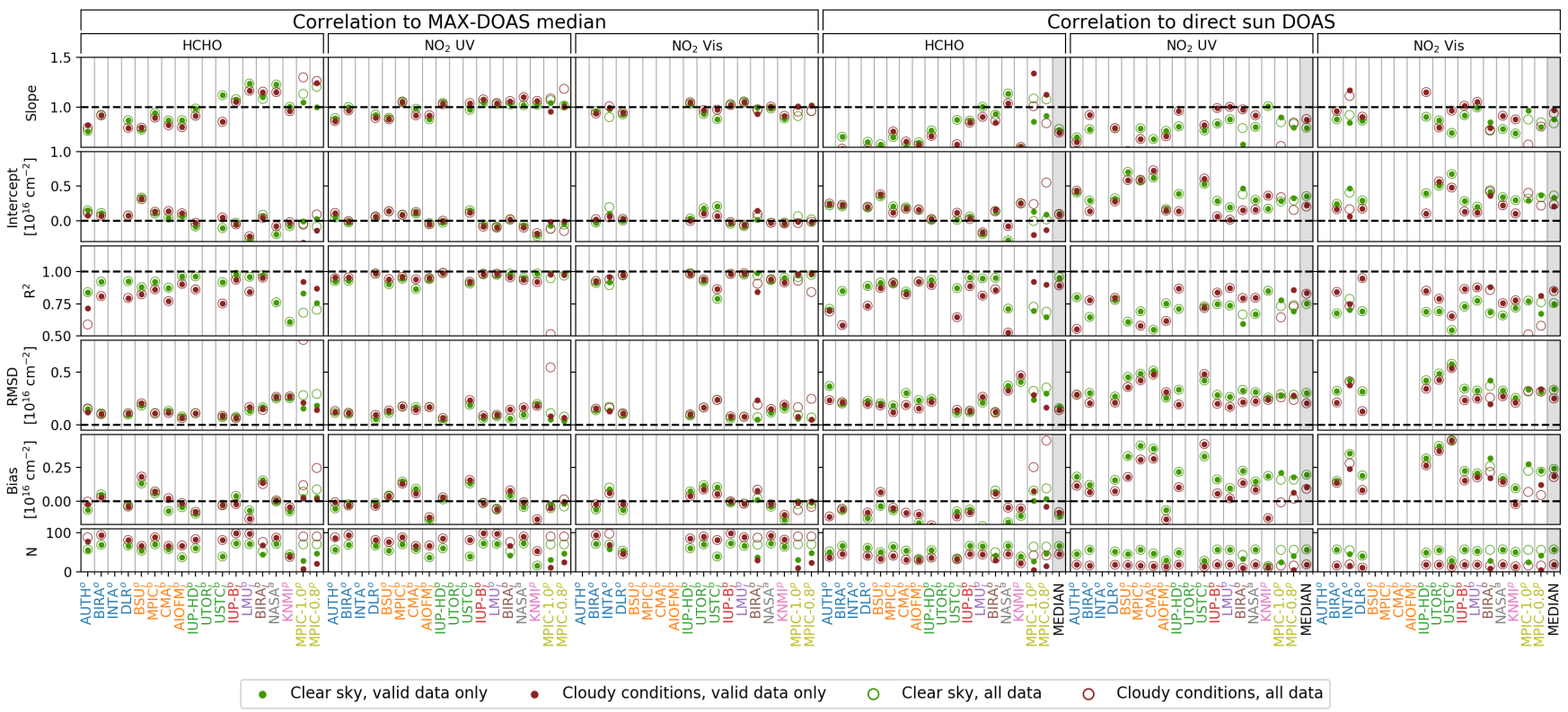

Figure S54. Correlation statistics of trace gas VCDs retrieved from the participant's own dSCDs. Legends and description of Fig. S51 apply. 


\section{S10.6 Trace gas surface concentrations}

This section is equivalent to Sect. S10.6 in the main text.

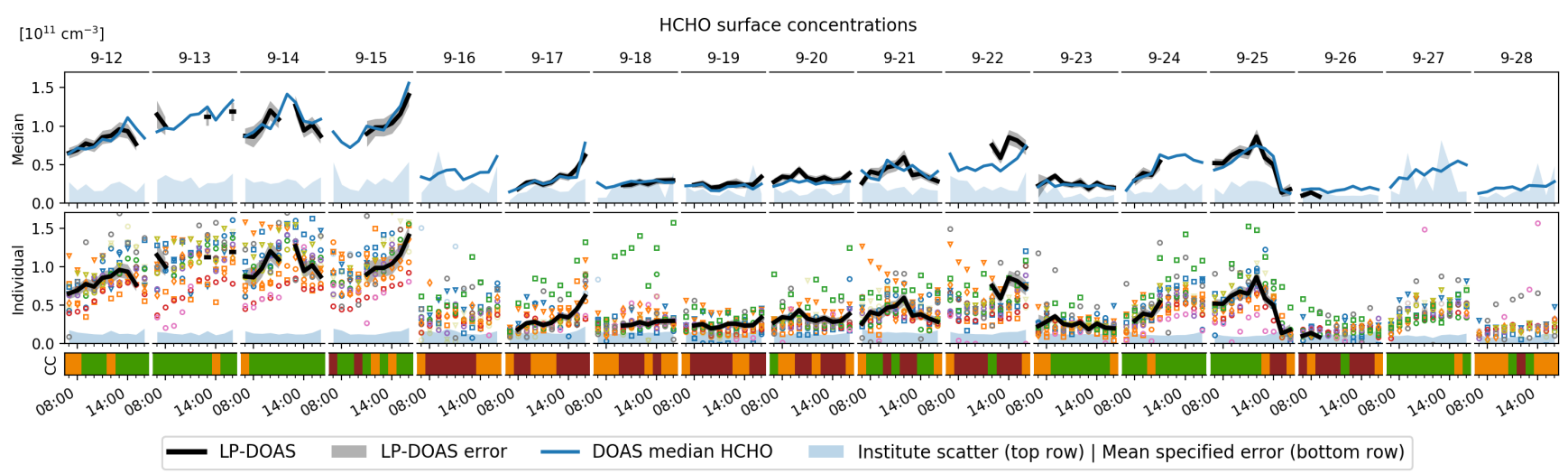

Figure S55. Comparison of MAX-DOAS HCHO surface concentrations retrieved from the participant's own dSCDs. Description of Fig. S50 applies.

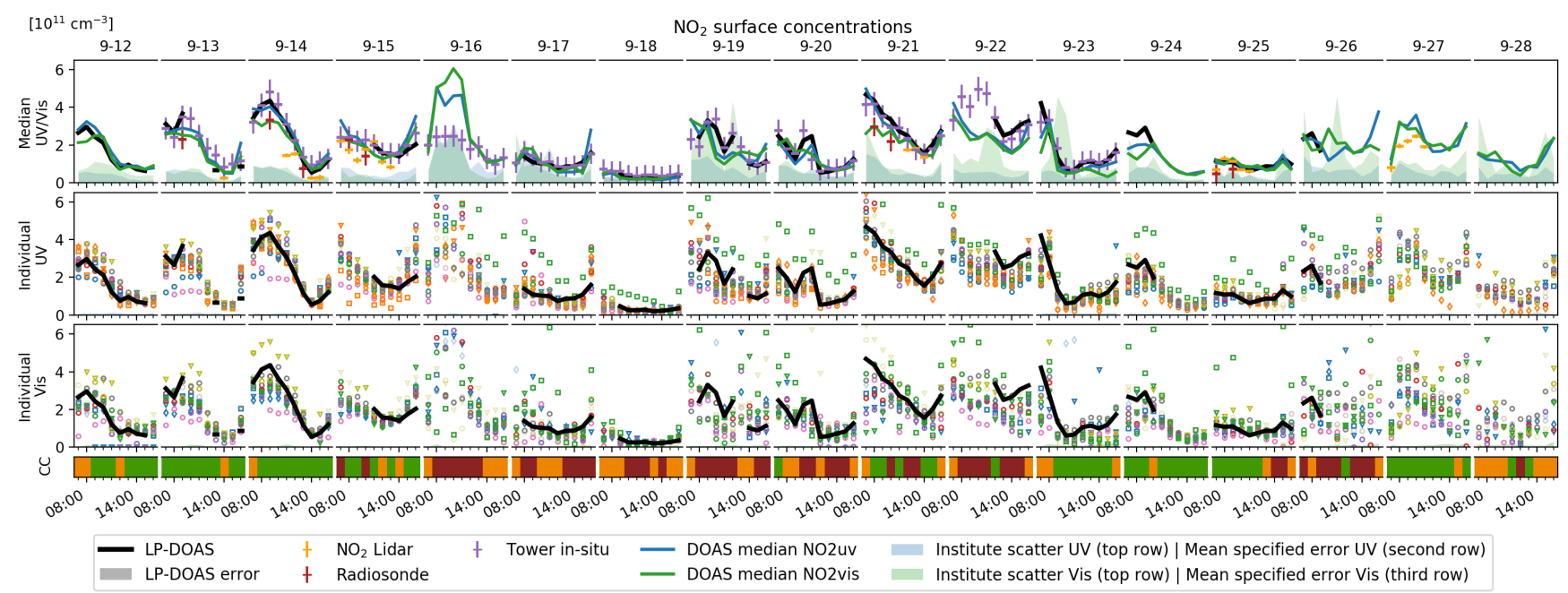

Figure S56. Comparison of MAX-DOAS NO 2 surface concentrations retrieved from the participant's own dSCDs. Description of Fig. S50 applies. 


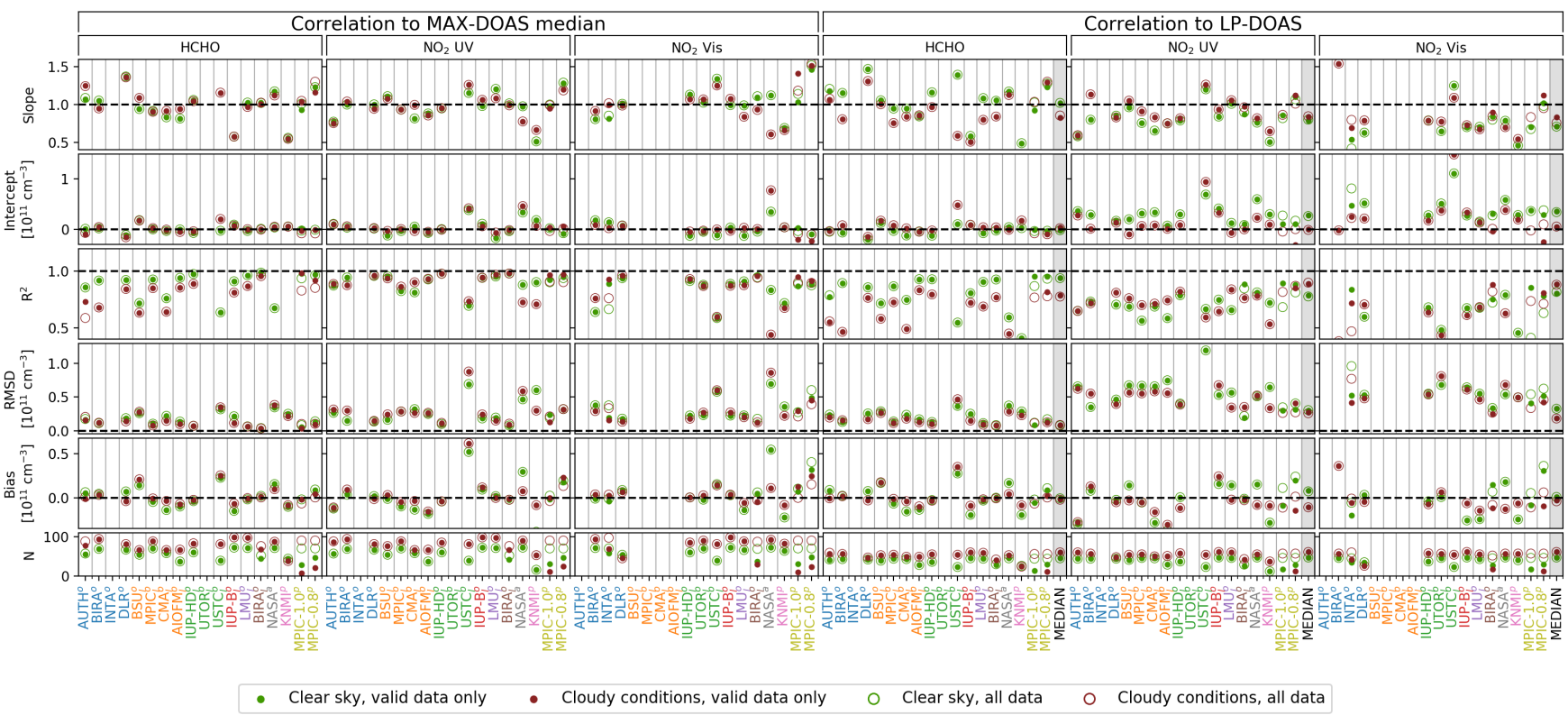

Figure S57. Correlation statistics of trace gas surface concentrations retrieved from the participant's own dSCDs. Basic description of Fig. S51 applies. 


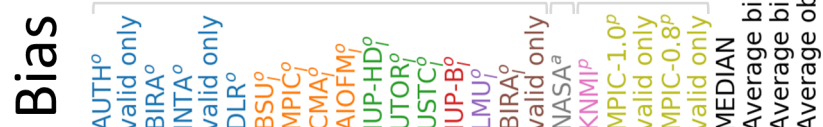

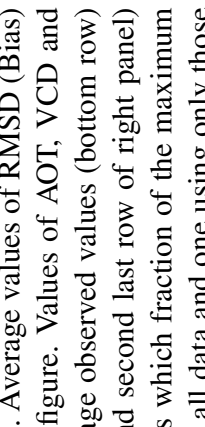

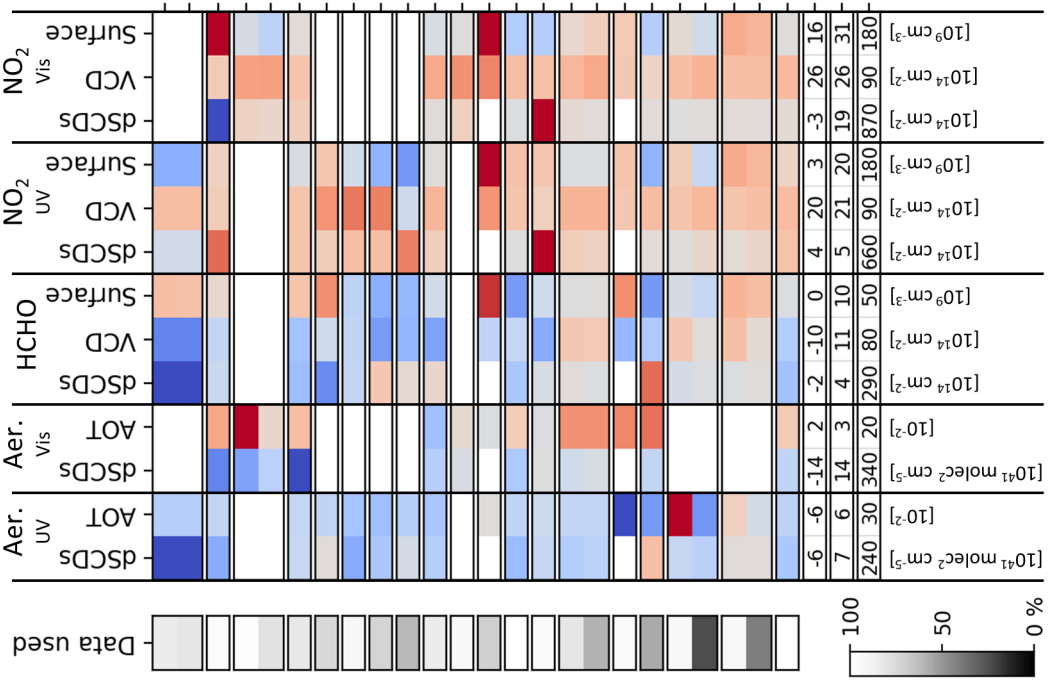

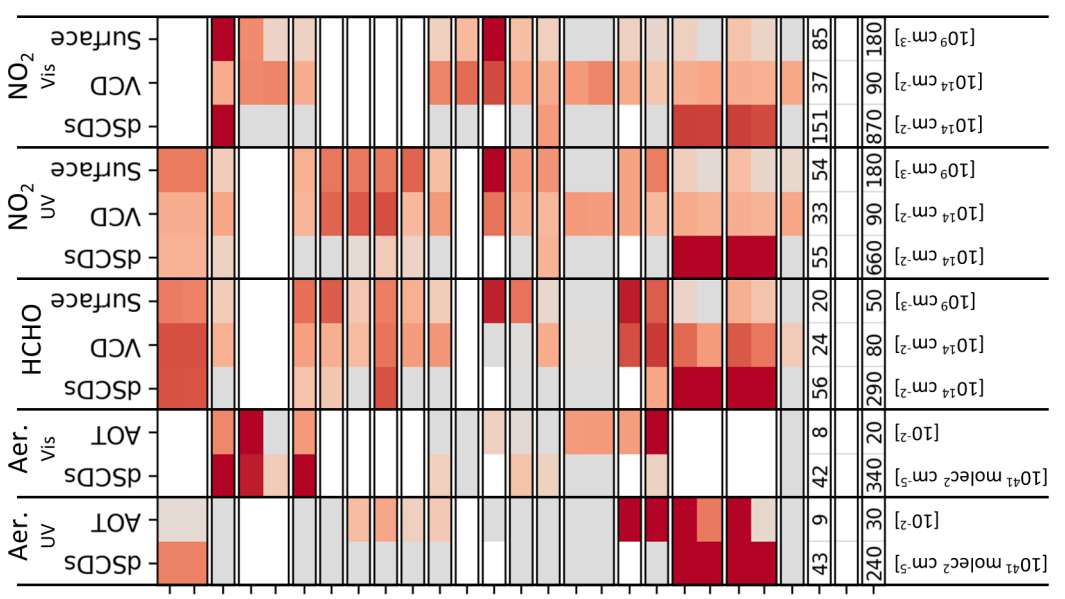

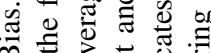

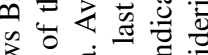

วิ

D

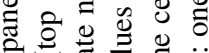
Е

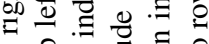

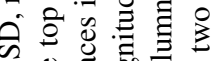

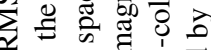

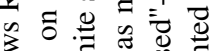

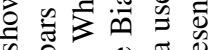
む)

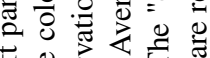

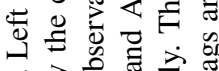

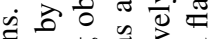

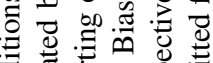

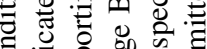

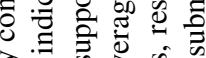
齐合 ‡ี

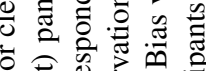

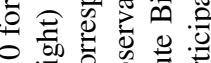

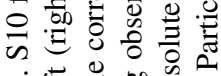

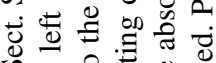
\&

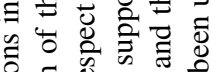

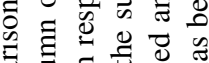

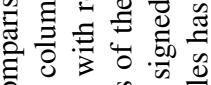

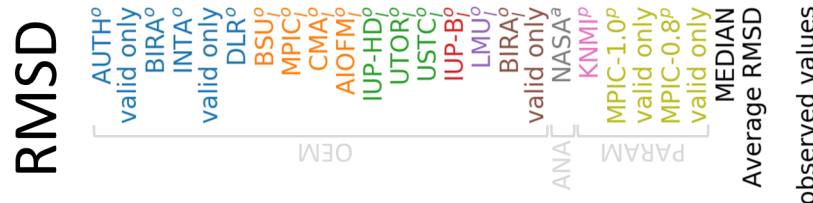

ठ듀 ¿ पे 츨 敢 ปี
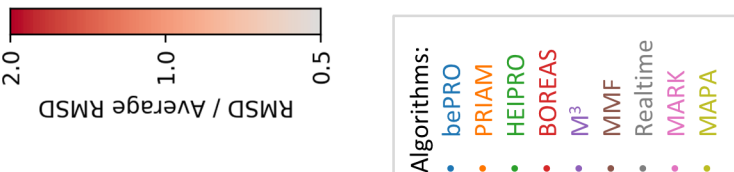

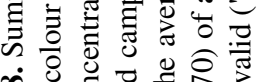

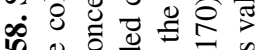

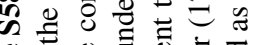

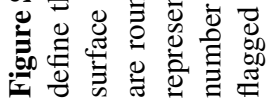

$\sum_{\substack{0 \\ \frac{\pi}{2}}}^{\frac{1}{4}}$ 


\section{References}

Apituley, A., Wilson, K., Potma, C., Volten, H., and de Graaf, M.: Performance Assessment and Application of Caeli-A highperformance Raman lidar for diurnal profiling of Water Vapour, Aerosols and Clouds, in: Proceedings of the 8th International Symposium on Tropospheric Profiling, pp. 19-23, S06-O10-1-4, Delft/KNMI/RIVM Delft, Netherlands, 2009.

5 Beirle, S., Dörner, S., Donner, S., Remmers, J., Wang, Y., and Wagner, T.: The Mainz profile algorithm (MAPA), Atmospheric Measurement Techniques, 12, 1785-1806, https://doi.org/10.5194/amt-12-1785-2019, https://www.atmos-meas-tech.net/12/1785/2019/, 2019.

Bösenberg, J., Matthias, V., Amodeo, A., Amoiridis, V., Ansmann, A., Baldasano, J. M., Balin, I., Balis, D., Böckmann, C., Boselli, A., Carlsson, G., Chaikovsky, A., Chourdakis, G., Comeron, A., Tomasi, F. D., Eixmann, R., Freudenthaler, V., Giehl, H., Grigorov, I., Hagard, A., Iarlori, M., Kirsche, A., Kolarov, G., Komguem, L., S. Kreipl, W. K., Larcheveque, G., Linné, H., Matthey, R., Mattis, I., Mekler, A., Mironova, I., Mitev, V., Mona, L., Müller, D., Music, S., Nickovic, S., Pandolfi, M., Papayannis, A., Pappalardo, G., Pelon, J., Perez, C., Perrone, R., Persson, R., Resendes, D. P., Rizi, V., Rocadenbosch, F., Rodrigues, J. A., Sauvage, L., Schneidenbach, L., Schumacher, R., Shcherbakov, V., Simeonov, V., Sobolewski, P., Spinelli, N., Stachlewska, I., Stoyanov, D., Trickl, T., Tsaknakis, G., Vaughan, G., Wandinger, U., Wang, X., Wiegner, M., Zavrtanik, M., and Zerefos, C.: EARLINET: A European Aerosol Research Lidar Network to establish an aerosol climatology, Report 348, ISSN 0937-1060, 192 pp., Max-Planck-Institut für Meteorologie, 2003.

Chan, K. L., Wang, Z., Ding, A., Heue, K.-P., Shen, Y., Wang, J., Zhang, F., Hao, N., and Wenig, M.: MAX-DOAS measurements of tropospheric $\mathrm{NO}_{2}$ and $\mathrm{HCHO}$ in Nanjing and the comparison to OMI observations, Atmospheric Chemistry and Physics Discussions, 2019, 1-25, https://doi.org/10.5194/acp-2018-1266, https://www.atmos-chem-phys-discuss.net/acp-2018-1266/, 2019.

Clémer, K., Van Roozendael, M., Fayt, C., Hendrick, F., Hermans, C., Pinardi, G., Spurr, R., Wang, P., and De Mazière, M.: Multiple wavelength retrieval of tropospheric aerosol optical properties from MAXDOAS measurements in Beijing, Atmospheric Measurement Techniques, 3, 863-878, https://doi.org/10.5194/amt-3-863-2010, https://www.atmos-meas-tech.net/3/863/2010/, 2010.

Esri, EsriNL, Rijkswaterstaat, Intermap, NASA, NGA, Kadaster, U. ., Esri, HERE, Garmin, P, I., and METI: arcGIS World Topo Map, 2018.

Mayer, B. and Kylling, A.: Technical note: The libRadtran software package for radiative transfer calculations - description and examples of use, Atmospheric Chemistry and Physics, 5, 1855-1877, https://doi.org/10.5194/acp-5-1855-2005, https://www.atmos-chem-phys.net/5/ 1855/2005/, 2005.

Ortega, I., Berg, L. K., Ferrare, R. A., Hair, J. W., Hostetler, C. A., and Volkamer, R.: Elevated aerosol layers modify the O2-O2 absorption measured by ground-based MAX-DOAS, Journal of Quantitative Spectroscopy and Radiative Transfer, 176, 34 - 49, https://doi.org/https://doi.org/10.1016/j.jqsrt.2016.02.021, http://www.sciencedirect.com/science/article/pii/S0022407315301746, 2016.

Pappalardo, G., Amodeo, A., Apituley, A., Comeron, A., Freudenthaler, V., Linné, H., Ansmann, A., Bösenberg, J., D’Amico, G., Mattis, I., Mona, L., Wandinger, U., Amiridis, V., Alados-Arboledas, L., Nicolae, D., and Wiegner, M.: EARLINET: towards an advanced sustainable European aerosol lidar network, Atmospheric Measurement Techniques, 7, 2389-2409, https://doi.org/10.5194/amt-7-2389-2014, https: //www.atmos-meas-tech.net/7/2389/2014/, 2014.

Peters, E., Ostendorf, M., Bösch, T., Seyler, A., Schönhardt, A., Schreier, S. F., Henzing, J. S., Wittrock, F., Richter, A., Vrekoussis, M., and Burrows, J. P.: Full-azimuthal imaging-DOAS observations of $\mathrm{NO}_{2}$ and $\mathrm{O}_{4}$ during CINDI-2, Atmospheric Measurement Techniques Discussions, 2019, 1-30, https://doi.org/10.5194/amt-2019-33, 2019.

35 Wagner, T. and Beirle, S.: Estimation of the horizontal sensitivity range from MAX-DOAS O 4 observations, Tech. rep., QA4ECV, http: //www.qa4ecv.eu/sites/default/files, 2016.

Wagner, T., Deutschmann, T., and Platt, U.: Determination of aerosol properties from MAX-DOAS observations of the Ring effect, Atmospheric Measurement Techniques, 2, 495-512, https://doi.org/10.5194/amt-2-495-2009, https://www.atmos-meas-tech.net/2/495/2009/, 2009.

40 Wagner, T., Beirle, S., Benavent, N., Bösch, T., Chan, K. L., Donner, S., Dörner, S., Fayt, C., Frieß, U., García-Nieto, D., Gielen, C., González-Bartolome, D., Gomez, L., Hendrick, F., Henzing, B., Jin, J. L., Lampel, J., Ma, J., Mies, K., Navarro, M., Peters, E., Pinardi, G., Puentedura, O., Pukīte, J., Remmers, J., Richter, A., Saiz-Lopez, A., Shaiganfar, R., Sihler, H., Van Roozendael, M., Wang, Y., and Yela, M.: Is a scaling factor required to obtain closure between measured and modelled atmospheric $\mathrm{O}_{4}$ absorptions? An assessment of uncertainties of measurements and radiative transfer simulations for 2 selected days during the MAD-CAT campaign, Atmospheric Measurement Techniques, 12, 2745-2817, https://doi.org/10.5194/amt-12-2745-2019, https://www.atmos-meas-tech.net/12/2745/2019/, 2019. 